\title{
Dispositional Optimism and Autonomic Reactivity during Difficult and Easy Stress Tasks
}

Daniel Stephenson

Follow this and additional works at: https://researchrepository.wvu.edu/etd

\section{Recommended Citation}

Stephenson, Daniel, "Dispositional Optimism and Autonomic Reactivity during Difficult and Easy Stress Tasks" (2018). Graduate Theses, Dissertations, and Problem Reports. 6722.

https://researchrepository.wvu.edu/etd/6722

This Dissertation is protected by copyright and/or related rights. It has been brought to you by the The Research Repository @ WVU with permission from the rights-holder(s). You are free to use this Dissertation in any way that is permitted by the copyright and related rights legislation that applies to your use. For other uses you must obtain permission from the rights-holder(s) directly, unless additional rights are indicated by a Creative Commons license in the record and/ or on the work itself. This Dissertation has been accepted for inclusion in WVU Graduate Theses, Dissertations, and Problem Reports collection by an authorized administrator of The Research Repository @ WVU.

For more information, please contact researchrepository@mail.wvu.edu. 
Dispositional Optimism and Autonomic Reactivity During Difficult and Easy Stress Tasks

\author{
Daniel Stephenson \\ Dissertation submitted \\ to the Eberly College of Arts and Sciences \\ at West Virginia University \\ in partial fulfillment of the requirements for the degree of \\ Doctor of Philosophy in Psychology
}

Kevin Larkin, Ph.D. - Chair

Amy Fiske, Ph.D.

Daniel McNeil, Ph.D.

Nicholas Turiano, Ph.D.

Stephanie Frisbee, Ph.D.

Department of Psychology

Morgantown, West Virginia

2018

Keywords: optimism, pessimism, stress task, autonomic reactivity

Copyright 2018 Daniel Stephenson 


\author{
ABSTRACT \\ Dispositional Optimism and Autonomic Reactivity During \\ Difficult and Easy Stress Tasks \\ Daniel Stephenson
}

Studies examining the association between dispositional optimism and autonomic reactivity to stress have yielded mixed results, with some studies finding associations between optimism and less reactivity, some studies finding no association between optimism and reactivity, and some finding that optimism was associated with greater reactivity. One factor not considered previously in this literature is difficulty of the stressful task employed to elicit autonomic reactivity. The current study was based on Carver and Scheier's Behavioral Self-Regulation Model (Carver \& Scheier, 2000), that states that optimists are more likely to persist in overcoming challenging obstacles than pessimists. The current study investigated whether the relation between optimism and autonomic reactivity to stress differed depending on the difficulty of the stressful task. This study employed a quasi-experimental design in which participants were classified as optimists or pessimists based on their score on a validated measure of optimism. Participants were randomized to complete either an easy Raven's Matrices stress task or a difficult Raven's Matrices stress task. Blood pressure (systolic, diastolic, mean arterial), heart rate, and heart rate variability were measured throughout the pre-task rest period, the task period, and a recovery period. It was hypothesized that optimists would exhibit increased cardiovascular reactivity when confronting a difficult stress task compared to pessimists, due to fully engaging their resources to overcome the task. Conversely, pessimists were hypothesized to exhibit less cardiovascular reactivity during the difficult task, because they were not fully engaged in solving the problems. No differences in cardiovascular reactivity between optimists and pessimists were hypothesized during the easy task, because both groups would be equally engaged with the task.

Results revealed that optimists had greater diastolic blood pressure reactivity to both the easy and difficult stress tasks compared to pessimists, suggesting they may have been more engaged with the tasks compared to pessimists. Indeed, optimists reported being more persistent in completing the problems and performing better on them compared to pessimists. Analysis of affective responses to the tasks showed that optimists reported more positive affect and less negative affect than pessimists during the laboratory session. However, there were no differences between optimists and pessimists on task performance, ratings of task self-efficacy, and ratings of task difficulty, stressfulness, discomfort, or perceived effort. Significant task effects were revealed as well, verifying that the easy and difficult tasks were experienced differently. Participants completing the difficult task performed more poorly, reported less positive and more negative affect in response to the task, and rated the task as more difficult, stressful, effortful, and upsetting than participants completing the easy task. Although results of the study failed to confirm study hypotheses, they added credence to the Behavioral SelfRegulation Model because optimists appeared to be engaging more with both easy and difficult versions of the stress task than pessimists, and consequently, experienced greater DBP reactions during the task period than pessimists. 


\section{TABLE OF CONTENTS}

Introduction

Dispositional Optimism and its Associated Health Benefits

Mechanisms through which Optimism Improves Health

Optimism and Decreased Autonomic Reactivity to Stress

The Behavioral Self-Regulation Model

The Behavioral Self-Regulation Model and Reactivity to Stress Tasks

Aims of Proposed Study

Method

Participants

Measures

Experimental Design

Stress task development and pilot testing

Procedure

Results

Data Cleaning and Reduction

Preliminary Analyses

Cardiovascular Measures at Rest

Primary Analyses: Cardiovascular Reactivity to the Task

Primary Analyses: Cardiovascular Recovery from Stress

Task Score

Measures of Affect

Post-Experimental Questionnaire 
Self-efficacy Ratings $\quad 44$

Analysis of Optimism and Pessimism Subscales 45

Health Behaviors and Demographic Differences Between Optimists 46

and Pessimists

$\begin{array}{ll}\text { Chaos Theory } & 47\end{array}$

$\begin{array}{ll}\text { Discussion } & 48\end{array}$

Health Behaviors and Demographic Differences Between Optimists 59 and Pessimists

$\begin{array}{ll}\text { Strengths and Limitations } & 60\end{array}$

$\begin{array}{ll}\text { Future Directions } & 63\end{array}$

$\begin{array}{ll}\text { Summary and Conclusions } & 64\end{array}$

$\begin{array}{ll}\text { References } & 66\end{array}$

$\begin{array}{ll}\text { Tables } & 79\end{array}$

$\begin{array}{ll}\text { Figures } & 83\end{array}$

$\begin{array}{lr}\text { Appendices } & 90\end{array}$ 


\section{Dispositional Optimism and Autonomic Reactivity During Difficult and Easy Stress Tasks}

The influence of psychosocial factors on physical health is well documented. For several decades, evidence demonstrating that negative psychosocial factors, including depression, anxiety, hostility, social isolation, and chronic stress are related to poor physical health has accrued. For example, depression and social isolation are both related to increased risk of allcause mortality (e.g., House, Landis, \& Umberson, 1988; Zivin et al., 2015). Both depression and anxiety are related to increased experience of chronic pain and increased disability related to chronic pain (e.g., Lerman, Rudich, Brill, Shalev, \& Shahar, 2015). Depression, anxiety, and social isolation are also linked to poorer prognosis following the diagnosis of several chronic diseases (Boden-Albala, Litwak, Elkind, Rundek, \& Sacco, 2005; Chan, Wan Ahmad, Yusof, Ho, \& Krupat, 2015; Noyes Jr, \& Kathol, 1985).

Negative psychosocial factors also specifically influence cardiovascular health. For example, depression, anxiety, social isolation, chronic life stress, and hostility each contribute to the etiology of coronary artery disease (CAD; e.g., Rozanski, Blumenthal, \& Kaplan, 1999; Shimbo et al., 2009; Whooley \& Wong, 2013). Depression, anxiety, hostility, and social isolation are also related to increased initial cardiac events among community samples and higher mortality rate among patients already diagnosed with CAD (e.g., Barth, Schumacher, \& Herrmann-Lingen, 2004; Roest, Martens, Denollet, \& de Jonge, 2010; Wong, Sin, \& Whooley, 2014). Despite the importance of considering psychosocial risk factors along with the standard risk factors for CAD (i.e., sex; family history of CAD; smoking; hypercholesterolemia, hypertension, diabetes), considerable variance in predicting onset of CAD remains unexplained. This has led toward the examination of additional constructs that may be useful in predicting the negative health consequences associated with CAD. 
Recently, evidence that positive psychosocial factors are associated with improved physical health has been accumulating. For example, those with high levels of social support have better health outcomes than those with low social support (Uchino, 2006). Specifically, high social support is related to lower mortality caused by cancer, infectious diseases, and cardiovascular disease. Forgiveness is also linked to improved health; following a traumatic injury, those who forgave the person responsible for the accident experienced faster recovery and improved health status than those who did not engage in forgiveness (Webb, Toussaint, Kalpakjian, \& Tate, 2010). Furthermore, numerous constructs from positive psychology, including forgiveness, emotional vitality, social support, and optimism, have all been linked to a decreased risk of developing CAD (Tay, Tan, Diener, \& Gonzalez, 2013; Tindle et al., 2009; Waltman, et al., 2009). The proposed study aims to examine one of these constructs, dispositional optimism, by exploring the proposed physiological mechanisms through which it could exert its salubrious effects on cardiovascular health.

\section{Dispositional Optimism and its Associated Health Benefits}

Dispositional optimism is a positive psychosocial trait that has received considerable attention. Dispositional optimism is defined as a pattern of expecting that, in the future, good things will be more abundant than bad things (Scheier \& Carver, 1992). Optimists generally expect the future to be favorable, and believe that they are capable of obtaining their goals (Scheier \& Carver, 1992). Conversely, those low in optimism expect future outcomes to be less positive, and believe that their goals may not be entirely obtainable. Dispositional optimism is most frequently measured using the Life Orientation Test or the Life Orientation Test - Revised (LOT and LOT-R, respectively; Scheier \& Carver, 1992), a 10-item self-report scale. Many theorists have conceptualized the LOT/LOT-R as representing a single construct, with high and 
low scores falling on a single continuum of "optimism" (i.e., low optimism is equivalent to pessimism). However, several investigators have found that the LOT/LOT-R has a two-factor structure, each measuring distinct constructs of optimism and pessimism (Kubzansky, Kubzansky, \& Maselko, 2004; Raikkonen, \& Matthews, 2008; Scheier, Carver, \& Bridges, 1994). From this perspective, being low on optimism does not necessarily translate into being pessimistic. Based upon this conceptualization of this positive psychology construct, developers of the LOT/LOT-R have recommended that initial "total optimism score" analyses should be followed by analyzing the optimism and pessimism subscales separately (Scheier et al., 1994). Although several studies have found that the LOT/LOT-R has two separate factors, the majority of research examining the relation between optimism and health has utilized the LOT/LOT-R as a measure of a single construct (Rasmussen, Scheier, \& Greenhouse, 2009). Optimism as a construct is conceptually and inversely related to other personality traits such as neuroticism and trait anxiety, and it has been suggested that these variables be included as covariates when assessing relations between optimism and health (Scheier et al., 1994; Kennedy \& Hughes, 2004).

The health benefits related to dispositional optimism are well documented. For instance, in a longitudinal study by Peterson, Seligman, and Vaillant (1988), 99 healthy male graduates of Harvard University were followed from age 25 to age 60 years. Those with high levels of optimism had better overall health and lower mortality rates 30 years later than males with low optimism scores. Evidence also suggests that optimism may increase immune functioning. Using a self-report weekly stress log, Cohen et al. (1999) found that during weeks with high levels of acute stress (e.g., stressors lasting less than one week), immune markers such as CD4 helper t-cell and CD8 cytotoxic t-cell counts were significantly higher among individuals with 
high dispositional optimism (Cohen et al., 1999). Similarly, among law students in their first semester of law school, optimistic students were found to have better immune functioning (e.g., higher numbers of helper T cells and higher natural killer cell cytotoxicity) than less optimistic students (Segerstrom, Taylor, Kemeny, \& Fahey, 1998). Optimism may also influence pulmonary functioning; among men aged 45-89 years, those with high optimism had a slower decline in pulmonary functioning than those with low optimism over the course of approximately 10 years (Kubzansky et al., 2002).

While dispositional optimism clearly is associated with a broad range of positive health outcomes, the best-documented association between optimism and health is the link between optimism and cardiovascular-related health outcomes. Substantial evidence from prospective studies confirms that having an optimistic disposition is associated with reduced risk of cardiovascular disease (CVD). A longitudinal study that followed initially healthy males (mean age 60.8 years) in a community sample showed that those who were optimistic were less likely to have developed or died from CVD 10 years later than those with low scores on optimism (Kubzansky, Sparrow, Vokonas, \& Kawachi, 2001). Lower rates of CVD and death due to CVD have also been found among post-menopausal women high in optimism aged 50-79 years who were followed for approximately eight years (Tindle et al., 2009). Indeed, some evidence suggests that having high dispositional optimism may be associated with a reduction in risk of CVD by up to $50 \%$ (Boehm \& Kubzansky, 2012). While being optimistic is associated with a reduction in the likelihood that one will develop CVD in the future, it also is associated with better prognosis after developing the disease; cardiac patients high in optimism have fewer subsequent cardiac events, lower cardiovascular-related mortality rates, report less pain, have fewer complications, and recover more quickly than those low in optimism following myocardial 
infarction and/or cardiac surgery (e.g., Grewen et al., 2000; Mahler, \& Kulik, 2000; Scheier, \& Carver, 1987).

\section{Mechanisms through which Optimism Improves Health}

The relation between dispositional optimism and physical health, especially

cardiovascular health, is well established. However, the specific mechanisms through which optimism influences health are unknown. One possible mechanism by which optimism influences physical health is through the range and type of coping strategies an individual uses to manage stress. According to Carver and Scheier (2000), when an obstacle is encountered, individuals typically assess the likelihood that they can overcome the obstacle. Because optimists believe they can obtain their goals, they are more likely to approach and strive to overcome obstacles. Less optimistic individuals may not believe they are able to overcome obstacles, and are therefore less likely to attempt to overcome them. Indeed, optimistic individuals tend to use approach-focused coping strategies, in which they work to overcome or remove the stressor by dealing with it directly, more than other coping strategies (Billingsley, Waehler, \& Hardin, 1993; Scheier, Weintraub, \& Carver, 1986). Optimists may also use problem-focused coping strategies when faced with health-related obstacles. For example, if optimists know that they have a family history of heart disease (obstacle), they are more likely to address the obstacle directly by exercising or eating a healthy diet, so that health can be maintained (goal). Conversely, pessimists who have family histories of heart disease may be less likely to see future health as attainable, and therefore, be less likely to engage in preventive measures.

Another clue to how optimism may improve health is found in the relation between optimism and health behaviors. Dispositional optimism has been linked to higher levels of 
physical activity, greater consumption of nutrient-rich foods, and lower levels of tobacco use (e.g., Giltay, Geleijnse, Zitman, Buijsse, \& Kromhout, 2007; Kelloniemi, Ek, \& Laitinen, 2005). Health behaviors engaged in by optimists may be conceptualized as approach-style coping strategies in which a desired health outcome is the goal. Consequently, it is likely that the improved cardiovascular health observed among optimists is related to their adherence to a healthier lifestyle.

Several researchers have suggested a third mechanism through which dispositional optimism influences health outcomes: the magnitude and pattern of one's autonomic nervous system response to stress. The autonomic nervous system consists of the sympathetic branch and the parasympathetic branch, both of which are responsive to exposure to stress (McEwen \& Stellar, 1993). In brief, during stress, both branches of the autonomic nervous system interact, resulting in increased blood pressure (BP), respiration rate, sweating on the hands and feet (resulting in increased electrical skin conductance), dilation of the pupils, accelerated heart rate (HR), and decreased gastro-intestinal activity and heart-rate variability (HRV). Multiple studies have demonstrated that the magnitude of one's autonomic response (especially cardiovascular response) to stress is predictive of future cardiovascular disease (e.g., Carroll et al., 2012; Krantz \& Manuck, 1984; Treiber et al., 2003). Furthermore, prolonged elevation of cardiovascular parameters following a stressful experience (i.e., delayed recovery) is also indicative of future cardiovascular disease (e.g., Chida \& Steptoe, 2010; Steptoe \& Marmot, 2005). Thus, those whose autonomic nervous systems exhibit the highest reactivity during stress and slowest recovery to resting levels following stress are more likely to develop CVD.

Several researchers have examined the possibility that the link between optimism and physical health is due, at least in part, to lower autonomic reactivity and/or quicker autonomic 
recovery when exposed to stress among those high in optimism. Because BP and HR reactivity to stress are the most closely linked to future CVD, most of the research on this topic has focused on these two indicators of autonomic reactivity. However, other indices of autonomic activity, such as skin conductance, have also been examined in relation to dispositional optimism.

\section{Optimism and Decreased Autonomic Reactivity to Stress}

In all, 13 studies completed between 1990 and 2017 have examined the relation between dispositional optimism and attenuated autonomic reactivity to stress. Of these studies, 11 assessed autonomic parameters during an acute laboratory stressor and two assessed ambulatory blood pressure over an extended period of time. BP, HR, and skin conductance are the only autonomic parameters that have been examined in these studies. A brief description of each of these 13 studies follows.

Williams, Riels, and Roper (1990) were the first to examine the association between optimism and BP response to stress. Fifty-six undergraduate students completed both a mental arithmetic stress task, during which their mistakes were corrected, and a Simon $\circledast$ stress task, during which the participant replicated a pattern of lights displayed as quickly as possible. Both stress tasks were six minutes in duration and were preceded by rest periods. They found that those high in dispositional optimism had lower diastolic blood pressure (DBP) reactivity during the mental arithmetic stress task only, in comparison to those low in optimism. Optimism did not influence systolic blood pressure (SBP) or HR reactivity during the mental arithmetic task, and did not affect SBP, DBP, or HR reactivity during the Simon ${ }_{\circledast}$ stress task. The authors concluded that their results supported the hypothesis that the mechanism through which dispositional optimism was associated with improved health could be reduced autonomic reactivity to stress (Williams et al., 1990). 
Eleven years later, Segerstrom (2001) examined the relation between optimism and attentional bias. Forty-seven undergraduate students completed an "emotional Stroop task" containing words with emotional valence (positive or negative). They found that when words with negative emotional meaning were presented, optimism was negatively related to skin conductance, indicating less autonomic arousal. However, when words with positive emotional meaning were presented, the association between optimism and skin conductance was positive, (albeit a weaker relation than when negative stimuli were presented). The authors noted, however, that after controlling for trait anxiety, the interaction between optimism and emotional content of the words was no longer significant in predicting skin conductance reactivity.

In 2004, Kennedy and Hughes (2004) sought to replicate the findings of Williams et al. (1990) and explore neuroticism as a possible moderator of the relation between optimism and $\mathrm{BP} / \mathrm{HR}$ reactivity to an acute laboratory stressor. After a rest period, each of the 50 female undergraduate participants completed a brief ( 3 minute) mental arithmetic task (without correction of mistakes), followed by a 5-minute recovery period. They found no differences between high-optimists and low-optimists in SBP, DBP, or HR reactivity or recovery during or after the stress task. The main effect for optimism was not significant either with or without neuroticism included as a covariate. However, they found that neuroticism was directly related to both SBP and DBP reactivity during the stress task. They concluded that dispositional optimism did not influence BP or HR reactivity during stress, but that other personality variables, such as neuroticism, may be underlying factors that account for any optimism-stress reactivity relations observed in prior work (Kennedy \& Hughes, 2004).

Following the recommendation by Kennedy and Hughes (2004) to examine the relation between dispositional optimism and stress reactivity in light of other variables, several later 
studies included various moderator variables in their examination of the association between dispositional optimism and reactivity to stress. Bonfiglio (2005) examined the moderating effects of social support on the optimism-stress reactivity relation. After a rest period, all 85 female undergraduate participants completed a five minute mental arithmetic task during which they were instructed to "work faster and more accurately." The author found that neither optimism nor social support was associated with SBP, DBP, or HR reactivity during stress. Furthermore, dispositional optimism and social support did not interact to influence BP or HR reactivity to stress. Dispositional optimism was also unrelated to SBP, DBP, or HR recovery following the stress task.

Contrary to the majority of researchers examining the optimism-autonomic arousal association, Nes, Segerstrom, and Sephton (2005) predicted that optimists, in contrast to pessimists, were likely to engage more and persist in a task longer when their goals were viewed as obtainable (see Carver and Scheier, 2000), and therefore experience more autonomic nervous system (HR and skin conductance) reactivity to a stressor. They also hypothesized that this relation would be moderated by self-awareness (measured by the Self-Consciousness Scale), which makes one's current status related to goals more salient. If one was optimistic and aware of their current standing with their goals, they would be more likely to persist and have greater arousal. Fifty-four undergraduates completed a 20-minute anagram stress task compromised of 11 anagrams, of which the first was insoluble, and the remaining 10 were solvable and of moderate difficulty. Optimism was not associated with either HR or skin conductance reactivity to the anagram task. During recovery, however, optimism interacted with self-awareness to predict skin conductance recovery; optimism was associated with slower skin conductance recovery, but only for those participants in the high self-awareness condition. 
One year later, Clark, Benkert, and Flack (2006) examined how optimism and history of violence exposure interacted to predict BP and HR reactivity to stress. One-hundred seventy-two black youth (mean age of 11.5 years) underwent a 10-minute rest period followed by a six minute digits-forward and digits-backward recollection task. Using the Perceived Life Chances Scale (Jessor, Donovan \& Costa, 1996) as an index of optimism, they found that optimism alone was not a significant predictor of SBP, DBP, or HR reactivity to stress. However, dispositional optimism moderated the effect of violence exposure on both SBP and HR reactivity to the task. For those high in optimism, violence exposure was inversely related to SBP reactivity. For those low in optimism, no relation between violence exposure and SBP reactivity was observed. However, for those low in optimism, violence exposure was positively related to HR reactivity to stress, while no relation was observed for those high in optimism.

Richman, Bennett, Pek, Siegler, and Williams, (2007) examined the association between several variables (optimism, race, past discrimination, trait-hostility) and cardiovascular reactivity to stress. Participants from a community sample consisting of 165 adults (ages 18-50) completed a 5 minute "stress" task during which they were supposed to recall and relate a personal experience that made them very angry. While they did not find a main effect of optimism on any cardiovascular reactivity parameter, they found a three-way interaction between race, perceived discrimination, and optimism on DBP reactivity to the anger-recall task. DBP increased among participants who had high perceived past discrimination and were high in optimism, and this relation was more pronounced among black participants. While there was no main effect of dispositional optimism on BP or HR reactivity or recovery, the observed interaction is contrary to the hypothesis that optimism is associated with reduced cardiovascular reactivity to stress. 
Later, Geers, Wellman, Helfer, Fowler, and France (2008) examined the relation between dispositional optimism and pain. They hypothesized that priming participants with either "health" or neutral primes would influence reactivity to the task. Seventy-two undergraduate participants underwent a 10-minute rest period, followed by a sentence-scramble task and a twominute cold-pressor task. Their results indicated that high dispositional optimism was associated with lower HR reactivity to the cold-pressor task; however, this finding was qualified by a significant interaction between optimism and prime condition on HR reactivity. High optimism was associated with lower HR reactivity only in the neutral primed group. A similar interaction between optimism and prime condition for DBP was observed; high optimism was related to lower DBP reactivity only in the group that received the neutral prime.

Terrill, Ruiz, and Garofalo (2010) sought to determine if the buffering effect of optimism on cardiovascular reactivity to stress depended on the nature of the stressor. Ninety undergraduate participants completed both a three-minute cold-pressor task and an 8-minute social speech task (3 minutes mental rehearsal, 5 minutes of speech delivery) during which they related a personally embarrassing experience in front of a video camera. When subscales of the LOT-R were analyzed separately, higher optimism was linked to less MAP reactivity to the mental rehearsal portion of the speech task. The authors also noted that optimism had a marginal inverse association with DBP reactivity during mental rehearsal $(p=0.06)$. Furthermore, higher optimism was associated with faster SBP and MAP recovery following the speech task. The authors commented that given their results, the cardiovascular benefits of optimism (e.g., attenuated BP response and faster BP recovery) may only be present during social stress, as opposed to non-social stressors. 
Puig-Perez et al. (2015) examined the association between optimism and HR response to a stressor among an older sample (ages: 55-76 years). Participants were randomized into either a stress group or a control group. In the stress group, participants completed a 10-minute Trier Social Stress Task (TSST), in which they gave a 5-minute speech about why they were a good job candidate, followed by five minutes of serial subtraction, both performed in front of two confederate observers. The control group task involved giving a five-minute speech about a neutral topic, followed by five minutes of easy serial addition. In the control group, neither task was performed in front of a committee. Puig-Perez et al. (2015) first ran their analyses with a total LOT-R score, and did not find significant results. However, when running separate analyses for optimism and pessimism subscales, they found that optimism, but not pessimism, was related to HR reactivity. They found that optimism had a negative association with HR reactivity in both the stress group and the control group during the task. Optimism was not linked with faster HR recovery following the task.

Most recently, Puig-Perez, Hacket, Salvador, and Steptoe (2017) exposed 140 participants with Type II Diabetes to a laboratory stress task. Participants completed both a fiveminute Stroop color-word task and a five-minute mirror-trace stress task. SBP, DBP, and HR were assessed throughout the tasks. They found that optimism was related to increased SBP and DBP reactivity during the stress task.

Two other studies examining autonomic reactivity as a possible mechanism through which optimism increases health have employed ambulatory assessment methods instead of using a laboratory stressor (Räikkönen \& Matthews, 2008; Räikkönen, Matthews, Flory, Owens, \& Gump, 1999). In both of these studies, measures of BP were obtained during daily living on samples of 201 adolescents aged 14-16 years (Räikkönen \& Matthews, 2008) and 100 adults, 
aged 30-45 years (Räikkönen et al., 1999). Both studies found that dispositional optimism was associated with reduced ambulatory blood pressures over several days. Räikkönen and Matthews (2008) found that, when experiencing daily stress, however, optimists' BP was just as elevated as that of pessimists.

Overall, studies examining the relation between optimism and autonomic reactivity to stress have reported mixed findings. Some studies found support for relations between dispositional optimism and attenuated physiological reactivity to stress (e.g., Geers et al., 2008; Puig-Perez et al., 2015; Terrill et al., 2010; Williams et al., 1990), but others failed to find any relation between optimism and physiological response parameters (e.g., Bonfiglio, 2005; Kennedy \& Hughes, 2004). Still other studies found that the relation between optimism and physiological response to stress was moderated by a third variable (e.g., Clark et al., 2006; Segerstrom, 2001). Finally, three studies found support for an association between optimism and increased reactivity to and delayed recovery from stress (Nes et al., 2005; Richman et al., 2007; Puig-Perez et al., 2017). Based upon this constellation of findings, the question of whether optimism is associated with attenuated autonomic reactivity remains largely unanswered.

The literature examining the relation between optimism and autonomic response to stress cited above has several weaknesses that warrant attention. For example, only seven of the 13 studies reviewed controlled for (either experimentally or statistically) extraneous variables that were relevant to physiological assessment (e.g., sex, BMI), or the optimism construct itself (other personality characteristics such as trait anxiety, neuroticism, etc.). Furthermore, only seven of the 13 studies controlled for other important variables that are known to influence autonomic activity, such as caffeine, nicotine, and prescription drug use prior to the experiment. Also, the majority of studies did not analyze pessimism and optimism subscales of the LOT/LOT-R 
separately as suggested by Scheier and colleagues (1994). In at least two cases (Puig-Perez et al., 2015; Terrill et al., 2010), no association was observed between LOT/LOT-R total score and autonomic reactivity parameters, but an association emerged once subscale scores were analyzed.

\section{The Behavioral Self-Regulation Model}

As noted above, three studies contained in this literature found that optimists' autonomic systems were more reactive to a stressor in certain situations (Nes et al., 2005; Richman et al., 2007; Puig-Perez et al., 2017). This finding is conceivable in light of Carver and Scheier's (2000) behavioral self-regulation model. According to this model, optimists are more likely to employ approach-focused coping when faced with a stressor; they engage in efforts to reduce or eliminate strains induced by a stressor to overcome it as a barrier. Accordingly, when optimists believe that their desired goals are attainable, they are likely to put forth more effort to reach their goals compared to persons low in optimism or high in pessimism (Carver \& Scheier, 2000). Research has shown that pessimists are more likely to give up when their goals are blocked than optimists because they do not see their desired goals as attainable (e.g., Carver, Lehman, \& Antoni, 2003; Strack, Carver, \& Blaney, 1987).

Based upon this Behavioral Self-Regulation Model, it follows that during times of stress, particularly during especially difficult stressors, optimists may experience greater autonomic arousal than pessimists as they attempt to solve the problems they are confronting. From this perspective, task difficulty may be an important factor that has yet to be explored in this literature. It seems likely that the degree to which optimists and pessimists react to a given challenge would depend upon its perceived difficulty or solvability. Indeed, research supports the idea optimists and pessimists react and perform differently during stressors of varying 
difficulty. During particularly difficult tasks, optimists tend to perform better than pessimists.

For example, Seligman and Schulman (1986) studied job performance among insurance salesman, an especially stressful job. They found that optimistic insurance agents sold approximately $27 \%$ more insurance plans compared to pessimistic agents during a specific time period. Helton, Dember, Warm, and Matthews (1999) also found that optimists performed better than pessimists on a particularly difficult computerized vigilance task. Seligman and Schulman (1986) also found that optimists were more persistent in difficult tasks; the pessimistic insurance agents quit their jobs at twice the rate of optimistic agents. Nes et al. (2005) also found that optimists persisted longer on a difficult anagram task compared to pessimists. In contrast, these performance and persistence differences between optimists and pessimists are not typically observed while engaging in easy tasks. Werenfels (2006) had optimists and pessimists complete three trials of a relatively easy clerical checking task, and found no performance differences. Similarly, Geers et al. (2008) employed a cold-pressor task (although uncomfortable, this is a simple task), and found no difference in length of time that optimists and pessimists persisted in the task.

\section{The Behavioral Self-Regulation Model and Reactivity to Stress Tasks}

It follows that during a very difficult and challenging stressor, optimists are likely to fully engage behavioral and cognitive resources to overcome the stressor, which may result in a significant increase in autonomic activity. In contrast, pessimists are less likely to fully engage all of their resources during a particularly difficult stressor, perhaps resulting in a smaller increase in autonomic activity during the stressor. When confronting tasks that are easily solved, optimists may not differ from pessimists on measures of physiological reactivity because they 
will continue to exert effort to solve the problem at hand and the pessimists may engage more fully in solving easy problems.

Unfortunately, studies that have examined optimism and autonomic reactivity to acute stress have employed various laboratory stressors without considering difficulty of the task. Stressors examined included mental arithmetic (Williams et al., 1990; Kennedy \& Hughes, 2004; Bonfiglio, 2005), digit-forward/digit backward (Clark et al., 2006), Simon® (Williams et al., 1990), anger experience recall (Richman et al., 2007), cold pressor (Geers et al., 2008; Terril et al., 2010), delivery of a speech (Puig-Perez et al., 2015; Terril et al., 2010), Stroop word-color task (Puig-Perez et al., 2017; Segerstrom, 2001), and anagram tasks (Nes et al., 2005). All of these tasks have been shown to elicit BP and HR reactivity in prior studies, so they represent appropriate methods for eliciting cardiovascular reactivity to stress in the studies that comprise this literature (Krantz, Manuck, \& Wing, 1986; Tuomisto, Majahalme, Kahonen, Fredrikson, \& Turjanmaa, 2005). However, all of these tasks were developed for purposes of eliciting a consistent level of task performance across an entire task period by maintaining constant attention to the mental task. Consequently, tasks employed in this literature were not devised for use in studies where exposure to tasks of varying levels of difficulty was desired. In fact, with the exception of the first anagram problem presented in Nes et al.'s study that was described as "insolvable," all other stimuli used in these studies were presented as solvable to study participants if they exerted some degree of effort on the task. Interestingly, the Nes et al. study was one of the two studies in this literature that demonstrated a slower recovery in skin conductance response among participants high in optimism, albeit only those with high selfawareness. Congruent with the Behavioral Self-Regulation Model, it is possible that participants low in optimism in this study gave up early and consequently recovered more quickly from the 
stressful task. Because the role of task difficulty has yet to be examined with respect to the relation between optimism and cardiovascular reactivity to stress, a task amenable to modification on the basis of task difficulty was required.

In the current study, puzzles from Raven's Progressive Matrices intelligence test were used as stimuli for the stress task (Raven, Raven, \& Court, 2004; see Stress Task Development section of the study method for details). The Raven's Progressive Matrices test includes a range of puzzles that vary widely in difficulty, allowing for the creation of difficult and easy versions of stress tasks that contain similar stimulus formats and task instructions. Additionally, the Raven's Matrices test is considered an active coping task in that each participant has instrumental control over the outcome (i.e., good or poor performance) and is known to elicit beta-adrenergic responses to stress (Hollenberg, Williams, \& Adams, 1981; Larkin, Polefrone, \& Francis, unpublished report). Because Raven's Matrices stimuli have been used to measure intelligence, a digit-symbol task (Wechsler, 2008), which has also been used to assess intelligence, was completed. Scores on the digit-symbol task were used as a covariate to account for the effects of intelligence on Raven's Matrices task performance.

\section{Aims of the Proposed Study}

The purpose of the proposed study was twofold. First, because the current literature assessing the association between dispositional optimism and autonomic reactivity to stress has significant shortcomings and findings have been mixed regarding study outcomes, this study sought to explore the association between optimism and cardiovascular reactivity to stress by addressing several of the shortcomings of previous studies. Second, this study sought to test Carver and Scheier's Behavioral Self-Regulation Model, which hypothesizes that optimists, compared to pessimists, are likely to engage more with mental tasks (and potentially experience 
more autonomic arousal) when their goals are blocked by obstacles. The results of this study aimed to explain why previous studies examining optimism and autonomic reactivity have exhibited mixed findings. Participants high and low in optimism were recruited from the student population at West Virginia University. To test whether participants high and low in optimism reacted differently based on the difficulty of the stressor, half of the study participants completed a highly difficult stress task while the other half completed a stress task of low difficulty. Based upon the Behavioral Self-Regulation Model, during the high difficult task, we hypothesized that participants high in optimism would use approach-focused coping and display more autonomic reactivity and slower recovery than those low in optimism, who would be more likely to disengage from a difficult task. Evidence for task engagement was examined by comparing task performance scores of high and low optimism participants. In response to the difficult task, we expected high optimism participants to perform better than those low in optimism. In contrast, during the easy task, we hypothesized that there would be no difference in autonomic reactivity or recovery between participants high and low in optimism because both groups would be equally engaged and view puzzles as solvable.

\section{Method}

\section{Participants}

One hundred fifty-two participants were recruited from undergraduate classes at West Virginia University. Participants were excluded if they smoked or used any kind of tobacco, had any chronic major health concerns (i.e., heart disease, cancer, diabetes), or were taking medications that influenced heart rate or blood pressure. Participants were asked via email to abstain from caffeine, alcohol, and vigorous exercise for two hours prior to the experimental session. 
The sample size for this study was determined using $\mathrm{G}^{*}$ Power 3.1.9.2, by entering the study design as "a priori, ANCOVA: Fixed effects, main effects, and interactions," with an effect size of $f=.2723, \alpha=.05$, and power of .80. This effect size was obtained from Puig-Perez et al., (2015), in which optimism accounted for $6.9 \%$ of the variance in HR reactivity $\left(R^{2}=.069\right.$ converts to an effect size f of .2723). This effect size represented a medium effect size, which was consistent with effect sizes reported by other studies that examined the relation between optimism and autonomic reactivity to stress. The power analysis indicated that a sample size of 152 was needed to detect an effect size of this magnitude.

Participants were selected from a screening sample of 1167 students enrolled in undergraduate courses based upon their scores on the LOT-R. The total screening sample consisted of 938 women and 229 men. In regard to racial composition, 44 identified as African American, 40 identified as Asian (Chinese, Korean, Japanese, Filipino, Indian), 992 identified as White, 66 identified as mixed race, 13 identified as other race, one identified as Native American or Alaskan Native, and 11 declined to answer. A tertile split of all participants completing the LOT-R was performed. Results indicated that participants scoring 22 or above were considered high in optimism (i.e., optimists) and participants scoring 17 or below were considered low in optimism (i.e., pessimists). Two previous studies examining optimism and cardiovascular reactivity selected participants based on their LOT-R scores, similar to the current study (Bonfiglio, 2005; Kenedy \& Hughes, 2004). Bonfiglio considered participants pessimists if their LOT-R scores were less than or equal to 12 , and optimists if their LOT-R scores were greater than or equal to 18. Kennedy and Hughes did not report cut-offs for their groups, but the mean LOT-R score of their pessimist group was $8.93(S D=2.8)$ and the mean LOT-R score of the optimist group was $20(S D=1.64)$. Compared to optimist and pessimist groups employed in 
these prior studies, the sampling distribution of students examined in the current study was more optimistic.

Of the 152 participants who completed the laboratory portion of the study, 130 were women and 22 were men. In regard to race/ethnicity, eight identified as African American, eight identified as Asian, 124 identified as White, seven identified as mixed race, one identified as American Indian or Alaskan Native, one identified as other race, and three declined to answer. Comparisons of the groups invited to participate in the experimental session revealed that optimists had a mean LOT-R score of $24.99(S E=.26)$, and pessimists had a mean LOT-R score of $13.33(S E=.29)$. When broken down into study groups, the optimist group completing the difficult task had 32 women and five men, of which 29 were White, three were African American, one was Asian, two were mixed race, and 1 identified as Other race. The optimists completing the easy task consisted of 32 women and five men, of which 32 were White, two were African American, two were Asian, and one declined to answer. Among the pessimists completing the difficult task, 33 were women and six were men, of which 31 were White, one was African American, two were Asian, three were mixed race, and two declined to answer. Among the pessimists completing the easy task, 33 were women and six were men, among which 32 were White, two were African American, three were Asian, and two were mixed race.

\section{Measures}

Blood pressure. An Industrial and Biomedical Sensors, Inc. Model SD-700A (Waltham, MA) automated sphygmomanometer was used to measure SBP, DBP, and MAP. This device uses an automated occluding cuff positioned on the brachial artery of the participants' nondominant arm to detect Kortokoff sounds (via a microphone), ensuring accurate BP 
measurement. Maximum cuff inflation was set at 165 millimeters of Mercury $(\mathrm{mm} \mathrm{Hg})$ and rate of deflation was set at $3 \mathrm{~mm} \mathrm{Hg}$ per sec.

Heart rate (HR). HR was measured using a Polar heart rate monitor Model 810i (Lake Success, New York). This device measures HR continuously throughout data collection by sending ECG signals from a sensor strapped around the participants' chest to a receiver attached to a computer. Three measures of heart rate variability (HRV) were determined from the continuous HR signals: standard deviation of the normal sinus interbeat interval-to-normal sinus interbeat interval (SDNN); low frequency (LF) HRV, and high frequency (HF) HRV. Kubios HRV v2.0 software was used to examine HR signals for clarity and conduct the spectral waveform analyses (Niskanen et al., 2004).

\section{Self-report measures}

Demographic form. A short demographic form used in previous studies in the Behavioral Physiology Laboratory (e.g., Stephenson, 2015) was used in this study. This questionnaire includes items pertaining to age, sex, height, weight, race/ethnicity, year in school, and parental socioeconomic status. In regard to parental socioeconomic status, an adaptation of the MacArthur Subjective Social Status Ladder, which has been used in numerous studies as a measure of subjective SES and has demonstrated good construct validity (Cundiff, Smith, Uchino, \& Berg, 2013), was used. Participants are asked to imagine a ladder representing social/economic status of families in the United States, including factors such as money, education, and respected jobs. Those higher on the ladder have more money, more education, and more respected jobs. Participants were asked to identify which rung of the ladder (there are 10 rungs) their respective family falls. The form also includes general questions about participants' health status and behaviors (See Appendix B). 
Life Orientation Test - Revised (LOT-R). The LOT-R is a six-item questionnaire (with four additional distractor items) designed to assess dispositional optimism (Scheier, Carver, \& Bridges, 1994). The creators of the LOT-R intended it to assess a single construct of optimism. However, some have argued that that a two-factor model, with optimism and pessimism factors, fit the data better (Chang and McBride-Chang 1996; Glaesmer et al., 2012; Robinson-Whelen et al. 1997), while others have argued a single factor fits the data better and makes better conceptual sense (Rauch, Schweizer, \& Moosbrugger, 2007; Scheier et al., 1994). Scheier et al. (1994) suggests that total LOT-R scores should be followed-up by analyzing optimism and pessimism subscales separately. The LOT-R total score has demonstrated good internal consistency $($ alpha $=0.78)$ and test-retest reliability $(28$-month correlation $=0.79$; Scheier et al., 1994). Individual optimism and pessimism subscales, each containing 3 items, also demonstrate good internal consistency (alpha $=0.70$, alpha $=0.74$, respectively; Glaesmer et al., 2012). The LOT-R has also demonstrated acceptable discriminant validity, sharing only modest amounts of variance with conceptually similar constructs such as neuroticism, trait anxiety, and self-esteem (Scheier et al., 1994). In the current study, the LOT-R total score demonstrated good internal consistency $($ alpha $=0.90)$. The optimism and pessimism subscales also demonstrated good internal consistency (alphas $=0.78$ and 0.90 , respectively) in the current study.

State-Trait Anxiety Inventory (STAI). The STAI has both state and trait anxiety subscales. For the purposes of this study only the trait anxiety subscale was used, which is comprised of 20 items. The trait anxiety subscale of the STAI has previously demonstrated good internal consistency $($ alpha $=0.90)$ and good test-retest reliability $(30$-day correlation $=0.73$; Spielberger, Gorsuch, Lushene, Vagg, \& Jacobs, 1983). The trait anxiety subscale also demonstrated good concurrent validity and discriminant validity, as evidenced by its strong 
association with the IPAT Anxiety Scale and the Manifest Anxiety Scale, and its weak associations with other personality factors on the Edwards Personal Preference Checklist (a personality inventory) and school aptitude (e.g., GPA, class rank, etc.; Spielberger et al., 1983). In the current study, the trait anxiety subscale of the STAI demonstrated good internal consistency $($ alpha $=0.94)$.

Big Five Inventory (BFI-2). The BFI-2 is a 60-item questionnaire that assesses the Big Five personality domains: Extraversion, Agreeableness, Conscientiousness, Negative Emotionality, and Open-Mindedness. Additionally, it assesses 15 more-specific facet traits. Each item is a brief adjective or description of an attribute or interest; the participant is instructed to endorse to what degree the adjective/description describes him or her on a five-point Likerttype scale. All five domain scales have demonstrated alpha reliabilities over 0.83 , and test-retest reliability of at least 0.76 (Soto \& John, 2016). In the current study, all subscales demonstrated good internal consistency: Extraversion $($ alpha $=0.88)$, Agreeableness $($ alpha $=0.82)$, Conscientiousness $($ alpha $=0.84)$, Neuroticism $($ alpha $=0.90)$, and Openness to Experience $($ alpha $=0.80)$. The BFI-2 has demonstrated good discriminant and concurrent validity as evidenced by strong correlations with corresponding personality traits on the NEO Personality Inventory. For purposes of the proposed study, only the (Negative Emotionality) Neuroticism scale was used.

Multiple Affect Adjective Checklist-Revised (MAACL-R). The MAACL-R (Zuckerman \& Lubin, 1985) is a checklist-type questionnaire containing 66 adjectives describing state and/or trait affect. Participants were asked to complete the MAACL-R after the completion of the recovery phase, and asked to indicate how they felt during the stress task. This measure traditionally has five sub-scales: Anxiety, Depression, Hostility, Positive Affect, and Sensation 
Seeking. However, evidence suggests the MAACL-R may be better represented with a twofactor model: positive affect and negative affect (Hunsley, 1990). For the purpose of this study, the two-factor model was utilized. This scale has demonstrated good concurrent validity as evidenced by strong correlations with similar state affect scores on the State Trait Personality Inventory, Sensation Seeking Scale, and Affect Balance Scale. It has also demonstrated good discriminant validity as evidenced by weak associations with less similar constructs also measured by these scales (Lubin, Van Whitlock, Reddy, \& Petren, 2001).

Self-efficacy Questionnaire. The purpose of this questionnaire was to ensure the participants' understanding of the types of puzzles they encountered during the stress task and to assess confidence in their ability to complete the task. The self-efficacy questionnaire included a sample item from the Raven's Matrices (Raven, Raven, \& Court, 2004), similar to the items that they would encounter during the stress task. It then instructed participants to rate how confident they are that they will be able to complete all of the items during the stress task accurately. Participants responded to this item on a four-point Likert type scale. This questionnaire was designed specifically for the proposed study. Although its psychometric characteristics have not been reported, it was formatted based on similar self-efficacy scales in the literature.

Post-Task Questionnaire. The post-task questionnaire consisted of items that assessed the stress level experienced during the task, perceived difficulty of the task, and other factors related to the participants' experiences during the stress task.

Digit-Symbol Task. The digit-symbol task is a simple task which is a component of several well-known IQ tests, including the Wechsler Adult Intelligence scale (WAIS; Wechsler, 2008). This task is a measure of processing speed, a major component of IQ. Participants are given a coding key and a series of numbers, and must record the corresponding symbol for as 
many numbers in the series as they are able in 90 seconds. The digit-symbol task has shown good test-retest reliability ( $r=0.74$ over an 80-day period; Morrison, Simone, $\mathrm{Ng}, \&$ Hardy, 2015). This measure was included in order to account for the influence of participants' intelligence on task completion. The score from this task was used as a covariate in analyses examining the stress task score.

\section{Experimental design}

This study employed a quasi-experimental design. The independent variables of interest were optimism level of participant (optimist, pessimist), and difficulty of stress task (difficult vs. easy). Participants were assigned to the optimism or pessimism group based on their LOT-R total score; participants scoring in the top and bottom tertiles were invited to participate in the laboratory portion of the study. Participants were assigned to complete either the difficult or the easy stress task based on a random number generator after they arrived in the laboratory.

\section{Stress task development and pilot testing}

Raven's Matrices puzzles were obtained from the Standard Progressive Matrices Sets A, B, C, D, and E test booklet (Raven, 1998). Puzzles from these sets range in difficulty, with easier puzzles occurring toward the beginning of each set and more difficult puzzles toward the end of each set. Fourteen puzzles that were judged by the researcher to be easy and 14 that were judged to be difficult were selected to be piloted for consideration as test stimuli for the primary study. During both the pilot and experimental portions of the study, all Raven's Matrices were presented electronically on a Dell Inspiron (Model 1525) laptop computer. Eight graduate students in the Department of Psychology completed the 28 puzzles (difficult and easy) and the duration for stating an answer was timed for each puzzle. The average time to answer the easy puzzles was approximately seven seconds (ranged from 5.1 - 14.9 seconds), while the average 
time to answer the difficult puzzles was approximately 28 seconds (ranged from 13.6 - 36.9 seconds). Based upon these data showing that all easy puzzles were completed in less than 16 sec and most difficult puzzles took longer than $16 \mathrm{sec}$ to complete, a 16-sec response interval was selected for all 28 puzzles, followed by a five sec period in which the participant was instructed to state their answer aloud and the researcher would inform them whether it was correct or not.

Data were collected on two graduate students using the timing selected to determine if 16 seconds was a sufficient amount of time for each puzzle to be displayed. The graduate student who completed the difficult stress task was unable to correctly answer any of the puzzles correctly, and reported that the time limit (16 seconds) was not enough time to grasp any of the patterns. The graduate student who completed the easy stress task correctly answered 13 out of 14 puzzles.

Out of concern that the puzzle-viewing period (16 seconds) was too short to solve the difficult puzzles, we decided to compare viewing 14-puzzles (seeing each puzzle for 16 seconds) with viewing 12-puzzles (seeing each puzzle for 20 seconds) on a sample of 10 undergraduate students. We asked five pilot participants who completed the difficult task whether the allotted time was enough time to come up with an answer, whether they were able to at least eliminate 23 of the possible answers, and how difficult the task was on a scale of 1-10. We asked five pilot participants who completed the easy task if they were able to solve the puzzle during the first 5-8 seconds, or if it took them the entire time to get the answer. They were also asked what they did during the remaining time if they got the answer in the first 5-8 seconds. Finally, they were asked how difficult the task was on a scale of 1-10. 
For the three students who completed the difficult stress task with 14 puzzles, the average number of correctly solved puzzles was 1.66 . They reported that 16 seconds was not enough time to complete the puzzle, that they only had enough time to eliminate 1 of 8 possible answers, and that the task was judged a 10 out of 10 on the scale of difficulty. For the three students who completed the easy stress task with 14 puzzles, the average number of correctly solved puzzles was 10.66. They indicated that they were able to solve most of the puzzles in the first 5-8 seconds, and that they double-checked their answer during the remaining time. They said the task was a 4-5 on a 1-10 scale of difficulty.

Two students completed the difficult stress task using the 12-puzzle format. On average, they correctly solved two puzzles. They indicated that 20 seconds was enough time to solve a few of the puzzles, but it was not enough time to solve many of them. They indicated that 20 seconds was enough time to eliminate 2-3 of the possible alternatives. They rated the difficulty as 8-9 on a 10-point scale. The two students who completed the easy stress task with 12 puzzles both correctly solved all 12 puzzles. Both indicated that it took them approximately 10 seconds to solve each puzzle, and that they used the remaining time to check their answer. They rated the difficulty as 3-4 on a 10-point scale.

Based upon these pilot data, it was determined that 16 seconds was not a long enough duration to solve any of the difficult puzzles. To ensure that participants did not become discouraged during the difficult task, the 12-puzzle format was adopted in which each puzzle appeared for 20 seconds for both easy and difficult matrices.

\section{Procedure}

Participants completed the demographic and other pertinent questionnaires online using the SONA system. Those who scored either in the top or bottom tertile on the LOT-R and met 
all other inclusion criteria (no medications that would affect cardiovascular activity, etc.) were invited to schedule a session in the Behavioral Physiology Laboratory. Upon entering the laboratory, the participant met the experimenter, was dressed in a white lab coat and behaved in a professional manner. The experimenter described the study, went over potential risks and benefits with the participant, and obtained his/her informed consent using an approved consent agreement. Then, the experimenter measured the height and weight of the participant and confirmed that he or she had abstained from caffeine, alcohol, and exercise for the previous two hours. The experimenter then left the room so the participant could attach the Polar heart rate monitor around his or her chest privately. The experimenter attached the blood pressure cuff to the participants' non-dominant upper arm and HR and BP signals were examined to assure clarity. Participants were then instructed to sit quietly with both feet on the floor for a 15-minute rest period. Blood pressure measurements began eight minutes into the rest period and were taken every two minutes for the remainder of the rest period and HR was measured continuously during the rest period.

Following completion of the rest period, participants were provided instruction about how to complete the problems on the Raven's Matrices stress task and, after viewing the sample problem, completed the self-efficacy questionnaire. Once the experimenter gave the participant the signal to begin, the participant pressed a single key on a laptop computer, which launched the stress task. As noted above, participants were randomly assigned to receive either the easy or difficult version of the task. In both the easy and difficult stress tasks, each puzzle appeared for 20 seconds, followed by a screen that stated "Answer?" for five seconds. During the 20 second period in which the puzzle was shown, the participant was expected to attempt to solve the puzzle. Task performance was monitored by watching the participant through a one-way 
mirrored window and listening to answers on an intercom. When they saw “Answer?" screen, they were instructed to state their answer aloud so that the experimenter could record it and provide them verbal feedback (e.g., "correct" or "incorrect) regarding their answer via an intercom. After the screen that prompted them to give their answer was displayed for five seconds, this screen disappeared and the next puzzle was presented. Both the difficult and easy stress tasks contained a total of 12 puzzles and lasted five minutes. Both tasks were completed in an identical manner using identical instructions and format, so that the only difference between conditions was level of difficulty of the puzzles. BP was measured during the first, third, and fifth minutes of the task period and HR was measured continuously.

Following the completion of the stress task, participants sat quietly for a five-minute recovery period. $\mathrm{BP}$ and $\mathrm{HR}$ measures were obtained in an identical manner to measures during the task period. Following the recovery period, participants completed the post-task questionnaire and the MAACL-R. They were then given instructions and completed the 90second digit-symbol task. Following the digit-symbol task, experimental apparatuses were detached and participants were debriefed and paid $\$ 10$ for their time.

\section{Results}

\section{Data Cleaning and Reduction}

Invalid or questionable measures of BP were removed using the criteria outlined by Marler, Jacob, Lehoszky, and Shapiro (1988). Accordingly, SBPs below $70 \mathrm{~mm} \mathrm{Hg}$ or above $250 \mathrm{~mm} \mathrm{Hg}$ or DBPs below $45 \mathrm{~mm} \mathrm{Hg}$ or above $150 \mathrm{~mm} \mathrm{Hg}$ were replaced with the most proximate valid BP value within that experimental period. Furthermore, when pulse pressure between a SBP and its paired DBP was less than $30 \mathrm{~mm} \mathrm{Hg}$, BPs that were inconsistent with their proximate BPs were replaced with the mean of two proximate, valid BPs. A total of $37 \mathrm{BP}$ 
measurements (out of 2980 total BP measurements or approximately $1 \%$ of BP measures) were flagged as questionable and replaced according to these criteria.

Heart rate data were analyzed for artefacts using the Polar $810 \mathrm{i}$ software set at a low filtering level. This software replaces erroneous HR values typically observed when participants move excessively or the signal from the Polar Monitor is momentarily lost. HRs were then calculated for each minute during the rest, task, and recovery periods. It should be noted that complete HR data were not obtained for three participants.

\section{Preliminary Analyses}

Rest Period. One way repeated measures ANOVAs were conducted to examine variation that might occur in each cardiovascular parameter across each minute of the rest period (See ANOVA Summary Tables 1-6 in Appendix B). Analysis of resting SBP, $F(2,302)=1.92, p=$ 0.148 , resting DBP, $F(2,302)=0.84, p=0.435$, and resting $\mathrm{MAP}, F(2,302)=0.32, p=0.730$, revealed no significant main effects, so BP values during the rest period were averaged to arrive at a mean resting level for each parameter (i.e., resting SBP, resting DBP, resting MAP). In contrast, the repeated measures ANOVA on resting HR revealed a significant main effect, $F(2$, 298) $=6.08, p=0.003, \eta_{p}{ }^{2}=0.039$. Follow-up mean comparisons showed that HR during minute 10 (76.05 bpm) was significantly lower than HR during minute 14 (77.07 bpm). These differences did not indicate any systematic change in HR across the baseline period, so all HRs were averaged to yield a single resting HR measure.

Because assessment of HRV is unreliable across durations as brief as one minute, interbeat intervals from all valid HR values during the rest period were subjected to HRV analysis, producing one measure at rest for each HRV parameter (SDNN, HF, LF). By 
convention, all HF and LF measures throughout the experiment were transformed using logarithmic transformations in order to normalize distributions for purposes of analysis.

Task Period. For purposes of analyzing cardiovascular reactivity to the task, measures of $\mathrm{HR}$ and $\mathrm{BP}$ were averaged across minutes to obtain average cardiovascular reactions to the entire Raven's Matrices task. Like the rest period, a single measure for each SDNN, HF, and LF was determined for the task period. To confirm that participants reacted to the Raven's Matrices tasks with increased autonomic activity, Group (Easy, Difficult) X Period (Rest, Task) mixed factors ANOVAs were conducted for each cardiovascular parameter (See ANOVA Summary Tables 7-19 in Appendix B). For SBP, the main effect of Period was significant, $F(1,150)=$ 149.18, $p=0.000, \eta_{p}{ }^{2}=0.499$. SBP was higher during the stress task $(M=118.4 \mathrm{~mm} \mathrm{Hg}, S E=$ 0.97), than during the rest period $(M=111.5 \mathrm{~mm} \mathrm{Hg}, S E=0.87)$. The Group X Period interaction effect, $F(1,150)=0.229, p=0.633, \eta_{p}{ }^{2}=0.002$ was not significant, indicating no significant difference in SBP reactivity between those completing the easy task compared to those completing the difficult task. Similarly, for DBP, the main effect of Period was significant, $F(1,150)=132.09, p=0.000, \eta_{p}{ }^{2}=0.468$. DBP was higher during the stress task $(M=71.1 \mathrm{~mm}$ $\mathrm{Hg}, S E=0.75)$, than during the rest period $(M=65.4 \mathrm{~mm} \mathrm{Hg}, S E=0.72)$. The Group X Period interaction effect, $F(1,150)=0.54, p=0.464, \eta_{p}{ }^{2}=0.004$, was not significant. Analysis of MAP revealed similar results; the main effect of Period was significant, $F(1,150)=203.0, p=0.000$, $\eta_{p}{ }^{2}=0.575$. MAP was higher during the stress task $(M=86.9 \mathrm{~mm} \mathrm{Hg}, S E=0.69)$, than during the rest period $(M=80.8 \mathrm{~mm} \mathrm{Hg}, S E=0.64)$. The Group X Period interaction effect, $F(1,150)$ $=0.13, p=0.724, \eta_{p}^{2}=0.001$, was not significant.

HR during the stress task $(M=81.3 \mathrm{bpm}, S E=0.91)$, was significantly higher than during rest $(M=77.4 \mathrm{bpm}, S E=0.89), F(1,147)=57.07, p=0.000, \eta_{p}{ }^{2}=0.280$. The Group X 
Period interaction effect was not significant, $F(1,147)=0.75, p=0.389, \eta_{p}^{2}=0.005$. For SDNN, neither the Period, $F(1,147)=2.46, p=0.119, \eta_{p}{ }^{2}=0.016$, nor the Period X Group interaction effect, $F(1,147)=3.81, p=0.053, \eta_{p}{ }^{2}=0.025$, were significant, indicating that the stressful task did not alter SDNN. HF-HRV showed a pattern similar to blood pressure and HR measures. The main effect of Period was significant, $F(1,147)=8.49, p=0.004, \eta_{p}{ }^{2}=0.055$. HF-HRV was lower during the stress task $\left(M=1334.6 \mathrm{~ms}^{2}, S E=223.18\right)$, than during the rest period $\left(M=2370.4 \mathrm{~ms}^{2}, S E=910.49\right)$. The Group X Period interaction effect, $F(1,147)=0.50$, $p=0.480, \eta_{p}{ }^{2}=0.003$, was not significant. For LF-HRV, the Period main effect, $F(1,147)=$ 4.99, $p=0.027, \eta_{p}{ }^{2}=0.033$ was significant. Additionally, the Group X Period interaction effect, $F(1,147)=5.16, p=0.025, \eta_{p}^{2}=0.034$, was significant. For those completing the difficult task, resting LF-HRV $\left(M=1379.8 \mathrm{~ms}^{2}, S E=134.19\right)$ was higher than during the stress task, $(M=$ $\left.998.7 \mathrm{~ms}^{2}, S E=132.05\right)$. However, for those completing the easy task, resting LF-HRV $(M=$ 1303.1 $\left.\mathrm{ms}^{2}, S E=135.10\right)$ was not significantly different from task LF-HRV $\left(M=1401.1 \mathrm{~ms}^{2}\right.$, $S E=132.94)$. In sum, with the exception of SDNN, autonomic arousal occurred in response to the difficult task and for all but LF-HRV in response to the easy task.

Group (Easy, Difficult) X Minute (Task minutes 1, 3, 5) mixed factors ANOVAs were also used to examine minute-to-minute differences in cardiovascular parameters during completion of the Raven's Matrices tasks (See ANOVA Summary Tables 20-29 in Appendix B). For SBP, the main effect for Period was significant, $F(2,300)=41.85, p=0.000, \eta_{p}{ }^{2}=0.218$. SBP during the first minute of the stress task $(M=120.8 \mathrm{~mm} \mathrm{Hg}, S E=1.04)$ was significantly higher than SBP during minute 3, $(M=118.7 \mathrm{~mm} \mathrm{Hg}, S E=1.07)$, which was significantly higher than SBP during minute 5, $(M=115.8 \mathrm{~mm} \mathrm{Hg}, S E=0.94)$. The Group X Period interaction effect, $F(2,300)=1.18, p=0.308, \eta_{p}^{2}=0.008$, was not significant, meaning there 
was no difference in patterns of SBP reactivity between those completing the easy and difficult tasks. For DBP, the main effect for Period, $F(2,300)=12.01, p=0.000, \eta_{p}{ }^{2}=0.074$, was significant, while the Group X Period interaction effect, $F(2,300)=0.905, p=0.406, \eta_{p}{ }^{2}=$ 0.006, was not significant. DBP during the first minute of the stress task $(M=73.09 \mathrm{~mm} \mathrm{Hg}, S E$ $=0.80)$ was significantly higher than DBP during minute $3,(M=70.24 \mathrm{~mm} \mathrm{Hg}, S E=0.88)$ and DBP during minute 5, $(M=70.04 \mathrm{~mm} \mathrm{Hg}, S E=0.87)$. There was no difference between DBP during minutes 3 and 5 of the task. The pattern of reactivity for MAP was similar to that of SBP; the main effect for Period, $F(2,300)=27.5, p=0.000, \eta_{p}{ }^{2}=0.155$, was significant, while the Group X Period interaction effect, $F(2,300)=1.52, p=0.220, \eta_{p}{ }^{2}=0.010$, was not significant. MAP during the first minute of the stress task $(M=89.0 \mathrm{~mm} \mathrm{Hg}, S E=0.72)$ was significantly higher than MAP during minute 3, $(M=86.38 \mathrm{~mm} \mathrm{Hg}, S E=0.79)$, which was significantly higher than MAP during minute 5, $(M=85.30 \mathrm{~mm} \mathrm{Hg}, S E=0.75)$.

For HR, both the main effect for Period, $F(2,294)=19.51, p=0.000, \eta_{p}{ }^{2}=0.117$, and the Group X Period interaction effect, $F(2,294)=4.41, p=0.013, \eta_{p}{ }^{2}=0.029$, were significant. For those completing the difficult task, HR significantly decreased from minute one, $(M=82.41$ bpm, $S E=1.49)$, to minute three, $(M=81.44 \mathrm{bpm}, S E=1.33)$, and again decreased from minute three to minute five, $(M=80.49 \mathrm{bpm}, S E=1.23)$. However, for those completing the easy task, HR significantly decreased from minute one, $(M=83.40 \mathrm{bpm}, S E=1.50)$, to minute three, $(M=$ $79.80 \mathrm{bpm}, S E=1.34)$, but did not decrease from minute three to minute five $(M=80.31 \mathrm{bpm}$, $S E=1.24)$. For those completing the difficult task, HR decreased more slowly during the task compared to those completing the easy task. Across all BP and HR parameters, the greatest reactions occurred during the first minute of the task. 
For purposes of analyzing cardiovascular reactivity to the Raven's Matrices tasks to examine the primary study hypotheses, measures of BP were averaged across minutes to obtain average cardiovascular reactions for the entire task. The average of continuous HR for the entirety of the task was used for HR analyses to examine study hypotheses.

Recovery Period. Individual values for each cardiovascular parameter during the recovery period were used to calculate area under the curve (AUC) using the formula used by Whited et al. (2010), Neumann, Waldstein, Sellers, Thayer, and Sorkin (2004), and Friedberg, Suchday, and Shelov (2007). The formula used was:

Excursion $=(0.5 * 120) *(($ cardiovascular measure at Task min 4$)+(2 *$ cardiovascular measure at recovery $\min 1)+(2 *$ cardiovascular measure at recovery min 3$)+$ (cardiovascular measure at recovery min 5) - (cardiovascular measure at baseline * 360). By transforming values into this measure of area, rate of recovery can be captured in a single value for each cardiovascular measure. A larger number, or larger area under the curve, indicated a more prolonged recovery.

Consideration of Covariates. Potential covariates were assessed by calculating correlation coefficients between each potential covariate and resting and reactivity measures for each cardiovascular parameter (See Correlation Summary Tables 30-34 in Appendix B). Continuous variables assessed as potential covariates included BMI, trait anxiety, and neuroticism/negative affect. BMI was significantly related to resting SBP $(r=0.412, p=0.000)$, task $\operatorname{SBP}(r=0.350, p=0.000)$, resting DBP $(r=0.261, p=0.001)$, task $\mathrm{DBP}(r=0.253, p=$ $0.002)$, resting MAP $(r=0.382, p=0.000)$, and task MAP $(r=0.347, p=0.000)$. BMI was therefore entered as a covariate in all BP analyses. Trait anxiety was significantly related to optimism, $(r=-0.777, p=0.000)$. Neuroticism/negative emotionality was also significantly 
correlated with optimism $(r=-0.660, p=0.000)$. Therefore, as the literature suggests, trait anxiety and neuroticism were used as covariates in all analyses. BMI was not related to any measure of HR, SDNN, HF-HRV, or LF-HRV. Intelligence (measured by digit-symbol task) was not related to any cardiovascular parameter,

\section{Cardiovascular Measures at Rest}

Optimism (optimist, pessimist) X Task Difficulty (Easy, Difficult) ANCOVAs were conducted for each cardiovascular parameter to determine if there were any differences during the initial rest period between groups (See ANCOVA Summary Tables 35-41 in Appendix B). Covariates included BMI, trait anxiety, and Neuroticism. There were no significant differences between groups at rest. See the first panel of Figures 1-4 and Table 2 for means, standard errors, and standard deviations for resting SBP, DBP, MAP, and HR.

\section{Primary Analyses: Cardiovascular Reactivity to the Task}

Because the primary hypotheses of this study pertain to differences between optimists and pessimists to stressors of differing difficulty, two-way Optimism (optimist, pessimist) X Task Difficulty (Easy, Difficult) ANCOVAs were conducted for each parameter, covarying resting levels, BMI (for BP analyses), trait anxiety, and negative emotionality (See ANCOVA Summary Tables 42-51 in Appendix B). See the middle panel of Figures 1-4 for means and standard errors for SBP, DBP, MAP, and HR during the Raven's Matrices task.

Systolic Blood Pressure. The ANCOVA on SBP reactivity to the stress tasks revealed no significant main effects for Optimism, $F(1,143)=3.62, p=0.059, \eta_{p}{ }^{2}=0.025$, or Task Difficulty, $F(1,143)=0.623, p=0.431, \eta_{p}{ }^{2}=0.004$. The Optimism X Task Difficulty interaction effect was also not significant, $F(1,143)=0.329 p=0.567, \eta_{p}^{2}=0.002$. It should be noted a post-hoc power analysis using the obtained effect size from the analysis of SBP 
reactivity to the task $\left(\eta_{p}^{2}=0.025\right)$ revealed the obtained power of this experiment was 0.500 , indicating there was a 50.0\% chance statistically significant difference would be found when such a difference truly existed.

Diastolic Blood Pressure. The ANCOVA on DBP reactivity to the Raven's Matrices task revealed a main effect for Optimism, $F(1,143)=5.82, p=0.017, \eta_{p}{ }^{2}=0.039$. Optimists exhibited greater DBP reactivity to the task (covariate adjusted $M=72.8 \mathrm{~mm} \mathrm{Hg}, S E=0.88$ ) compared to pessimists (covariate adjusted $M=69.3 \mathrm{~mm} \mathrm{Hg}, S E=0.84$ ). Neither the main effect for Task Difficulty, $F(1,143)=0.686, p=0.409 ., \eta_{p}{ }^{2}=0.005$, nor the Optimism X Task Difficulty interaction, $F(1,143)=0.457, p=0.500, \eta_{p}{ }^{2}=0.003$, was significant.

Mean Arterial Pressure. Analysis of MAP during the Raven's Matrices' task revealed that main effects for Optimism, $F(1,143)=0.989, p=0.322, \eta_{p}{ }^{2}=0.007$, Task Difficulty, $F(1$, 143) $=0.092, p=0.762, \eta_{p}^{2}=0.001$, and the Optimism $\mathrm{X}$ Task Difficulty interaction effect, $F(1$, 143) $=0.662, p=0.417, \eta_{p}^{2}=0.005$, were not significant.

Heart Rate. The ANCOVA on HR reactivity to the tasks revealed no significant main or interaction effects. Neither the main effects for Optimism, $F(1,140)=0.628, p=0.430, \eta_{p}{ }^{2}=$ 0.004, or Task Difficulty, $F(1,140)=0.723, p=0.396, \eta_{p}{ }^{2}=0.005$, nor the Optimism X Task Difficulty interaction, $F(1,140)=0.340, p=0.561, \eta_{p}^{2}=0.002$, were significant.

High Frequency Heart Rate Variability. The ANCOVA on HF-HRV reactivity to the tasks revealed no significant main or interaction effects. Neither the main effects for Optimism, $F(1,140)=0.005, p=0.945, \eta_{p}{ }^{2}=0.000$, or Task Difficulty, $F(1,140)=2.095, p=0.150, \eta_{p}{ }^{2}=$ 0.015, nor the Optimism X Task Difficulty interaction, $F(1,140)=0.010, p=0.922, \eta_{p}{ }^{2}=0.000$, were significant. 


\section{Standard Deviation of Normal to Normal R-R Intervals (SDNN). The ANCOVA on} SDNN reactivity to the tasks revealed the main effect for Optimism, $F(1,140)=0.370, p=$ $0.544, \eta_{p}{ }^{2}=0.003$, was not significant. However, the main effect for Task Difficulty, $F(1,140)$ $=4.97, p=0.027, \eta_{p}{ }^{2}=0.034$, was significant. Those completing the difficult task exhibited greater SDNN reactivity to the task (covariate adjusted $M=58.0 \mathrm{~ms}, S E=2.83$; lower SDNN indicates greater reactivity) compared to those completing the easy task (covariate adjusted $M=$ $67.0 \mathrm{~ms}, S E=2.83)$. The Optimism X Task Difficulty interaction, $F(1,140)=3.26, p=0.073$, $\eta_{p}{ }^{2}=0.023$, was not significant.

Low Frequency Heart Rate Variability. Similar to SDNN, the ANCOVA on LF-HRV reactivity to the tasks revealed neither the main effect for Optimism, $F(1,140)=1.09, p=0.298$, $\eta_{p}{ }^{2}=0.008$, nor a Optimism X Task Difficulty interaction effect, $F(1,140)=1.27, p=0.261, \eta_{p}^{2}$ $=0.009$. The main effect for Task Difficulty, $F(1,140)=8.17, p=0.005, \eta_{p}{ }^{2}=0.055$, was significant. Those completing the difficult task exhibited greater LF-HRV reactivity to the task (covariate adjusted $M=969.9 \mathrm{~ms}^{2}, S E=118.07$; lower LF-HRV indicates greater reactivity) compared to those completing the easy task (covariate adjusted $M=1427.5 \mathrm{~ms}^{2}, S E=117.78$ ).

Comparisons of Reactivity during the first minute of the task. Analyses indicated that SBP, DBP, MAP, and HR increased from baseline significantly during the first minute of the task, then decreased from minute one to minute three. Due to the tendency of participants to habituate to stress tasks, follow-up two-way Optimism X Task Difficulty ANCOVAs were conducted for each parameter, using just the first minute of the task as the dependent variable instead of the averaged reactivity over the course of the task (See ANCOVA Summary Tables 52-55 in Appendix B). The goal of this analysis was to capture participants when they are displaying the most reactivity to the task. Using this approach, there were no significant 
Optimism or Task Difficulty main effects or Optimism X Task Difficulty interaction effects for any cardiovascular parameter.

\section{Comparisons of Reactivity between "true pessimists" and "slight pessimists." Given}

samples from some previous studies were more pessimistic than the current sample, pessimists in the current sample were divided into "true pessimists," (LOT-R 12 or under; $n=28$ ) and "slight pessimists," (LOT-R between 13 and 17; $n=50$ ). A series of one-way ANCOVAs (covarying BMI, trait anxiety, neuroticism, and resting levels of the cardiovascular parameter) were conducted to compare reactivity levels between the two pessimistic groups (See ANCOVA Summary Tables 56-63 in Appendix B). For SBP, there was a significant effect of pessimist group, $F(1,72)=5.41, p=0.023, \eta_{p}{ }^{2}=0.070$. Slight pessimists (covariate adjusted $M=120.3$ $\mathrm{mm} \mathrm{Hg}, S E=1.05$ ) had higher reactivity compared to true pessimists (covariate adjusted $M=$ 116.1 mm Hg, $S E=1.42$ ). There were no differences between true and slight pessimists for any other cardiovascular parameter.

\section{Primary Analyses: Cardiovascular Recovery from Stress}

To assess whether optimists and pessimists differed in cardiovascular recovery following stress, two-way Optimism X Task Difficulty ANCOVAs were conducted on the Area under the curve (AUC) for each HR and BP parameter. Averaged reactivity during each task, trait anxiety, neuroticism, and BMI were included as covariates for each BP analysis (See ANCOVA Summary Tables 64-71 in Appendix B). BMI was not included as a covariate in any HR or HRV analyses. See the final panel of Figures 1-4 for means and standard errors for measures of SBP, DBP, MAP, and HR during the recovery period.

Systolic Blood Pressure. Analysis indicated that there were no significant main effects for either Optimism, $F(1,143)=0.751, p=0.387, \eta_{p}{ }^{2}=0.005$, or Task Difficulty, $F(1,143)=$ 
3.03, $p=0.084, \eta_{p}{ }^{2}=0.021$ on SBP AUC. Likewise, the interaction between Optimism and Task Difficulty was not significant, $F(1,143)=0.31, p=0.580, \eta_{p}{ }^{2}=0.002$.

Diastolic Blood Pressure. For DBP AUC, the main effects of Optimism, $F(1,143)=$ $1.57, p=0.214, \eta_{p}{ }^{2}=0.011$, and Task Difficulty, $F(1,143)=3.74, p=0.055, \eta_{p}{ }^{2}=0.026$, were not significant. The Optimism X Task Difficulty interaction was also not significant, $F(1,143)=$ $1.81, p=0.180, \eta_{p}^{2}=0.013$

Mean Arterial Pressure. The main effects for Optimism, $F(1,143)=0.372, p=0.543$, $\eta_{p}{ }^{2}=0.003$, and Task Difficulty, $F(1,143)=0.816, p=0.368, \eta_{p}{ }^{2}=0.006$, were not significant for MAP AUC. The Optimism X Task Difficulty interaction effect was also not significant, $F(1$, 143) $=1.825, p=0.179, \eta_{p}^{2}=0.013$.

Heart Rate. Analysis indicated that there were no significant main effects for either Optimism, $F(1,142)=0.000, p=0.992, \eta_{p}^{2}=0.000$, or Task Difficulty, $F(1,142)=1.96, p=$ $0.164, \eta_{p}{ }^{2}=0.014$, on HR AUC. Likewise, the interaction between Optimism and Task Difficulty was not significant, $F(1,142)=0.12, p=0.732, \eta_{p}{ }^{2}=0.001$.

$\boldsymbol{H F}-\boldsymbol{H R} \boldsymbol{V}$. Because HRV can only be measured reliably over longer periods of time (e.g., at least five minutes), AUC was not calculated for HF-HRV, LF-HRV, or SDNN. Instead, recovery analysis used single values for the entire five-minute recovery period. For HF HRV recovery, the Optimism, $F(1,142)=0.23, p=0.630, \eta_{p}{ }^{2}=0.002$, and Task Difficulty, $F(1,142)$ $=0.67, p=0.415, \eta_{p}^{2}=0.005$, main effects were not significant. The Optimism X Task Difficulty interaction effect, $F(1,142)=0.078, p=0.78, \eta_{p}{ }^{2}=0.001$, was also not significant.

SDNN. For SDNN recovery, the Optimism, $F(1,142)=0.04, p=0.841, \eta_{p}^{2}=0.000$, and Task Difficulty, $F(1,142)=0.73, p=0.394, \eta_{p}{ }^{2}=0.005$, main effects were not significant. The 
Optimism X Task Difficulty interaction effect, $F(1,142)=2.20, p=0.140, \eta_{p}{ }^{2}=0.015$, was also not significant.

$\boldsymbol{L F}-\boldsymbol{H} \boldsymbol{R} \boldsymbol{V}$. For LF-HRV recovery, the Optimism main effect, $F(1,142)=1.40, p=0.238$, $\eta_{p}{ }^{2}=0.010$, and the Optimism X Task Difficulty interaction effect, $F(1,142)=0.09, p=0.766$, $\eta_{p}{ }^{2}=0.001$, were not significant. The main effect for Task Difficulty, $F(1,142)=5.84, p=$ $0.017, \eta_{p}{ }^{2}=0.040$, however, was significant. Those completing the difficult task exhibited greater LF-HRV recovery from the task (covariate adjusted $M=1614.36 \mathrm{~ms}^{2}, S E=135.26$; higher LF-HRV indicates more complete recovery, because LF-HRV is high at rest, then dips during stress) compared to those completing the easy task (covariate adjusted $M=1330.4 \mathrm{~ms}^{2}$, $S E=136.05)$.

\section{Task Score}

Scores on the Raven's Matrices task were analyzed in order to determine if there were performance differences between optimists and pessimists on the difficult and easy tasks. A two-way (Optimism X Task Difficulty) ANCOVA (covarying digit-symbol score) was conducted (See ANCOVA Summary Tables 72-76 in Appendix B). Results indicated that the main effect for Task Difficulty, $F(1,147)=808.42, p=0.000, \eta_{p}{ }^{2}=0.846$, was significant. Participants completing the difficult task solved fewer of the puzzles correctly $(M=2.45, S E=$ $0.18)$ than those completing the easy task $(M=9.58, S E=0.18)$. Neither the Optimism main effect, $F(1,147)=0.237, p=0.627, \eta_{p}{ }^{2}=0.002$, nor the Optimism X Task Difficulty interaction effect, $F(1,147)=1.50, p=0.229, \eta_{p}^{2}=0.010$, were significant.

Participants were divided into "true optimists" (LOT-R total score of 25-30) and "true pessimists" (LOT-R score of 12 or below) in order to determine whether a more distinctive gap between optimists and pessimists would result in task performance differences. A two-way 
(True optimist/true pessimist X Task Difficulty) ANCOVA (covarying digit-symbol score) was conducted to assess task performance differences between true optimists and true pessimists. The optimist group main effect, $F(1,62)=2.38, p=0.128, \eta_{p}{ }^{2}=0.037$, and optimist group $\mathrm{X}$ task difficulty interaction effect, $F(1,62)=2.39, p=0.127, \eta_{p}^{2}=0.037$, were both not significant. The Task Difficulty main effect, $F(1,62)=341.59, p=0.000, \eta_{p}{ }^{2}=0.846$, was significant. Participants completing the difficult task solved fewer of the puzzles correctly $(M=$ 2.36, $S E=0.29)$ than those completing the easy task $(M=9.58, S E=0.26)$.

Task performance can also be conceptualized as an indicator of task engagement. Because differences in task performance may account for the increased DBP reactivity observed among optimists in contrast to pessimists, an additional Optimism X Task Difficulty ANCOVA was conducted on DBP reactivity, covarying BMI, trait anxiety, neuroticism, resting levels, and task score. Results were similar to the initial analyses of DBP reactivity without adding task score as a covariate. The Optimism main effect, $F(1,142)=6.25, p=0.014, \eta_{p}{ }^{2}=0.042$, remained significant, while the Task Difficulty main effect, $F(1,142)=0.56, p=0.457, \eta_{p}{ }^{2}=$ 0.004 , and the Optimism X Task Difficulty interaction effect, $F(1,142)=0.31, p=0.581, \eta_{p}{ }^{2}=$ 0.002, were not significant. These results suggest that task engagement did not account for the difference in DBP reactivity between optimists and pessimists.

\section{Measures of Affect}

The MAACL-R was given immediately after the completion of the recovery period. Scores on three MAACL-R subscales (Anxiety, Depression, and Hostility) were combined to obtain a single negative affect score. For means and standard deviations of positive and negative affective responses during the experiment, see Table 3. Because measures of positive and negative affect were positively skewed, all affect scores were transformed using a square root 
transformation to reach normality. Separate two-way ANOVAs (Optimism vs. Task Difficulty) were conducted on the measure of positive affect and negative affect (See ANOVA Summary Tables 77-82 in Appendix B).

Positive affect. The ANOVA on positive affect revealed a significant main effect for Optimism, $F(1,148)=35.36, p=0.000, \eta_{p}{ }^{2}=0.193$. Optimists reported more positive affect $(M$ $=4.03, S E=0.27)$ than pessimists $(M=1.82, S E=0.27)$. The main effect for Task Difficulty was also significant, $F(1,148)=54.97, p=0.000, \eta_{p}{ }^{2}=0.271$. Those completing the easy task reported more positive affect $(M=4.18, S E=0.27)$ compared to those who completed the difficult task $(M=1.67, S E=0.27)$. The Optimism $X$ Task Difficulty interaction effect, $F(1$, 148) $=0.002, p=0.962, \eta_{p}^{2}=0.000$, however, was not significant.

Negative affect. The ANOVA on negative affect also showed a significant main effect for Optimism, $F(1,148)=4.33, p=0.039, \eta_{p}{ }^{2}=0.028$. Optimists reported less negative affect $(M=3.32, S E=0.35)$ than pessimists $(M=4.21, S E=0.34)$. The main effect for Task Difficulty was also significant, $F(1,148)=22.71, p=0.000, \eta_{p}{ }^{2}=0.133$. Those completing the difficult task reported more negative affect $(M=4.95, S E=0.35)$ compared to those who completed the easy task $(M=2.58, S E=0.35)$. The Optimism X Task Difficulty interaction effect, $F(1,148)=1.57, p=0.212, \eta_{p}^{2}=0.011$, however, was not significant.

\section{Post-experimental questionnaire}

To examine responses to items on the Post-Experiment Questionnaire, a series of 2 X 2 (Optimism by Task Difficulty) ANOVAs was conducted (See ANOVA Summary Tables 83-96 in Appendix B). Means and standard errors for each item of the Post-Experiment Questionnaire are shown in Table 4. For purposes of presenting these results, only significant effects will be reported here. 
How stressful was the task? There was a significant Task Difficulty main effect for the item "How stressful was the task?" $F(1,148)=64.94, p=0.000, \eta_{p}{ }^{2}=0.305$. Those completing the difficult task rated the task as more stressful $(M=3.44, S E=0.10)$ compared to those completing the easy task $(M=2.33, S E=0.10)$.

How difficult were the problems? There was a significant Task Difficulty main effect for the item "How difficult were the problems on this task?" $F(1,148)=190.11, p=0.000, \eta_{p}{ }^{2}=$ 0.562. Those completing the difficult task rated the problems as more difficult $(M=4.33, S E=$ $0.10)$ compared to those completing the easy task $(M=2.57, S E=0.10)$.

How much effort to complete the task? The Task Difficulty main effect was also significant for the item "How much effort did you put into completing the problems?" $F(1,148)$ $=17.17, p=0.000, \eta_{p}{ }^{2}=0.104$. Those completing the difficult task indicated that they put more effort into completing the problems $(M=4.18, S E=0.09)$ compared to those completing the easy task $(M=3.70, S E=0.09)$.

Perceived performance Rating. There was also a significant Task Difficulty main effect for the item "How well do you think you performed on the task?" $F(1,148)=327.19, p=0.000$, $\eta_{p}{ }^{2}=0.689$. Participants completing the easy task reported performing better $(M=3.73, S E=$ $0.09)$ compared to completing the difficult task $(M=1.53, S E=0.09)$. The Optimism main effect was also significant for this item, $F(1,148)=5.43, p=0.021, \eta_{p}{ }^{2}=0.035$. Optimists perceived that they performed better on the task $(M=2.77, S E=0.09)$ compared to pessimists $(M=2.49, S E=0.09)$.

Persistence Rating. Main effects for both Optimism, $F(1,148)=6.51, p=0.012, \eta_{p}{ }^{2}=$ 0.042, and Task Difficulty, $F(1,148)=20.54, p=0.000, \eta_{p}{ }^{2}=0.122$, were significant for the item "How persistent were you in completing the task?" Optimists rated themselves as more 
persistent in completing the task $(M=4.08, S E=0.11)$ compared to pessimists $(M=3.71, S E=$ 0.10). Those completing the easy task rated themselves as more persistent $(M=4.23, S E=0.10)$ compared to those completing the difficult task $(M=3.56, S E=0.10)$.

Discontent with performance Rating. There was a significant Task Difficulty main effect for the item "How upset are you about your performance on the task?" $F(1,148)=30.96$, $p=0.000, \eta_{p}{ }^{2}=0.173$. Participants completing the difficult task were more upset with their performance $(M=2.71 S E=0.12)$ compared to those completing the easy task $(M=1.76, S E=$ $0.12)$.

\section{Self-efficacy Ratings.}

Participants completed the self-efficacy questionnaire to assess confidence in their ability to complete the task prior to task engagement. There was little variation among participants, as nearly every participant endorsed being "somewhat confident" or "very confident" they would be able to accurately complete all of the items during the task. Regardless, an Optimism X Task Difficulty ANOVA was performed to determine if there were differences between groups in regard to self-efficacy (See ANOVA Summary Table 97-99 in Appendix B). There were no differences between optimists and pessimists, $F(1,148)=0.149, p=0.700, \eta_{p}{ }^{2}=0.001$, or between participants completing the easy versus difficult tasks, $F(1,148)=0.10, p=0.756, \eta_{p}{ }^{2}=$ 0.001 .

Additionally, to determine whether self-efficacy and digit-symbol score predicted one's task performance score, regression analyses were conducted for those completing the difficult task and those completing the easy task separately. For those completing the difficult task, neither self-efficacy, $\beta=0.119, p=0.305$, nor digit-symbol task score, $\beta=0.124, p=0.285$, were significantly associated with task performance. However, for those completing the easy 
task, self-efficacy, $\beta=0.288, p=0.011$, significantly predicted task performance, such that higher self-efficacy was related to higher task performance. Digit-symbol score, $\beta=-0.191, p=$ 0.088, did not predict task performance for those completing the easy task.

\section{Analysis of Optimism and Pessimism Subscales.}

Two previous studies examining the relation between optimism and cardiovascular reactivity to stress (Puig-Perez et al., 2015; Terrill et al., 2010) found no relation when utilizing the LOT-R total score, but found a significant relation when LOT-R optimism and pessimism subscales were analyzed separately. Therefore, additional analyses examining optimism and pessimism subscales were warranted.

Reactivity to task. Hierarchical regressions entering resting levels of the designated cardiovascular parameter, BMI (for BP analyses), trait anxiety, and neuroticism in the first step and LOT-R optimist and pessimist subscales and task difficulty in the second step, were performed to predict reactivity to the stress task for each cardiovascular parameter (See Regression Summary Tables 100-107 in Appendix B). The pessimism scale was a significant predictor of reactivity to the stress task for both $\mathrm{DBP}, \beta=0.177, p=0.023$, and MAP, $\beta=0.183$, $p=0.014$. In both cases, low pessimism was associated with increased reactivity to the task. Task difficulty was not related to reactivity for either DBP or MAP.

Task Difficulty was a significant predictor for reactivity for both SDNN, $\beta=0.128, p=$ 0.040, and LF-HRV, $\beta=0.171, p=0.007$. Previous analyses demonstrated those completing the difficult task had greater SDNN and LF-HRV reactivity compared to those completing the easy task. This finding was confirmed in this analysis.

Recovery from task. Hierarchical regressions entering BMI (for BP analyses), trait anxiety, and neuroticism in the first step and LOT-R optimist and pessimist subscales and task 
difficulty in the second step, were performed to predict recovery following the stress task for each cardiovascular parameter (See Regression Summary Tables in Appendix C on Pages 108113). For HRV analyses, task levels were entered in the first step of the regression. Neither optimism nor pessimism subscales were significant predictors of recovery for any cardiovascular parameter. Congruent with the primary analyses, Task Difficulty was a significant predictor of LF-HRV recovery: $\beta=-0.142, p=0.028$. Those completing the difficult task had more complete recovery to resting levels compared to those completing the easy task.

\section{Health behaviors and demographic differences between optimists and pessimists.}

In order to assess for differences in health behaviors and perceived SES between groups, Optimism X Task Difficulty ANOVAs were conducted on the following variables: caffeine intake, alcohol intake, exercise, and perceived SES (See ANOVA Summary Tables 114-118 in Appendix B). There were no significant main or interaction effects for caffeine intake,

[Optimism, $F(1,148)=1.48, p=0.226, \eta_{p}{ }^{2}=0.010$, Task Difficulty, $F(1,148)=0.05, p=0.821$, $\eta_{p}{ }^{2}=0.000$, Optimism X Task Difficulty interaction, $\left.F(1,148)=0.000, p=0.995, \eta_{p}^{2}=0.000\right]$, alcohol intake, [Optimism, $F(1,148)=1.53, p=0.218, \eta_{p}{ }^{2}=0.010$, Task Difficulty, $F(1,148)=$ $3.21, p=0.075, \eta_{p}{ }^{2}=0.021$, Optimism X Task Difficulty interaction, $F(1,148)=0.16, p=0.687$, $\eta_{p}{ }^{2}=0.001$ ], or exercise, [Optimism, $F(1,148)=0.53, p=0.470, \eta_{p}{ }^{2}=0.004$, Task Difficulty, $F(1,148)=0.01, p=0.932, \eta_{p}{ }^{2}=0.000$, Optimism $X$ Task Difficulty interaction, $F(1,148)=$ 3.30, $\left.p=0.071, \eta_{p}{ }^{2}=0.022\right]$. Results for SES revealed a significant main effect for Optimism, $F(1,148)=3.95, p=0.049, \eta_{p}{ }^{2}=0.026$. Optimists perceived themselves as having higher SES (based on a scale of one to 10, with one being lower SES and 10 being higher SES; $M=6.01, S E$ $=0.19)$, compared to pessimists $(M=5.49, S E=0.19)$. Neither the main effect for Task 
Difficulty, $F(1,148)=0.003, p=0.959, \eta_{p}{ }^{2}=0.000$, nor the Optimism X Task Difficulty interaction effect, $F(1,148)=0.003, p=0.959, \eta_{p}{ }^{2}=0.000$, was significant.

\section{Chaos theory}

In the current study, BP and HR was averaged across time periods for analytic purposes. Another perspective, chaos theory, is interested in individual differences in changes or fluctuations of cardiovascular parameters that occur across a time period, as opposed to averaging across a time period (Goldberger, 2000). For example, HR naturally fluctuates in a somewhat chaotic manner across time, however, when under stress, these fluctuations are reduced and HR becomes more patterned. Both HF-HRV and LF-HRV are measures that are calculated by examining the variability of waveforms across time using spectral waveform analysis, and therefore reflect values that take into account variations in time associated with chaotic activity.

In the current study, BP was measured only three times per period (rest, task, recovery), and thus chaotic fluctuations in BP occurring continuously were not able to be assessed. However, one could attempt to explore patterns of reactivity by examining changes which occurred across the task period from the perspective of chaos theory. To examine differential patterns of reactivity during the stress task, participants were classified as falling into one of five patterns: (1) sustained reactors (BP reaction stays stable across entire task), (2) habituators (BP reaction declines across the task), (3) sensitizers (BP reactions intensify over the duration of the task), (4) mixed (BP reactions increases from minute one to minute three, but then decreases from minute three to minute five), or (5) non-reactors (BP does not increase more than two mm $\mathrm{Hg}$ above resting levels at any point during the stress task). Because task differences in BP reactivity were not observed in this study, task difficulty was not considered in categorizing 
participants in this way. LOT-R scores and performance scores of participants categorized into these five patterns of reactivity were compared using one-way ANCOVA's, using trait-anxiety and neuroticism as covariates (See ANCOVA Summary Tables 119-123 in Appendix B). Patterns of SBP reactivity, $F(4,145)=0.726, p=0.576, \eta_{p}^{2}=0.020$, and MAP reactivity, $F(4$, $145)=2.197, p=0.072, \eta_{p}{ }^{2}=0.057$, were not associated with LOT-R score. However, LOT-R score differed across patterns of DBP reactivity, $F(4,145)=4.01, p=0.004, \eta_{p}{ }^{2}=0.100$. Those who were categorized as non-reactors had significantly lower LOT-R scores (more pessimistic) $(M=16.39, S E=0.97)$ than those categorized as either sustained reactors $(M=20.18, S E=$ $0.744)$ or sensitizers $(M=20.64, S E=0.774)$. Patterns of SBP reactivity, $F(4,145)=1.195, p=$ $0.315, \eta_{p}{ }^{2}=0.032$, DBP reactivity, $F(4,145)=0.511, p=0.728, \eta_{p}{ }^{2}=0.014$, and MAP reactivity, $F(4,145)=0.286, p=0.887, \eta_{p}{ }^{2}=0.008$, were not associated with task performance.

\section{Discussion}

Several previous studies have examined the relation between optimism and cardiovascular reactivity to stress; however, many of these studies had significant shortcomings. The purpose of this study was to examine the association between optimism and cardiovascular reactivity to stress by addressing several of the shortcomings of previous studies. This study also sought to test Carver and Scheier's Behavioral Self-Regulation Model, which hypothesizes that optimists, compared to pessimists, are likely to engage more (and potentially experience more autonomic arousal) when their goals are blocked by obstacles. First, it was hypothesized during a difficult task, optimists would fully engage their resources, and thus display greater autonomic reactivity compared to pessimists. This was indeed true, as optimists displayed greater DBP reactivity compared to pessimists during the difficult task. It was also hypothesized optimists would display better performance in completing the difficult task, and slower recovery following 
the task compared to pessimists. Neither of these hypotheses were realized, as there were no differences in task performance or recovery following the task. Finally, it was hypothesized there would be no difference in autonomic reactivity or recovery between optimists and pessimists who completed the easy task. This hypothesis was not founded, as optimists displayed greater reactivity on the easy task. There was no difference in reactivity following the easy task. These findings are congruent with the Behavioral Self-Regulation Model, as optimists appeared to put forth more effort in both tasks and displayed greater autonomic reactivity to both tasks.

Previous studies have found mixed results regarding the relation between optimism and cardiovascular reactivity to stress. Some have found that optimists have smaller reactions to stress tasks compared to pessimists (Geers et al., 2008; Puig-Perez et al., 2015; Terrill et al., 2010; Williams et al., 1990), some have found no difference between optimists and pessimists (Bonfiglio, 2005; Kennedy \& Hughes, 2004; Nes et al., 2005), and some have found that optimists are actually more reactive to stress tasks than pessimists (Richman et al., 2007; PuigPerez et al., 2017). One study (Nes et al., 2005) found optimists had slower autonomic recovery following the stress task, although few studies have measured cardiovascular measures during recovery periods.

Although the current study found no significant differences between optimists and pessimists for most of the cardiovascular parameters assessed (i.e., MAP, HR, HF-HRV, SDNN, and LF-HRV), optimists exhibited larger DBP reactions to the experimental task than pessimists, regardless of task difficulty. This may indicate that optimists displayed greater effort in completing the task than pessimists. The pattern of reactivity was similar for SBP (optimists displaying slightly greater reactivity to both tasks), however, the difference in SBP reactivity 
between optimists and pessimists was not significant $(p=.059)$. This finding appears to support Carver and Scheier's Behavioral Self-Regulation model, which states that optimists engage/persist more in task completion in order to overcome the obstacle compared to pessimists. This finding is congruent with the findings of Richman et al. (2007) and Puig-Perez et al. (2017), who also found optimists were more reactive to stress tasks compared to pessimists. Indeed, following the completion of the stress tasks, optimists rated themselves as performing better and being more persistent on both easy and difficult versions of the task compared to pessimists' ratings of their perceived performance and persistence (despite task performance scores being similar for both groups). Together, these findings are consistent with the hypothesis that optimists engage more and display greater cardiovascular reactivity to a stress task compared to pessimists. Despite the differences between optimists and pessimists on measures of DBP reactivity and task persistence, no differences were observed on actual task performance between optimists and pessimists. This indicates that while optimists may have been more engaged with the task, it had no detectable impact on their performance. In this regard, the increased persistence and effort in completing these tasks did not have any tangible benefits for optimists.

Although significant differences were detected on how optimists and pessimists engaged with the Raven's Matrices task in this study, there were no differences in cardiovascular recovery from the task between optimism groups. This is consistent with previous studies measuring autonomic recovery among optimists and pessimists following stress tasks. Of the six studies measuring recovery following the task, four (Bonfiglio, 2005; Kennedy and Hughes, 2004; Puig-Perez, et al., 2015; Richman et al., 2007) found no relation between optimism and recovery following a stress task. Nes, Segerstrom, and Sephton (2005) found optimism was 
related with slower recovery from stress, and Terrill et al., (2010) found optimism was related with faster recovery from stress. The current finding lends credence to the majority of studies, which found no relation between optimism and recovery from stress.

Interestingly, optimists in the current study thought they performed better on the tasks than pessimists, but this difference was not reflected by differences in actual task scores between them. It seems optimists were overly confident regarding their performance. The definition of an optimist is someone who tends to believe he/she will perform well in the future (Carver, Scheier, Segerstrom, 2010); however, in the context of the current study, it appears that optimists may overestimate their past success or performance as well. Overestimating one's success or performance may actually be adaptive in some circumstances. One possible benefit to being overly confident in one's performance is that an optimist may tend to ruminate less regarding performances that have not gone very well. Indeed, rumination has been linked to poorer physical and psychological health (Williams et al., 2017; Zawadski, 2015). An alternative hypothesis is that optimists and pessimists interpreted the question 'How well do you think you performed on the task?' differently. For example, pessimists might interpret this question as referring to the number of problems they correctly solved (i.e., one out of 10), in which case, they would view their performance as poor. However, optimists may interpret this question in a manner friendlier to themselves (i.e., "Given I have never completed a problem like that, getting one out of 10 correct is pretty good"). Whether optimists actually believed they performed better or whether they interpreted the question differently, both scenarios would result in less rumination about their performance. To the extent that optimism reduces rumination, this may prove to be another possible mechanism through which optimism leads to better health. While optimists may react to stressors with increased autonomic arousal, they may ruminate less if they 
perceive their performance as acceptable (despite their actual poor performance), resulting in better overall health. Less rumination over the course of weeks, months, years, and a lifetime could lead to better health outcomes.

While optimists and pessimists did not actually differ in task performance in the current study, there were several significant task differences observed. First, those completing the difficult task rated the task as more stressful and rated the problems as more difficult compared to those completing the easy task. Additionally, those completing the difficult task reported putting more effort into completing the problems compared to those who completed the easy task and becoming more upset than those who completed the easy task. Finally, those who completed the easy task rated their task persistence and perceived performance higher than those who completed the difficult task. Of note, the increased perceived performance ratings for those completing the easy task accurately reflected their superior performance on the task in comparison to those completing the difficult task. Additionally, the type of task influenced ratings of affect obtained at the end of the study; participants completing the easy task reported much greater positive affect and lesser negative affect than those completing the difficult task. In sum, there is evidence that the experience of completing a difficult task in this study was quite different from the experience of completing an easy task.

In regard to cardiovascular differences between those completing the difficult and easy tasks, two (out of seven) parameters showed task differences. For both SDNN and LF-HRV, those completing the difficult task demonstrated greater reactivity. The task differences for SDNN and LF-HRV are what one would expect to find; greater reactivity to a more difficult stress task matches the participants' self-report ratings and affective responses to the difficult task. It is curious, then, that these differences were seen for SDNN and LF-HRV, and not for 
other autonomic parameters. This finding is actually consistent with some past research. For example, Solomon, Holmes, and McCaul (1980) found that there was no difference in HR reactivity between a difficult and easy stress task; however, those completing the difficult task reported more anxiety than those completing the easy task. Light and Obrist (1983) found similar results. In some cases, then, difficulty of the task may not be the most important factor when measuring cardiovascular responses to stress, at least when measuring HR and BP. In contrast to HR, that reflects the combined influences of the sympathetic and parasympathetic branches of the autonomic nervous system, measures of HRV are thought to be influenced predominantly by parasympathetic activity mediated by the vagal nerve. It is possible that task difficulty influences parasympathetic withdrawal more than sympathetic activation, and consequently, measures of BP and $\mathrm{HR}$ are not sensitive enough to detect these specific neural actions.

Another explanation for the lack of differences detected on measures of HR and BP in response to task difficulty, particularly with respect to comparing cardiovascular responses of optimists and pessimists, might be the failure of experimental work to examine how cardiovascular responses change over the course of the task period as optimists and pessimists encounter tasks of varying difficulty. For example, optimists may fully engage their resources early in the task period to overcome obstacles, regardless of the difficulty of the task, but as the task proceeds, optimists may continue to persist and engage full resources if the task is difficult, but decrease their effort if the task is easy, recognizing that less engagement/persistence is needed to complete the task. Some prior research supports this idea. For example, Hoffman (2001) found that for participants completing a longer duration difficult anagram task, in which the rules were constantly changing, optimism was positively related to task engagement. 
However, for those completing a longer duration straightforward anagram task in which the rules remained constant, optimism was not related to task engagement. In the current study, the stress task only lasted five minutes in duration. The five-minute stress task was long enough to capture the optimists' initial full engagement in the task (thus elevated DBP reactivity to both tasks), but may have been too short of a period to capture the optimists' decreased engagement in the easy task. Had the task periods in the current study been longer, DBP responses of optimists may have habituated to the easy task, while continuing to remain engaged in the difficult task, resulting in differences in reactivity for the two tasks. During the first minute of the stress task, there was no difference in DBP reactivity observed between optimists and pessimists; therefore, the differences in DBP emerged later as the task progressed. This suggests optimists continued to engage in task completion fully, while pessimists habituated to the tasks quickly, suggesting pessimists became less engaged in both tasks more quickly than optimists. Future research will be needed employing various task durations to examine this hypothesis thoroughly.

Examination of patterns of reactivity across the task revealed interesting information about participants' persistence during task completion. Analyses examining the patterns of reactivity over the course of the stress tasks suggest that optimists may have been more persistent during the tasks. For example, those who were categorized as sustained DBP reactors or sensitizers (DBP remained elevated or increased across the duration of the task) had significantly higher LOT-R scores (more optimistic) compared to those who were non-reactors. This sustained elevation or increase of DBP from the beginning to the end of the task possibly represents continued persistence and engagement throughout the entirety of the five-minute task. This is consistent with self-report data, in which optimists rated themselves as being more persistent compared to pessimists to both tasks. These findings are consistent with the 
Behavioral Self-Regulation model, in which optimists are hypothesized to engage more in pursuit of desired goals than pessimists.

Given substantial evidence suggesting optimists have better health outcomes, including cardiovascular health, compared to pessimists, it is interesting that optimists displayed increased reactivity to the stress task, especially since increased reactivity to stress tasks is generally associated with poorer cardiovascular health outcomes. There are several possible reasons why optimists have better health outcomes despite increased reactivity to stress. First, some studies have shown optimists have lower ambulatory BP over 3-day periods (Räikkönen \& Matthews, 2008; Räikkönen et al., 1999). If optimists are faced with an obstacle, they engage their resources and use approach-focused coping to overcome the obstacle and overcome an obstacle more quickly than pessimists. In this case, they would experience stress for a shorter period of time because the obstacle would be overcome more quickly, resulting in lower ambulatory BP. If the stressful experience is of longer duration, such as unemployment, housing issues, or relationship issues, an optimist's increased engagement and use of approach-focused coping could result in overcoming the stressor days, weeks, or months more quickly compared to a pessimist, and in turn, lower ambulatory BP. The result of less stress and lower ambulatory BP in general would be better health, specifically cardiovascular health. Additionally, as discussed previously, optimists may tend to ruminate less about past performance and experiences compared to pessimists, which could lead to less stress overall. In sum, optimism may be related to better health due to optimists experiencing less stress generally due to using approach-focused coping, lower ambulatory BP, less rumination, and being from higher SES backgrounds compared to pessimists. 
Another factor to consider in explaining why optimism has been associated with better health outcomes but was associated with greater DBP reactivity in this study is our lack of knowledge regarding the optimal level of reactivity that should accompany completion of the Raven's Matrices Task. It could be, for example, that optimists exhibited the appropriate DBP response for completing this type of cognitive task, but that pessimists displayed a less-thanoptimal under-aroused DBP response. Although McEwen and Stellar (1993) identified a blunted autonomic response as a form of allostatic load, not much research has focused on this pattern of physiological responding to stress until recently (e.g., al'Absi, 2018). al'Absi has demonstrated that such blunted cardiovascular responses are equally problematic as exaggerated responses and may shed light on behavioral risk for conditions like cardiovascular disease, pain disorders, and addiction. From this perspective, pessimists may display blunted cardiovascular responses to stress that render them incapable of solving cognitive challenges like the one used in this study.

In two previous studies (Puig-Perez et al., 2015; Terrill et al., 2010), initial analysis of total LOT-R scores did not demonstrate a relation between optimism and autonomic reactivity. However, when optimism and pessimism subscales were analyzed separately, a relation between the optimism subscale and autonomic reactivity was revealed. In contrast to these prior studies, in the current study, pessimism subscale scores, but not optimism subscale scores, were associated with DBP and MAP reactivity to the task. Higher pessimism was associated with decreased reactivity on both parameters. In other words, expecting negative outcomes in the future impacted reactivity more than a lack of expectations of positive outcomes. It could be that actively expecting bad things to happen changes how one reacts to stressful situations more than simply not expecting good things to happen. However, because these findings were not consistent with findings from the prior work, future investigations will need to examine potential 
reasons why pessimism was associated with the stress task used in the current study more than optimism, and the opposite pattern of findings was observed in studies that used social speech tasks as a stressor. It is interesting that the optimism subscale was related to autonomic reactivity in stress tasks involving social interaction, but the pessimism subscale was related to reactivity in the current task, which involved minimal social interaction. It may be expecting (or not expecting) good things to happen drives reactivity during social interaction, but expecting (or not expecting) negative outcomes drives reactivity in tasks not involving social interaction.

While the differing relation between reactivity and optimism and pessimism subscales may represent a difference in how expecting good things to happen vs. not expecting bad things to happen influences reactivity in different circumstances, some have argued the difference between optimism and pessimism subscales is simply a difference in wording. For example, the LOT-R pessimism scale consists of all negatively-worded items while the optimism subscale consists of all positively-worded items. Therefore, the nature of the LOT-R subscales makes it difficult to interpret differences between the subscales meaningfully. Indeed, the creators of the LOT-R point out that the meaning attached to separate optimism and pessimism subscales is unclear; they attribute the two-factor structure of the LOT-R to item wording rather than meaningful item content (Scheier et al., 1994). With this understanding, it may be the relation between pessimism subscales and reactivity in the current study, and optimism subscales in previous studies with social interaction stressors, is coincidental.

As noted earlier, the screening sample in the current study apparently was more optimistic than those reported in prior studies (e.g., Bonfiglio, 2005; Kennedy \& Hughes, 2004). Consequently, the cut-off values and mean scores on the LOT-R were somewhat higher in the current study than previous work. Samples of both Bonfiglio and Kennedy and Hughes 
consisted of undergraduate women in contrast the current study that consisted of both men and women (although predominantly women). There was no difference in optimism levels between men and women in the current study, however, so the difference between the current sample and those in previous studies does not seem to be related to sex of participants. Samples of previous studies were similar to the current sample with regard to age and undergraduate student status. It is possible that regional differences exist in optimism. Some have postulated that optimism is affected by the context of the culture from which a person comes (You, Fung, \& Isaacowitz, 2009); cultures that emphasize optimism tend to produce individuals who are more optimistic. From this perspective, however, it is difficult to generate reasons why students at West Virginia University would be more optimistic than students at other institutions. In fact, because a substantial number of students who attend West Virginia University come from Appalachia, the literature does not suggest that optimism is commonly associated with this culture (Smokowski, Evans, Cotto, \& Guo, 2014; Zullig \& Hendryx, 2011). It is also possible that the differences in optimism levels between the current sample and previous samples reflect generational differences in optimism. Students comprising Generation Y or the Millennial Generation have been reported to express considerable optimism (De Hauw \& De Vos, 2010; Salahuddin, 2010), so it is possible differences in sample characteristics in optimism are related to the predominant generation of the student sample. Regardless of the reason for this difference in sample characteristics, the current findings may not generalize to samples with lower levels of optimism. Interestingly, if the pessimist group was defined based on LOT-R cut-offs or levels reported in prior work, different between-group differences in cardiovascular reactivity to the stressor may have been observed. By adopting a lower cut-off score to define "true pessimists" in the current study (LOT-R 12 or below), lower SBP reactions were only observed in this group and not those 
categorized as "slight pessimists" (LOT-R between 13-17). This finding confirms that the least reactive participants were those with the lowest scores on the LOT-R, lending further support to the finding that they may have been the least engaged with the task.

\section{Health behaviors and demographic differences between optimists and pessimists}

Others have proposed that possible differences in health behaviors and other variables (e.g., socioeconomic status) between optimists and pessimists may contribute to their disparate health outcomes. The current study also considered several of these variables in assessing for differences in health behaviors that might exist between optimists and pessimists. Interestingly, our sample did not display differences between optimists and pessimists in regard to alcohol or caffeine intake, or amount of exercise. However, in our sample optimists reported to be from higher SES compared pessimists. Other studies have shown that higher SES is linked to improved health (Adler \& Ostrove, 1999), so given that optimists in our sample may come from higher SES backgrounds than pessimists, SES is possibly an additional contributing factor to explaining the health differences between optimists and pessimists. However, the nature of the relation between optimism and SES requires further exploration. In our sample, participants reported their perception of where they fall on a spectrum of perceived social status; however, their actual SES, including parents' education, occupation, and income was not assessed. Whether their perceived SES accurately reflects their actual SES is unclear. It is possible that optimistic participants tend to view their life circumstances as more favorable compared to pessimists, despite no real differences in SES. It is also possible that optimistic people are more optimistic because they have higher SES, and therefore have more resources and opportunities than participants with less optimism. Further, optimists may strive harder and seek out more opportunities than pessimists because they are confident that their plans will work, and therefore 
they move upward on the SES spectrum. Whatever the nature of the relation between optimism and SES, SES should be explored as a potential mechanism through which optimists obtain better health in future work.

\section{Strengths and Limitations}

There are several strengths of this study that lend credence to its findings. First, the majority of previous studies measuring the relation between optimism and autonomic reactivity to stress were designed to assess variables other than optimism, and optimism analyses were secondary research questions. The current study was designed specifically to assess the relation between optimism and autonomic reactivity to stress. Given the specific goal of this study, the study was powered appropriately to examine study hypotheses as well as control for several covariates known to be associated with optimism (e.g., trait anxiety, neuroticism).

Second, the current study possessed an adequate amount of internal validity, despite its quasi-experimental design. Variables such as sex, BMI, other pertinent personality variables, prescription medication use, caffeine intake, exercise, and tobacco and other drug use were all controlled either statistically or experimentally. Additionally, participants were randomly assigned to task difficulty conditions to provide some additional control over threats to experimental validity.

Third, the study employed "easy" and "difficult" stress tasks. Results clearly showed differences in task performance and perceived difficulty of the two tasks, indicating the tasks could be confirmed as "easy" and "difficult." Effect sizes for self-report questions related to the two tasks and task performance differences were generally in the medium to large range, demonstrating a clear difference in difficulty between the tasks. 
There were some limitations to this study. First, the Behavioral Self-Regulation Model stipulates optimists will engage all of their resources to overcome obstacles and obtain their goals more than pessimists. This study employed a brief, five-minute laboratory stressor, which is unlikely to be similar to stressors or obstacles faced on a day-to-day basis. The brevity of the Raven Matrices task used did not allow for a thorough examination of the pattern of reactivity among optimists and pessimists during prolonged stressors, such as preparing for a test, finding a job, dealing with relationship problems, etc. It is possible patterns of reactivity that occur during more prolonged stressors, like those encountered in daily life, would reveal a more complete picture of how optimists and pessimists react to stressors emotionally, cognitively, and physiologically.

The Raven's Matrices tasks were equal in all but difficulty, increasing internal validity of this study. However, the ecological validity of these stress tasks is limited. Day-to-day stressors optimists and pessimists encounter are highly variable, and may include stress due to unemployment, relationship problems, financial problems, or health problems. It is possible optimists and pessimists react differently to stressors that are more pertinent to their lives. Future research should examine both autonomic and behavioral reactions to real-life stressors among optimists and pessimists.

It should also be noted the Raven's Matrices Stress tasks used in this study are cognitive stress tasks. It is possible results may differ when social or physical stress tasks are employed.

Another limitation of this study was the time of the semester that optimists and pessimists were recruited. Significantly more optimists signed up to participate towards the beginning of the study, which commenced during the Fall, 2016 semester and the first month of the Spring, 2017 semester. Pessimists did not sign up for the study as readily as optimists, and thus, 
recruitment of these participants took longer. More than half of the pessimists participated in the second half of the Spring, 2017 semester and the Summer, 2017 term. To complete data collection, 10 pessimists participated in the study during the first month of the Fall, 2017 semester. It is possible that differences exist between volunteers who participate at the beginning of semesters and those who participate at the end of semesters. Because the majority of pessimists participated later during data collection than optimists, any differences that emerged may be influenced by this difference in participant recruitment employed in the current study. However, it is also possible that the measure of optimism used in this study was associated with other dispositional characteristics that influence participants to seek out opportunities to obtain extra credit in their courses early versus those who delay pursuit of these opportunities.

Another limitation of the study is that the sample in the current study was relatively homogenous. Participants were predominantly Caucasian and predominantly female, ranging in age from 18-25 years old. All participants were undergraduate university students. This study would need to be conducted with a more heterogeneous community sample to determine if the observed effects are generalizable to non-student populations. This would be important given that some previous studies using different samples found different results related to optimism and reactivity during a stress task (e.g., Nes et al., 2005; Puig-Perez et al., 2015).

Additionally, the unique sample of optimists and pessimists in the current study is a limitation. In the current study, both optimists and pessimists generally had higher LOT-R scores (were more optimistic) compared to previous studies. While some participants in the study would be considered true pessimists, the pessimist group contained several participants who would not have been characterized as pessimists according to criteria reported in prior work, 
but were considered relative pessimists in this sample because their LOT-R scores were within the bottom tertile of scores of our student sample distribution. As shown previously, slight pessimists in the current study had greater SBP reactivity compared to true pessimists. The current sample's higher optimism levels may have influenced the manner in which they reacted to the stress tasks. The current sample comprised of mostly Caucasian participants who are receiving a college education is likely different in levels of optimism and pessimism compared to the general population.

Another limitation to this study is that numerous analyses were conducted. It is possible that the few significant findings reported were due to an increased Type I error rate, given the large number of analyses that were conducted. However, the study was powered adequately to test study hypotheses and findings with smaller effect sizes make contributions to the literature in this area.

\section{Future Directions}

Few studies have been designed specifically to assess the difference in reactivity to stress between optimists and pessimists. Evidence is mounting that supports the idea that optimists have increased reactivity to stress tasks compared to pessimists. However, the majority of these studies have employed brief laboratory stressors. More studies designed to demonstrate this phenomenon in externally valid situations are necessary. For example, more studies employing ambulatory measurement methods would help shed light on how and under what circumstances optimists display exaggerated autonomic reactions to daily stressors. Such studies may distinguish between different types of stressors. For example, participants could provide information about the nature of the stressor: stressful social interactions, work-related stress (i.e., thinking about deadlines, etc.), or stress related to physical and/or emotional danger. 
Additionally, future laboratory studies designed to examine the relation between optimism and stress reactivity may employ stress tasks of varying lengths. Employing tasks of varying lengths would allow researchers to determine whether optimists initially engage more, but then adjust their level of engagement depending on the demands of the task. This type of research could also examine the temporal characteristics of task performance to determine whether task engagement is sustained throughout the entire task period or wanes as the task period progresses. If the Behavioral Self-Regulation Model is accurate, one would expect the performance of optimists and pessimists to differ, particularly in response to information regarding whether the participant is succeeding of failing at the designated task.

Finally, generational differences of the linkage between optimism and autonomic response to stress are worthy of future investigations. By solely studying undergraduate students, researchers are restricting the broad generalizations needed in order to make any firm conclusions about the beneficial aspects of optimism on health outcomes.

\section{Summary and Conclusions}

Among previous studies that examined the relation between optimism and cardiovascular reactivity to stress, four studies found that optimists were less reactive to tasks compared to pessimists (Geers et al., 2008; Puig-Perez et al., 2015; Terrill et al., 2010; Williams et al., 1990), three studies found no relation (Bonfiglio, 2005; Kennedy \& Hughes, 2004; Nes et al., 2005), and three studies found that in some situations optimists were more reactive to stress than pessimists (Richman et al., 2007; Puig-Perez et al., 2017). Although Nes et al. (2005) did not find an association between optimism and reactivity, they found that optimists had slower recovery than pessimists following the task. Many of these previous studies were designed to test various other hypotheses and findings examining associations between optimism and 
cardiovascular reactivity hypothesis reflected secondary analyses, so they often were not powered adequately or to control for important covariates to make meaningful contributions to the literature. The current study was designed specifically to test the optimism-cardiovascular reactivity relation. Unlike many of the previous studies, this current study controlled for several factors related to optimism (e.g., neuroticism, trait anxiety) and several factors that may influence cardiovascular reactivity, including caffeine/nicotine intake, prescription drugs, and BMI. The increased control of these factors in this study increases its internal validity, thus bolstering its findings in comparison with prior work in this area. This study adds credence to previous studies' findings that optimists are actually more reactive to stress compared to pessimists, at least in response to brief mental stress tasks. This study, however, failed to support the previous finding that optimists and pessimists differed in their cardiovascular recovery following stress tasks during recovery periods (Nes, Segerstrom, \& Sephton, 2005).

It is also important to acknowledge prior studies that found optimists have lower ambulatory BP compared to pessimists, but had similar BP reactivity to pessimists during acute stressors (Räikkönen \& Matthews, 2008; Räikkönen et al., 1999). Combined with the findings of the current study, it seems that during periods of acute stress, optimists' BP appears to be equally or more reactive than pessimists' BP. However, over the course of entire days, weeks, and months, optimists may have lower average BP than pessimists, and in the end, the prolonged positive physiological and emotional aspects of optimism are likely to make more substantial contributions to better health than how optimists and pessimists respond to brief, acute environmental stressors. 


\section{References}

Adler, N. E., \& Ostrove, J. M. (1999). Socioeconomic status and health: What we know and what we don't. Annals of the New York Academy of Sciences, 896(1), 3-15.

al'Absi, M. (2018). Stress and addiction: When a robust stress response indicates resiliency. Psychosomatic Medicine, 80, 2-16. doi: 10.1097/PSY.0000000000000520.

Barth, J., Schumacher, M., \& Herrmann-Lingen, C. (2004). Depression as a risk factor for mortality in patients with coronary heart disease: a meta-analysis. Psychosomatic Medicine, 66(6), 802-813.

Billingsley, K. D., Waehler, C. A., \& Hardin, S. I. (1993). Stability of optimism and choice of coping strategy. Perceptual and Motor Skills, 76(1), 91-97. doi:10.2466/pms.1993.76.1.91

Boden-Albala, B., Litwak, E., Elkind, M.S.V., Rundek, T., \& Sacco, R. L. (2005). Social isolation and outcomes post stroke. Neurology, 64(11), 1888-1892.

Boehm, J. K., \& Kubzansky, L. D. (2012). The heart's content: The association between positive psychological well-being and cardiovascular health. Psychological Bulletin, 138(4), 655691. doi:10.1037/a0027448

Bonfiglio, D. V. (2005). The interaction of dispositional optimism and social support in the moderation of cardiovascular responses to acute psychosocial stress. Dissertation Abstracts Internationa, 66, 3456.

Carroll, D., Ginty, A. T., Der, G., Hunt, K., Benzeval, M., \& Phillips, A. C. (2012). Increased blood pressure reactions to acute mental stress are associated with 16-year cardiovascular disease mortality. Psychophysiology, 49(10), 1444-1448. doi:10.1111/j.14698986.2012.01463.x. 
Carver, C. S., Lehman, J. M., \& Antoni, M. H. (2003). Dispositional pessimism predicts illnessrelated disruption of social and recreational activities among breast cancer patients. Journal of Personality and Social Psychology, 84(4), 813-821. doi:10.1037/0022-3514.84.4.813

Carver, C., \& Scheier, M. (2000). On the structure of behavioral self-regulation. In M. Boekaerts, P. Pintrich, \& M. Zeidner (Eds.), Handbook of self-regulation (pp. 41-84). San Diego: Academic.

Carver, C. S., Scheier, M. F., \& Segerstrom, S. C. (2010). Optimism. Clinical psychology review, 30(7), 879-889.

Chan, C. H., Wan Ahmad, W. A., Yusof, M. M., Ho, G., \& Krupat, E. (2015). Effects of depression and anxiety on mortality in a mixed cancer group: A longitudinal approach using standardized diagnostic interviews. Psycho-Oncology, 24(6), 718-725. doi:10.1002/pon.3714

Chang, L., \& McBride-Chang, C. (1996). The factor structure of the Life Orientation Test. Educational and Psychological Measurement, 56(2), 325-329.

Chida, Y., \& Steptoe, A. (2010). Greater cardiovascular responses to laboratory mental stress are associated with poor subsequent cardiovascular risk status a meta-analysis of prospective evidence. Hypertension, 55(4), 1026-1032.

Clark, R., Benkert, R. A., \& Flack, J. M. (2006). Violence Exposure and Optimism Predict TaskInduced Changes in Blood Pressure and Pulse Rate in a Normotensive Sample of InnerCity Black Youth. Psychosomatic Medicine, 68(1), 73-79.

doi:10.1097/01.psy.0000195744.13608.11 
Cohen, F., Kearney, K. A., Zegans, L. S., Kemeny, M. E., Neuhaus, J. M., \& Stites, D. P. (1999). Differential immune system changes with acute and persistent stress for optimists vs pessimists. Brain, Behavior, and Immunity, 13(2), 155-174.

Cundiff, J. M., Smith, T. W., Uchino, B. N., \& Berg, C. A. (2013). Subjective social status: construct validity and associations with psychosocial vulnerability and self-rated health. International Journal of Behavioral Medicine, 20(1), 148-158.

De Hauw, S., \& De Vos, A. (2010). Millennials' career perspective and psychological contract expectations: Does the recession lead to lowered expectations? Journal of Business and Psychology, 25(2), 293-302. doi:10.1007/s10869-010-9162-9

Friedberg, J. P., Suchday, S., \& Srinivas, V. S. (2009). Relationship between forgiveness and psychological indices in cardiac patients. International Journal of Behavioral Medicine, 16(3), 205-211. doi:10.1007/s12529-008-9016-2.

Geers, A. L., Wellman, J. A., Helfer, S. G., Fowler, S. L., \& France, C. R. (2008). Dispositional optimism and thoughts of well-being determine sensitivity to an experimental pain task. Annals of Behavioral Medicine, 36(3), 304-313.

Giltay, E., Geleijnse, J., Zitman, F., Buijsse, B., \& Kromhout, D. (2007). Lifestyle and dietary correlates of dispositional optimism in men: The Zutphen Elderly Study. Journal of Psychosomatic Research, 63, 483-490.

Glaesmer, H., Rief, W., Martin, A., Mewes, R., Brähler, E., Zenger, M., \& Hinz, A. (2012). Psychometric properties and population-based norms of the Life Orientation Test Revised (LOT-R). British Journal of Health Psychology, 17(2), 432-445. 
Goldberger, A.L. (2000). Nonlinear dynamics, fractals, and chaos theory for clinicians:

Implications for neuroautonomic heart rate control in health and disease. Circulation, 23, 215-220.

Grewen, K., Girdler, S. S., West, S. G., Bragdon, E., Costello, N., \& Light, K. C. (2000). Stable pessimistic attributions interact with socioeconomic status to influence blood pressure and vulnerability to hypertension. Journal of Women's Health \& Gender-based Medicine, 9(8), 905-915.

Helton, W. S., Dember, W. N., Warm, J. S., \& Matthews, G. (1999). Optimism, pessimism, and false failure feedback: Effects on vigilance performance. Current Psychology, 18(4), 311325.

Hoffman, R. I. (2001, March). The relation of optimism and self-mastery to responses to unfavorable contingency changes. Dissertation Abstracts International, 61, 5055.

House, J. S., Landis, K. R., \& Umberson, D. (1988). Social relationships and health. Science, $241(4865), 540-545$.

Hunsley, J. (1990). Dimensionality of the Multiple Affect Adjective Check List-Revised: A comparison of factor analytic procedures. Journal of Psychopathology and Behavioral Assessment, 12(1), 81-91.

Jessor, R., Donovan, J. E., \& Costa, F. (1996). Personality, perceived life chances, and adolescent behavior. In K. Hurrelmann, S. F. Hamilton, K. Hurrelmann, S. F. Hamilton (Eds.), Social problems and social contexts in adolescence: Perspectives across boundaries (pp. 219-233). Hawthorne, NY, US: Aldine de Gruyter.

Kelloniemi, H., Ek, E., \& Laitinen, J. (2005). Optimism, dietary habits, body mass index and smoking among young Finnish adults. Appetite, 45, 169-176. 
Kennedy, D. K., \& Hughes, B. M. (2004). The optimism-neuroticism question: An evaluation based on cardiovascular reactivity in female college students. Psychological Record, 54(3), 373-386.

Krantz, D. S., \& Manuck, S. B. (1984). Acute psychophysiologic reactivity and risk of cardiovascular disease: a review and methodologic critique. Psychological Bulletin, 96(3), 435-464.

Krantz, D., Manuck, S., \& Wing, R. (1986). Psychological stressors and task variables as elicitors of reactivity. In Handbook of Stress, Reactivity, and Cardiovascular Disease (pp. 85-108). New York, NY: John Wiley \& Sons Inc.

Kubzansky, L. D., Kubzansky, P. E., \& Maselko, J. (2004). Optimism and pessimism in the context of health: Bipolar opposites or separate constructs? Personality and Social Psychology Bulletin, 30, 943-956.

Kubzansky, L. D., Sparrow, D., Vokonas, P., \& Kawachi, I. (2001). Is the glass half empty or half full? A prospective study of optimism and coronary heart disease in the normative aging study. Psychosomatic Medicine, 63(6), 910-916.

Kubzansky, L. D., Wright, R. J., Cohen, S., Weiss, S., Rosner, B., \& Sparrow, D. (2002). Breathing easy: A prospective study of optimism and pulmonary function in the normative aging study. Annals of Behavioral Medicine, 24(4), 345-353.

Lerman, S. F., Rudich, Z., Brill, S., Shalev, H., \& Shahar, G. (2015). Longitudinal associations between depression, anxiety, pain, and pain-related disability in chronic pain patients. Psychosomatic Medicine, 77(3), 333-341. doi:10.1097/PSY.0000000000000158.

Light, K. C., \& Obrist, P. A. (1983). Task Difficulty, Heart Rate Reactivity, and Cardiovascular Responses to an Appetitive Reaction Time Task. Psychophysiology, 20(3), 301-312. 
Lubin, B., Van Whitlock, R., Reddy, D., \& Petren, S. (2001). A comparison of the short and long forms of the Multiple Affect Adjective Check List—Revised (MAACL-R). Journal of Clinical Psychology, 57(3), 411-416.

Mahler, H. I. M., \& Kulik, J. A. (2000). Optimism, pessimism and recovery from coronary bypass surgery: prediction of affect, pain, and functional status. Psychology, Health, and Medicine, 5(4), 347-358.

Marler, M. R., Jacob, R. G., Lehoszky, J. P., \& Shapiro, A. P. (1988). The statistical analysis of treatment effects in 24-hour ambulatory blood pressure recordings. Statistics in Medicine, 7, 697-716.

McEwen, B. S., \& Stellar, E. (1993). Stress and the individual: Mechanisms leading to disease. Archives of Internal Medicine, 153(18), 2093-2101. doi:10.1001/archinte.1993.00410180039004.

Morrison, G. E., Simone, C. M., Ng, N. F., \& Hardy, J. L. (2015). Reliability and validity of the NeuroCognitive Performance Test, a web-based neuropsychological assessment. Frontiers in Psychology, 6, 1652. http://doi.org/10.3389/fpsyg.2015.01652.

Nes, L. S., Segerstrom, S. C., \& Sephton, S. E. (2005). Engagement and arousal: Optimism's effects during a brief stressor. Personality and Social Psychology Bulletin, 31(1), 111120.

Neumann, S. A., Waldstein, S. R., Sellers III, J. J., Thayer, J. F., \& Sorkin, J. D. (2004). Hostility and distraction have differential influences on cardiovascular recovery from anger recall in women. Health Psychology, 23(6), 631-640.

Niskanen, J. P., Tarvainen, M. P., Ranta-Aho, P. O., \& Karjalainen, P. A. (2004). Software for advanced HRV analysis. Computer methods and programs in biomedicine, 76(1), 73-81. 
Noyes Jr, R., \& Kathol, R. G. (1985). Depression and cancer. Psychiatric Developments, 4(2), 77-100.

Peterson, C., Seligman, M. E., \& Vaillant, G. E. (1988). Pessimistic explanatory style is a risk factor for physical illness: a thirty-five-year longitudinal study. Journal of Personality and Social Psychology, 55(1), 23.

Puig-Perez, S., Hackett, R. A., Salvador, A., \& Steptoe, A. (2017). Optimism moderates psychophysiological responses to stress in older people with type 2 diabetes. Psychophysiology, 54(4), 536-543. doi:10.1111/psyp.12806

Puig-Perez, S., Villada, C., Pulopulos, M. M., Almela, M., Hidalgo, V., \& Salvador, A. (2015). Optimism and pessimism are related to different components of the stress response in healthy older people. International Journal of Psychophysiology, 98(2), 213-221.

Räikkönen, K., Matthews, K. A., Flory, J. D., Owens, J. F., \& Gump, B. B. (1999). Effects of optimism, pessimism, and trait anxiety on ambulatory blood pressure and mood during everyday life. Journal of Personality and Social Psychology, 76(1), 104.

Räikkönen, K., \& Matthews, K. A. (2008). Do dispositional pessimism and optimism predict ambulatory blood pressure during schooldays and nights in adolescents? Journal of Personality, 76, 605-630.

Rasmussen, H. N., Scheier, M. F., \& Greenhouse, J. B. (2009). Optimism and physical health: A meta-analytic review. Annals of Behavioral Medicine, 37(3), 239-256.

Rauch, W. A., Schweizer, K., \& Moosbrugger, H. (2007). Method effects due to social desirability as a parsimonious explanation of the deviation from unidimensionality in LOT-R scores. Personality and Individual Differences, 42(8), 1597-1607. doi:10.1016/j.paid.2006.10.035 
Raven, J. (1998). Standard Progressive Matrices Sets A, B, C, D, \& E. Bloomington, MN: Pearson Inc.

Raven, J., Raven, J. C., \& Court, J. H. (2004). Manual for Raven's Progressive Matrices and Vocabulary Scales. San Antonio, TX: Harcourt Assessment.

Richman, L. S., Bennett, G. G., Pek, J., Siegler, I., \& Williams, R. J. (2007). Discrimination, dispositions, and cardiovascular responses to stress. Health Psychology, 26(6), 675-683. doi:10.1037/0278-6133.26.6.675

Robinson-Whelen, S., Kim, C., MacCallum, R. C., \& Kiecolt-Glaser, J. K. (1997). Distinguishing optimism from pessimism in older adults: Is it more important to be optimistic or not to be pessimistic? Journal of Personality and Social Psychology, 73(6), 1345-1353. doi:10.1037/0022-3514.73.6.1345

Roest, A. M., Martens, E. J., Denollet, J., \& de Jonge, P. (2010). Prognostic association of anxiety post myocardial infarction with mortality and new cardiac events: A metaanalysis. Psychosomatic Medicine, 72(6), 563-569.

Rozanski, A., Blumenthal, J. A., \& Kaplan, J. (1999). Impact of psychological factors on the pathogenesis of cardiovascular disease and implications for therapy. Circulation, 99(16), 2192-2217.

Salahuddin, M. M. (2010). Generational differences impact on leadership style and organizational success. Journal of Diversity Management, 5(2), 1-6.

Scheier, M. F. \& Carver, C. S. (1987). Dispositional optimism and physical well-being: the influence of generalized outcome expectancies on health. Journal of Personality, 55(2), 169-210. 
Scheier, M. F., \& Carver, C. S. (1992). Effects of optimism on psychological and physical wellbeing: Theoretical overview and empirical update. Cognitive Therapy and Research, 16(2), 201-228. doi:10.1007/BF01173489

Scheier, M. F., Carver, C. S., \& Bridges, M. W. (1994). Distinguishing optimism from neuroticism (and trait anxiety, self-mastery, and self-esteem): A reevaluation of the Life Orientation Test. Journal of Personality and Social Psychology, 67(6), 1063-1078. doi:10.1037/0022-3514.67.6.1063

Scheier, M. F., Weintraub, J. K., \& Carver, C. S. (1986). Coping with stress: divergent strategies of optimists and pessimists. Journal of Personality and Social Psychology, 51(6), 12571264. doi:10.1037/0022-3514.51.6.1257.

Segerstrom, S. C., Taylor, S. E., Kemeny, M. E., \& Fahey, J. L. (1998). Optimism is associated with mood, coping, and immune changes in response to stress. Journal of Personality and Social Psychology, 74, 1646-1655.

Segerstrom, S. C. (2001). Optimism and attentional bias for negative and positive stimuli. Personality and Social Psychology Bulletin, 27(10), 1334-1343.

Seligman, M. E., \& Schulman, P. (1986). Explanatory style as a predictor of productivity and quitting among life insurance sales agents. Journal of Personality and Social Psychology, 50(4), 832-838. doi:10.1037/0022-3514.50.4.832.

Shimbo, D., Chaplin, W., Kuruvilla, S., Wasson, L. T., Abraham, D., \& Burg, M. M. (2009). Hostility and platelet reactivity in individuals without a history of cardiovascular disease events. Psychosomatic Medicine, 71(7), 741-747. doi:10.1097/PSY.0b013e3181ad18b6 
Smokowski, P. R., Evans, C. R., Cotter, K. L., \& Guo, S. (2014). Ecological correlates of depression and self-esteem in rural youth. Child Psychiatry \& Human Development, 45(5), 500-518. doi:10.1007/s10578-013-0420-8

Solomon, S., Holmes, D. S., \& McCaul, K. D. (1980). Behavioral control over aversive events: Does control that requires effort reduce anxiety and physiological arousal? Journal of Personality and Social Psychology, 39(4), 729-736. doi:10.1037/0022-3514.39.4.729

Soto, C. J., \& John, O. P. (2016). The next Big Five Inventory (BFI-2): Developing and assessing a hierarchical model with 15 facets to enhance bandwidth, fidelity, and predictive power. Journal of Personality and Social Psychology, 113(1), 117-143.

doi:10.1037/pspp0000096

Spielberger, C. D., Gorsuch, R. L., Lushene, R., Vagg, P. R., \& Jacobs, G. A. (1983). Manual for the State-Trait Anxiety Inventory. Palo Alto, CA: Consulting Psychologists Press.

Steptoe, A., \& Marmot, M. (2005). Impaired cardiovascular recovery following stress predicts 3year increases in blood pressure. Journal of Hypertension, 23(3), 529-536.

Strack, S., Carver, C. S., \& Blaney, P. H. (1987). Predicting successful completion of an aftercare program following treatment for alcoholism: The role of dispositional optimism. Journal of Personality and Social Psychology, 53(3), 579-584. doi:10.1037/00223514.53.3.579

Tay, L., Tan, K., Diener, E., \& Gonzalez, E. (2013). Social relations, health behaviors, and health outcomes: A survey and synthesis. Applied Psychology: Health and Well-being, 5(1), 28-78. doi:10.1111/aphw.12000 
Terrill, A. L., Ruiz, J. M., \& Garofalo, J. P. (2010). Look on the bright side: Do the benefits of optimism depend on the social nature of the stressor? Journal of Behavioral Medicine, 33(5), 399-414. doi: 10.1007/s10865-010-9268-6

Tindle, H. A., Chang, Y. F., Kuller, L. H., Manson, J. E., Robinson, J. G., Rosal, M. C., \& Matthews, K. A. (2009). Optimism, cynical hostility, and incident coronary heart disease and mortality in the Women's Health Initiative. Circulation, 120(8), 656-662.

Treiber, F. A., Kamarck, T., Schneiderman, N., Sheffield, D., Kapuku, G., \& Taylor, T. (2003). Cardiovascular reactivity and development of preclinical and clinical disease states. Psychosomatic Medicine, 65(1), 46-62.

Tuomisto, M. T., Majahalme, S., Kahonen, M., Fredrikson, M., \& Turjanmaa, V. (2005). Psychological stress tasks in the prediction of blood pressure level and need for antihypertensive medication: 9-12 years of follow-up. Health Psychology, 24(1), 77-87.

Uchino, B. N. (2006). Social support and health: a review of physiological processes potentially underlying links to disease outcomes. Journal of Behavioral Medicine, 29(4), 377-387.

Waltman, M. A., Russell, D. C., Coyle, C. T., Enright, R. D., Holter, A. C., \& Swoboda, C. M. (2009). The effects of a forgiveness intervention on patients with coronary artery disease. Psychology \& Health, 24(1), 11-27. doi:10.1080/08870440801975127

Webb, J. R., Toussaint, L., Kalpakjian, C. Z., \& Tate, D. G. (2010). Forgiveness and healthrelated outcomes among people with spinal cord injury. Disability and Rehabilitation, $32(5), 360-366$.

Wechsler, D. (2008). Wechsler Adult Intelligence Scale-Fourth Edition (WAIS-IV). San Antonio, TX: NCS Pearson, 22, 498. 
Werenfels, P. D. (2006). Effects of optimism on goal-setting performance. Dissertation Abstracts International, 66, 3988.

Whited, M. C., Wheat, A. L., \& Larkin, K. T. (2010). The influence of forgiveness and apology on cardiovascular reactivity and recovery in response to mental stress. Journal of Behavioral Medicine, 33(4), 293-304. doi:10.1007/s10865-010-9259-7

Whooley, M. A., \& Wong, J. M. (2013). Depression and cardiovascular disorders. Annual Review of Clinical Psychology, 9, 327-354.

Williams, D. P., Feeling, N. R., Hill, L. K., Spangler, D. P., Koenig, J., \& Thayer, J. F. (2017). Resting heart rate variability, facets of rumination and trait anxiety: Implications for the perseverative cognition hypothesis. Frontiers In Human Neuroscience, doi:10.3389/fnhum.2017.00520

Williams, R. D., Riels, A. G., \& Roper, K. A. (1990). Optimism and distractibility in cardiovascular reactivity. The Psychological Record, 40(3), 451-457.

Wong, J. M., Sin, N. L., \& Whooley, M. A. (2014). A comparison of Cook-Medley hostility subscales and mortality in patients with coronary heart disease: Data from the Heart and Soul Study. Psychosomatic Medicine, 76(4), 311-317.

doi:10.1097/PSY.0000000000000059

Zawadzki, M. J. (2015). Rumination is independently associated with poor psychological health: Comparing emotion regulation strategies. Psychology \& Health, 30(10), 1146-1163. doi:10.1080/08870446.2015.1026904

Zivin, K., Yosef, M., Miller, E. M., Valenstein, M., Duffy, S., Kales, H. C., Vijan, S., \& Kim, H. M. (2015). Associations between depression and all-cause and cause-specific risk of 
death: A retrospective cohort study in the Veterans Health Administration. Journal of Psychosomatic Research, 78(4), 324-331. doi:10.1016/j.jpsychores.2015.01.014

Zullig, K. J., \& Hendryx, M. (2011). Health-related quality of life among central Appalachian residents in mountaintop mining counties. American Journal Of Public Health, 101(5), 848-853. doi:10.2105/AJPH.2010.300073 
Table 1. Demographics

\begin{tabular}{|c|c|c|c|c|}
\hline & \multicolumn{2}{|c|}{ Optimist $(\mathrm{n}=74)$} & \multicolumn{2}{|c|}{ Pessimist $(\mathrm{n}=78)$} \\
\hline & $\operatorname{Mean}(\mathrm{SD})$ & Count $(\%)$ & $\operatorname{Mean}(\mathrm{SD})$ & Count $(\%)$ \\
\hline Women & & $64(85 \%)$ & & $66(84.6 \%)$ \\
\hline Men & & $10(15 \%)$ & & $12(15.4 \%)$ \\
\hline Age & $19.4(1.5)$ & & $19.2(1.5)$ & \\
\hline \multicolumn{5}{|l|}{ Race } \\
\hline White & & $61(82.4 \%)$ & & $63(80.8 \%)$ \\
\hline Black & & $5(6.8 \%)$ & & $3(3.8 \%)$ \\
\hline Asian & & $3(4.1 \%)$ & & $5(6.4 \%)$ \\
\hline Native American & & $1(1.4 \%)$ & & 0 \\
\hline Mixed & & $2(2.8 \%)$ & & $5(6.4 \%$ \\
\hline Other & & $1(1.4 \%)$ & & 0 \\
\hline Undisclosed & & $1(2.8 \%)$ & & $2(2.6 \%)$ \\
\hline LOT-R total & $25.0(2.3)^{\mathrm{a}}$ & & $13.3(2.6)^{\mathrm{a}}$ & \\
\hline Perceived SES & $6.0(1.5)^{\mathrm{a}}$ & & $5.5(1.7)^{\mathrm{a}}$ & \\
\hline BMI & $25.6(5.6)$ & & $25.3(4.8)$ & \\
\hline Resting SBP (mm & & & & \\
\hline $\mathrm{Hg})$ & 111.7(11.6) & & $111.3(9.8)$ & \\
\hline Resting DBP (mm & & & & \\
\hline $\mathrm{Hg})$ & $65.4(8.6)$ & & $65.5(9.1)$ & \\
\hline Resting MAP (mm & & & & \\
\hline $\mathrm{Hg})$ & $80.8(8.2)$ & & $80.7(7.6)$ & \\
\hline Resting HR & $78.0(11.0)$ & & $77.0(10.6)$ & \\
\hline Resting SDNN & $67.0(27.3)$ & & $64.2(28.8)$ & \\
\hline Trait Anxiety & $36.1(8.8)^{\mathrm{a}}$ & & $53.5(7.5)^{\mathrm{a}}$ & \\
\hline Neuroticism & $30.8(9.1)^{\mathrm{a}}$ & & $43.5(7.6)^{\mathrm{a}}$ & \\
\hline Agreeableness & $48.6(6.7)^{\mathrm{a}}$ & & $42.4(7.8)^{\mathrm{a}}$ & \\
\hline Open Mindedness & $46.3(7.7)^{\mathrm{a}}$ & & $42.1(7.2)^{\mathrm{a}}$ & \\
\hline Conscientiousness & $46.4(9.0)^{\mathrm{a}}$ & & $40.7(8.6)^{\mathrm{a}}$ & \\
\hline Extraversion & $42.9(8.9)^{\mathrm{a}}$ & & $34.7(8.8)^{\mathrm{a}}$ & \\
\hline
\end{tabular}

Note: ${ }^{a}$ indicates a significant difference between optimists and pessimists. 
Table 2. Means and standard deviations for cardiovascular parameters during rest,

Task, and recovery

\begin{tabular}{|c|c|c|c|c|c|c|}
\hline & \multicolumn{3}{|c|}{ Optimist } & \multicolumn{3}{|c|}{ Pessimist } \\
\hline & $\begin{array}{l}\text { Difficult } \\
\text { Task } \\
(\mathrm{n}=37)\end{array}$ & $\begin{array}{l}\text { Easy } \\
\text { Task } \\
(\mathrm{n}=37)\end{array}$ & $\begin{array}{l}\text { All } \\
\text { Optimist } \\
(\mathrm{n}=74)\end{array}$ & $\begin{array}{l}\text { Difficult } \\
\text { Task } \\
(\mathrm{n}=39)\end{array}$ & $\begin{array}{l}\text { Easy } \\
\text { Task } \\
(\mathrm{n}=39)\end{array}$ & $\begin{array}{l}\text { All } \\
\text { Pessimist } \\
(\mathrm{n}=78)\end{array}$ \\
\hline SBP Rest (mm Hg) & $\begin{array}{l}112.6 \\
(10.3)\end{array}$ & $\begin{array}{l}110.7 \\
(12.8)\end{array}$ & $\begin{array}{l}111.7 \\
(11.6)\end{array}$ & $\begin{array}{l}111.6 \\
(9.8)\end{array}$ & $\begin{array}{l}111 \\
(9.9)\end{array}$ & $\begin{array}{l}111.3 \\
(9.8)\end{array}$ \\
\hline SBP Task & $\begin{array}{l}118.5 \\
(11.1)\end{array}$ & $\begin{array}{l}117.7 \\
(12.7)\end{array}$ & $\begin{array}{l}118.1 \\
(11.8)\end{array}$ & $\begin{array}{l}119.1 \\
(12.5)\end{array}$ & $\begin{array}{l}118.5 \\
(11.6)\end{array}$ & $\begin{array}{l}118.8 \\
(12.0)\end{array}$ \\
\hline SBP Recovery & $\begin{array}{l}111.8 \\
(9.8)\end{array}$ & $\begin{array}{l}112.2 \\
(12.8)\end{array}$ & $\begin{array}{l}112.0 \\
(11.3)\end{array}$ & $\begin{array}{l}111.9 \\
(11.2)\end{array}$ & $\begin{array}{l}112.0 \\
(10.2)\end{array}$ & $\begin{array}{l}112.0 \\
(10.7)\end{array}$ \\
\hline DBP Rest (mm Hg) & $\begin{array}{l}66.4 \\
(7.6)\end{array}$ & $\begin{array}{l}64.3 \\
(9.4)\end{array}$ & $\begin{array}{l}65.4 \\
(8.6)\end{array}$ & $\begin{array}{l}64.6 \\
(9.9)\end{array}$ & $\begin{array}{l}66.4 \\
(8.2)\end{array}$ & $\begin{array}{l}65.5 \\
(9.1)\end{array}$ \\
\hline DBP Task & $\begin{array}{l}73.1 \\
(8.4)\end{array}$ & $\begin{array}{l}70.8 \\
(10.0)\end{array}$ & $\begin{array}{l}72.0^{\mathrm{a}} \\
(9.3)\end{array}$ & $\begin{array}{l}70.1 \\
(9.0)\end{array}$ & $\begin{array}{l}70.6 \\
(9.4)\end{array}$ & $\begin{array}{l}70.3^{a} \\
(9.2)\end{array}$ \\
\hline DBP Recovery & $\begin{array}{l}68 \\
(8.7)\end{array}$ & $\begin{array}{l}65.2 \\
(8.6)\end{array}$ & $\begin{array}{l}66.6 \\
(8.7)\end{array}$ & $\begin{array}{l}67.5 \\
(11.3)\end{array}$ & $\begin{array}{l}66.2 \\
(8.2)\end{array}$ & $\begin{array}{l}66.8 \\
(9.8)\end{array}$ \\
\hline MAP Rest (mm Hg) & $\begin{array}{l}81.8 \\
(6.7)\end{array}$ & $\begin{array}{l}79.8 \\
(9.5)\end{array}$ & $\begin{array}{l}80.8 \\
(8.2)\end{array}$ & $\begin{array}{l}80.2 \\
(8.4)\end{array}$ & $\begin{array}{l}81.2 \\
(6.8)\end{array}$ & $\begin{array}{l}80.7 \\
(7.6)\end{array}$ \\
\hline MAP Task & $\begin{array}{l}88.2 \\
(7.8)\end{array}$ & $\begin{array}{l}86.5 \\
(9.8)\end{array}$ & $\begin{array}{l}87.3 \\
(8.8)\end{array}$ & $\begin{array}{l}86.4 \\
(8.5)\end{array}$ & $\begin{array}{l}86.5 \\
(8.1)\end{array}$ & $\begin{array}{l}86.5 \\
(8.3)\end{array}$ \\
\hline MAP Recovery & $\begin{array}{l}82.6 \\
(7.2)\end{array}$ & $\begin{array}{l}80.9 \\
(8.3)\end{array}$ & $\begin{array}{l}81.7 \\
(7.8)\end{array}$ & $\begin{array}{l}82.3 \\
(9.9)\end{array}$ & $\begin{array}{l}81.5 \\
(6.7)\end{array}$ & $\begin{array}{l}81.9 \\
(8.4)\end{array}$ \\
\hline HR Rest (bpm) & $\begin{array}{l}78.8 \\
(10.3)\end{array}$ & $\begin{array}{l}77.1 \\
(11.8)\end{array}$ & $\begin{array}{l}78.0 \\
(11.0)\end{array}$ & $\begin{array}{l}77.7 \\
(9.8)\end{array}$ & $\begin{array}{l}76.3 \\
(11.5)\end{array}$ & $\begin{array}{l}77.0 \\
(10.6)\end{array}$ \\
\hline HR Task & $\begin{array}{l}81.9 \\
(9.7)\end{array}$ & $\begin{array}{l}81.7 \\
(11.6)\end{array}$ & $\begin{array}{l}81.8 \\
(10.6)\end{array}$ & $\begin{array}{l}81.4 \\
(10.7)\end{array}$ & $\begin{array}{l}80.1 \\
(12.6)\end{array}$ & $\begin{array}{l}80.9 \\
(11.6)\end{array}$ \\
\hline HR Recovery & $\begin{array}{l}80.0 \\
(9.8)\end{array}$ & $\begin{array}{l}78.7 \\
(11.3)\end{array}$ & $\begin{array}{l}79.3 \\
(10.5)\end{array}$ & $\begin{array}{l}78.2 \\
(9.3)\end{array}$ & $\begin{array}{l}77.9 \\
(11.2)\end{array}$ & $\begin{array}{l}78.0 \\
(10.2)\end{array}$ \\
\hline $\begin{array}{l}\text { HF-HRV Rest } \\
\left(\log \left(\mathrm{ms}^{2}\right)\right)\end{array}$ & $\begin{array}{l}4716 \\
(22058)\end{array}$ & $\begin{array}{l}1778 \\
(2026)\end{array}$ & $\begin{array}{l}3247 \\
(15626)\end{array}$ & $\begin{array}{l}1317 \\
(1862)\end{array}$ & $\begin{array}{l}1675 \\
(2010)\end{array}$ & $\begin{array}{l}1496 \\
(1933)\end{array}$ \\
\hline HF-HRV Task & $\begin{array}{l}842 \\
(850)\end{array}$ & $\begin{array}{l}1307 \\
(1529)\end{array}$ & $\begin{array}{l}1074 \\
(1251)\end{array}$ & $\begin{array}{l}1652 \\
(4553)\end{array}$ & $\begin{array}{l}1526 \\
(2360)\end{array}$ & $\begin{array}{l}1590 \\
(3617)\end{array}$ \\
\hline HF-HRV Recovery & $\begin{array}{l}1016 \\
(882)\end{array}$ & $\begin{array}{l}1430 \\
(1562)\end{array}$ & $\begin{array}{l}1223 \\
(1277)\end{array}$ & $\begin{array}{l}1348 \\
(2369)\end{array}$ & $\begin{array}{l}1419 \\
(2045)\end{array}$ & $\begin{array}{l}1383 \\
(2199)\end{array}$ \\
\hline $\begin{array}{l}\text { LF-HRV Rest } \\
\left(\log \left(\mathrm{ms}^{2}\right)\right)\end{array}$ & $\begin{array}{l}1451 \\
(1440)\end{array}$ & $\begin{array}{l}1444 \\
(1119)\end{array}$ & $\begin{array}{l}1448 \\
(1281)\end{array}$ & $\begin{array}{l}1310 \\
(1227)\end{array}$ & $\begin{array}{l}1163 \\
(758)\end{array}$ & $\begin{array}{l}1237 \\
(1016)\end{array}$ \\
\hline LF-HRV Task & $\begin{array}{l}941 \\
(680)\end{array}$ & $\begin{array}{l}1204 \\
(939)\end{array}$ & $\begin{array}{l}1072 \\
(825)\end{array}$ & $\begin{array}{l}1055 \\
(1017)\end{array}$ & $\begin{array}{l}1598 \\
(1687)\end{array}$ & $\begin{array}{l}1323 \\
(1406)\end{array}$ \\
\hline LF-HRV Recovery & $1511^{\mathrm{b}}$ & $1549^{b}$ & 1530 & $1546^{\mathrm{b}}$ & $1264^{\mathrm{b}}$ & 1405 \\
\hline
\end{tabular}




\begin{tabular}{llll|lll} 
& $(1053)$ & $(1401)$ & $(1231)$ & $(1588)$ & $(868)$ & $(1279)$ \\
SDNN Rest (ms) & 64.1 & 69.9 & 67.0 & 64.5 & 63.9 & 64.2 \\
& $(24.9)$ & $(29.5)$ & $(27.0)$ & $(32.3)$ & $(25.2)$ & $(28.8)$ \\
SDNN Task & 60.0 & 64.3 & 62 & 54.7 & 71.4 & 62.9 \\
\multirow{3}{*}{ SDNN Recovery } & $(21.5)$ & $(24.0)$ & $(22.8)$ & $(26.6)$ & $(49.5)$ & $(40.2)$ \\
& $64.9^{\mathrm{b}}$ & $69.7^{\mathrm{b}}$ & 67.3 & $64.6^{\mathrm{b}}$ & $63.6^{\mathrm{b}}$ & 64.1 \\
& $(23.1)$ & $(26.2)$ & $(24.7)$ & $(30.9)$ & $(23.5)$ & $(27.3)$ \\
\hline
\end{tabular}

Note: ${ }^{a}$ indicates a significant difference between optimists and pessimists at the $p<.05$ level; ${ }^{b}$ indicates a significant difference between difficult and easy tasks at the $p<.05$ level; Systolic Blood Pressure (SBP), Diastolic Blood Pressure (DBP), Mean Arterial Pressure (MAP), Heart Rate (HR), HighFrequency Heart Rate Variability (HF-HRV), Low Frequency Heart Rate Variability (LF-HRV), Standard Deviation of $N-N$ Intervals (SDNN) 
Table 3. Means and standard errors for responses to the post-experimental questionnaire

\begin{tabular}{|c|c|c|c|c|}
\hline & \multicolumn{2}{|c|}{ Optimist $(\mathrm{n}=74)$} & \multicolumn{2}{|c|}{ Pessimist $(\mathrm{n}=78)$} \\
\hline & $\begin{array}{l}\text { Difficult task } \\
(\mathrm{n}=37)\end{array}$ & $\begin{array}{l}\text { Easy task } \\
(\mathrm{n}=37)\end{array}$ & $\begin{array}{l}\text { Difficult task } \\
(\mathrm{n}=39)\end{array}$ & $\begin{array}{l}\begin{array}{l}\text { Easy task } \\
(\mathrm{n}=39)\end{array} \\
\end{array}$ \\
\hline $\begin{array}{l}\text { How stressful } \\
\text { was the task? }\end{array}$ & $3.3(.15)$ & $2.4(.13)$ & $3.6(.15)$ & $2.3(.12)$ \\
\hline $\begin{array}{l}\text { How difficult } \\
\text { were the } \\
\text { problems on this } \\
\text { task? }\end{array}$ & $4.2(.14)$ & $2.6(.15)$ & $4.5(.09)$ & $2.5(.13)$ \\
\hline $\begin{array}{l}\text { How much effort } \\
\text { did you put into } \\
\text { completing the } \\
\text { problems? }\end{array}$ & $4.2(.10)$ & $3.4(.15)$ & $4.2(.10)$ & $3.6(.15)$ \\
\hline $\begin{array}{l}\text { How well do you } \\
\text { think you } \\
\text { performed on the } \\
\text { task? }\end{array}$ & $1.6(.14)$ & $3.9(.12)$ & $1.4(.09$ & $3.6(.14)$ \\
\hline $\begin{array}{l}\text { How persistent } \\
\text { were you in } \\
\text { completing the } \\
\text { task? }\end{array}$ & $3.8(.16)$ & $4.4(.10)$ & $3.3(.19)$ & $4.1(.11)$ \\
\hline $\begin{array}{l}\text { How upset are } \\
\text { you by your } \\
\text { performance on } \\
\text { the task? }\end{array}$ & $2.5(.19)$ & $1.7(.14)$ & $2.9(.18)$ & $1.8(.16)$ \\
\hline
\end{tabular}


Figure 1: SBP of optimist easy (OE), optimist difficult (OD), pessimist easy (PE), and pessimist difficult (PD) during rest, task period, and recovery.

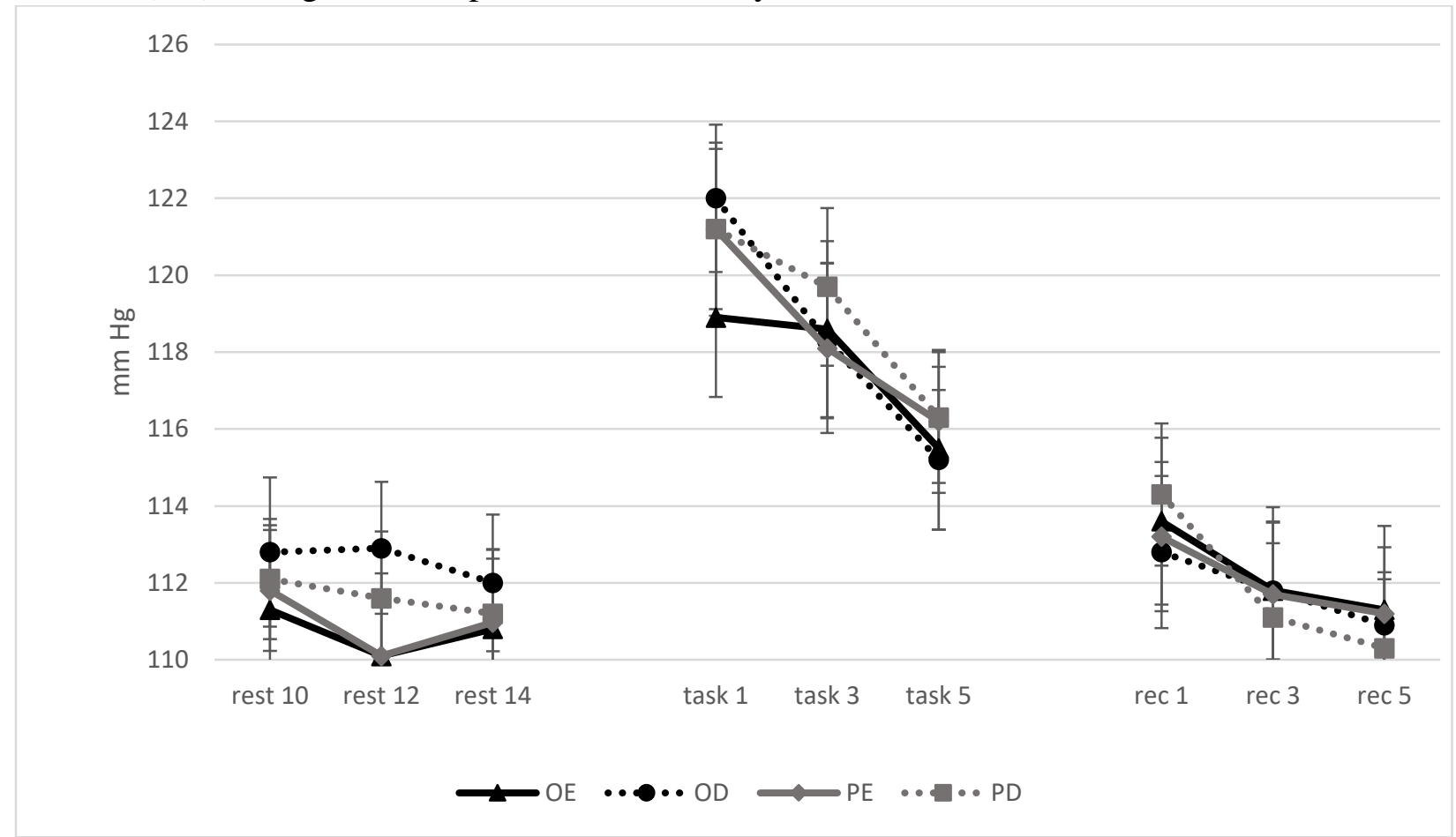


Figure 2: DBP of optimist easy (OE), optimist difficult (OD), pessimist easy (PE), and pessimist difficult (PD) during rest, task period, and recovery.

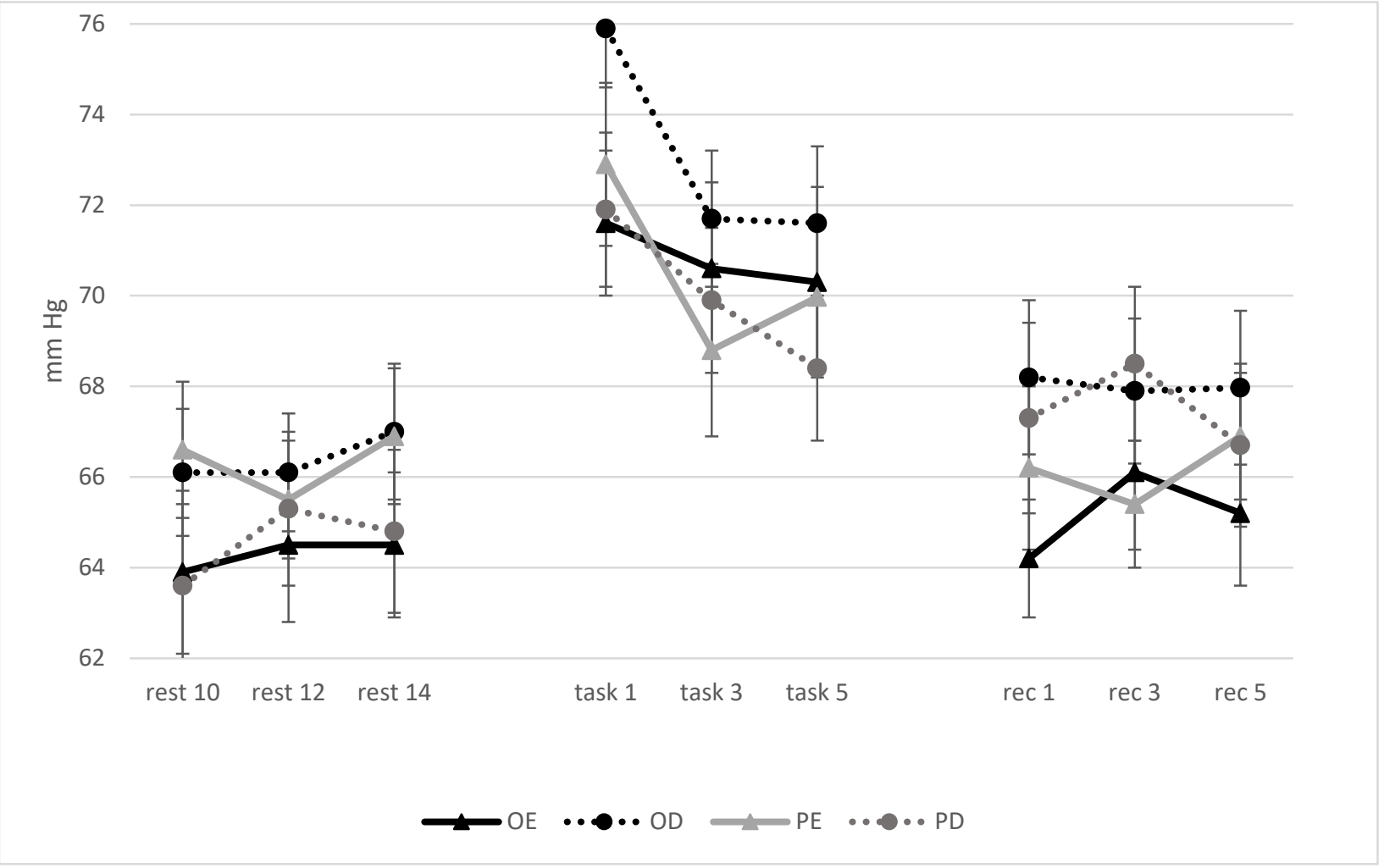


Figure 3: MAP of optimist easy (OE), optimist difficult (OD), pessimist easy (PE), and pessimist difficult (PD) during rest, task period, and recovery.

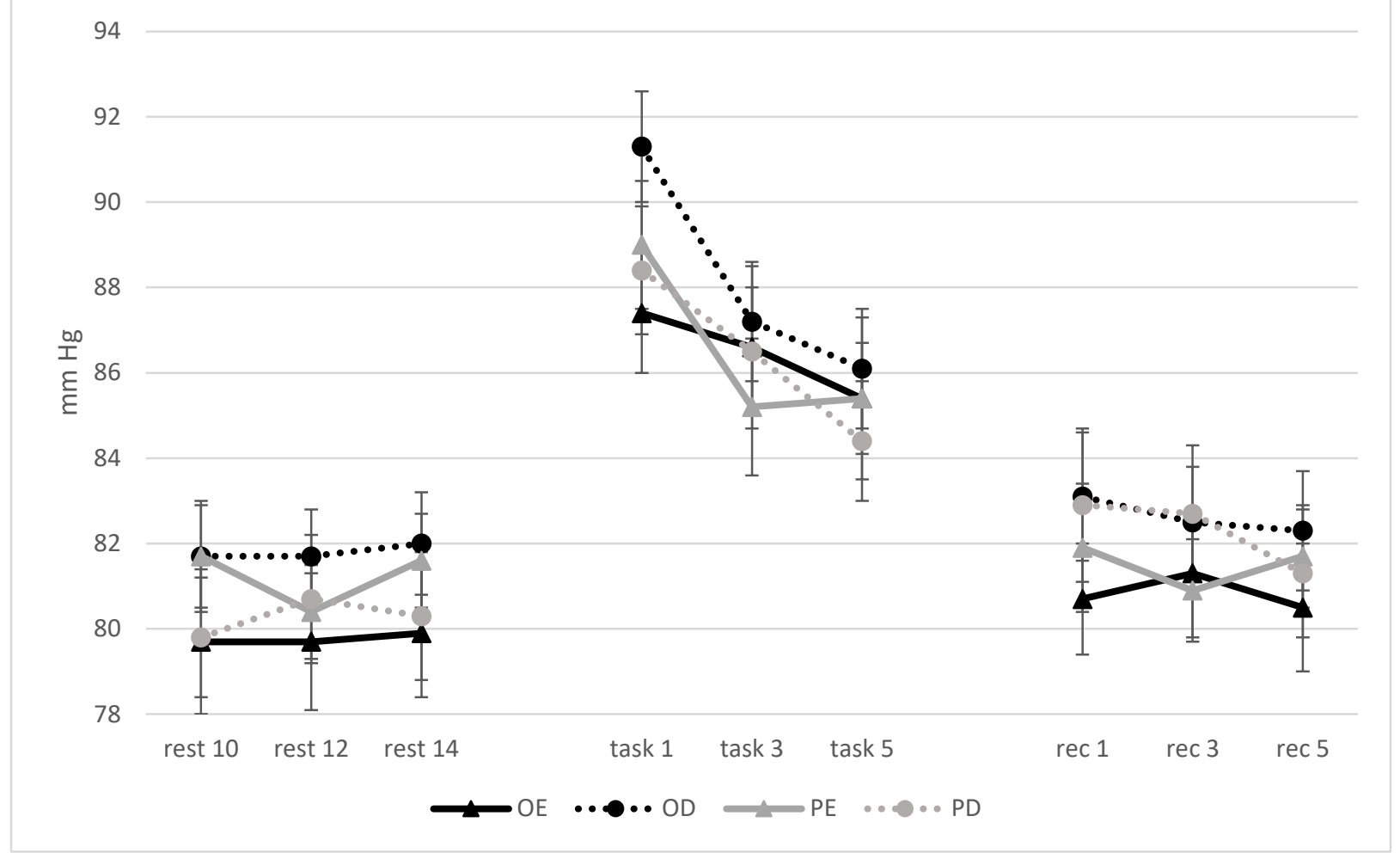


Figure 4: HR of optimist easy (OE), optimist difficult (OD), pessimist easy (PE), and pessimist difficult (PD) during rest, task period, and recovery.

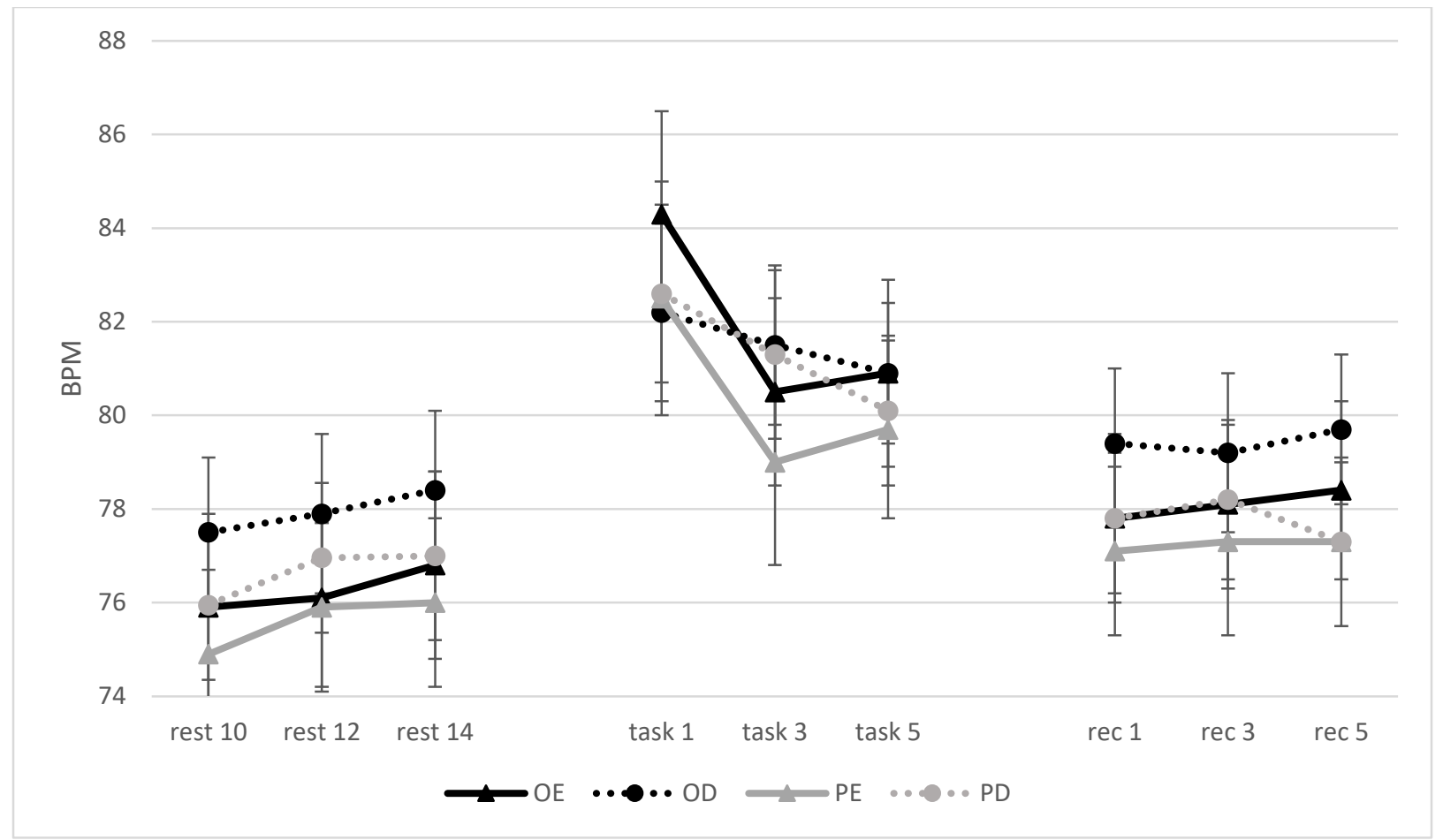


Figure 5: HF-HRV of optimist easy (OE), optimist difficult (OD), pessimist easy (PE), and pessimist difficult (PD) during rest, task period, and recovery.

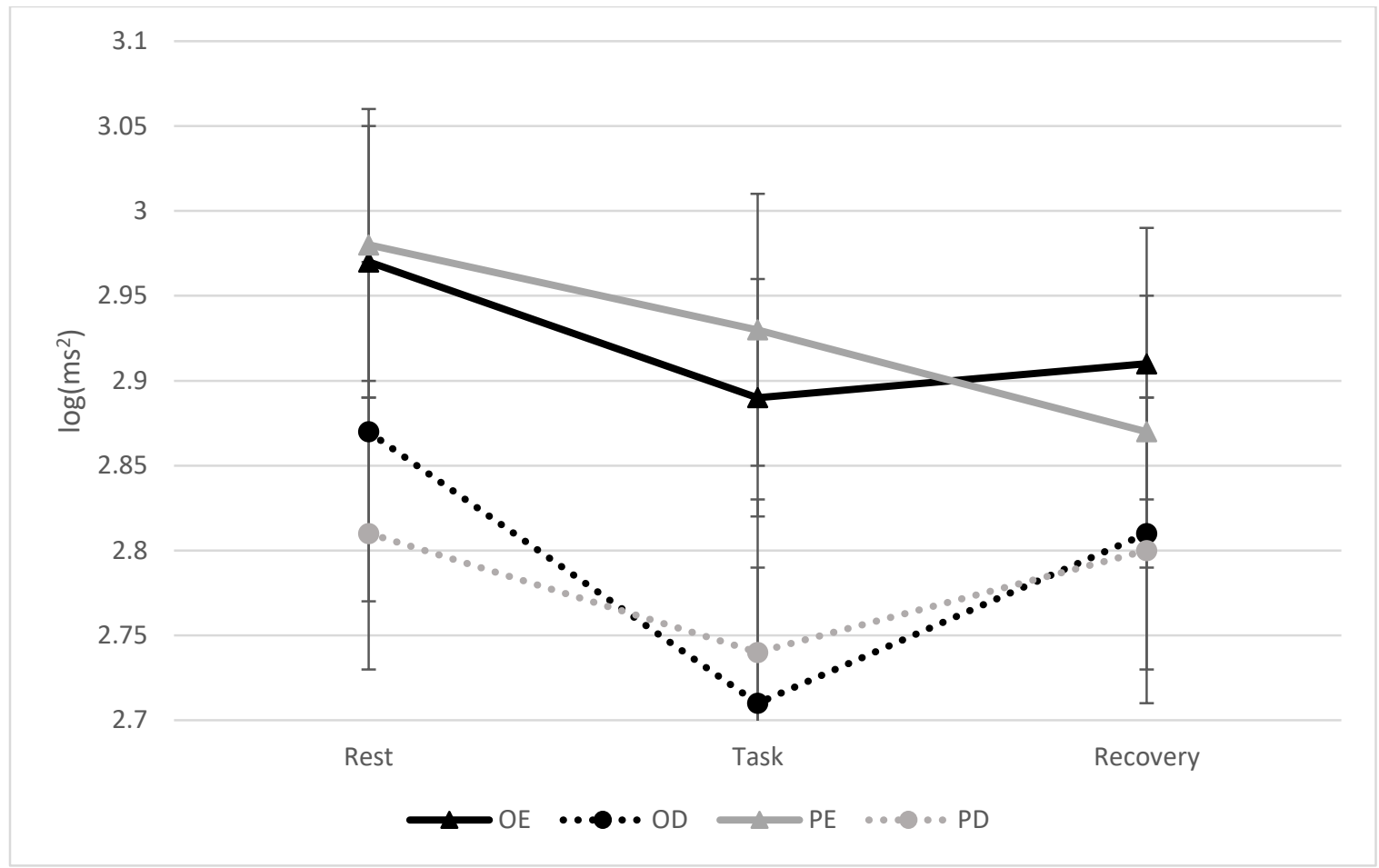


Figure 6: SDNN of optimist easy (OE), optimist difficult (OD), pessimist easy (PE), and pessimist difficult (PD) during rest, task period, and recovery.

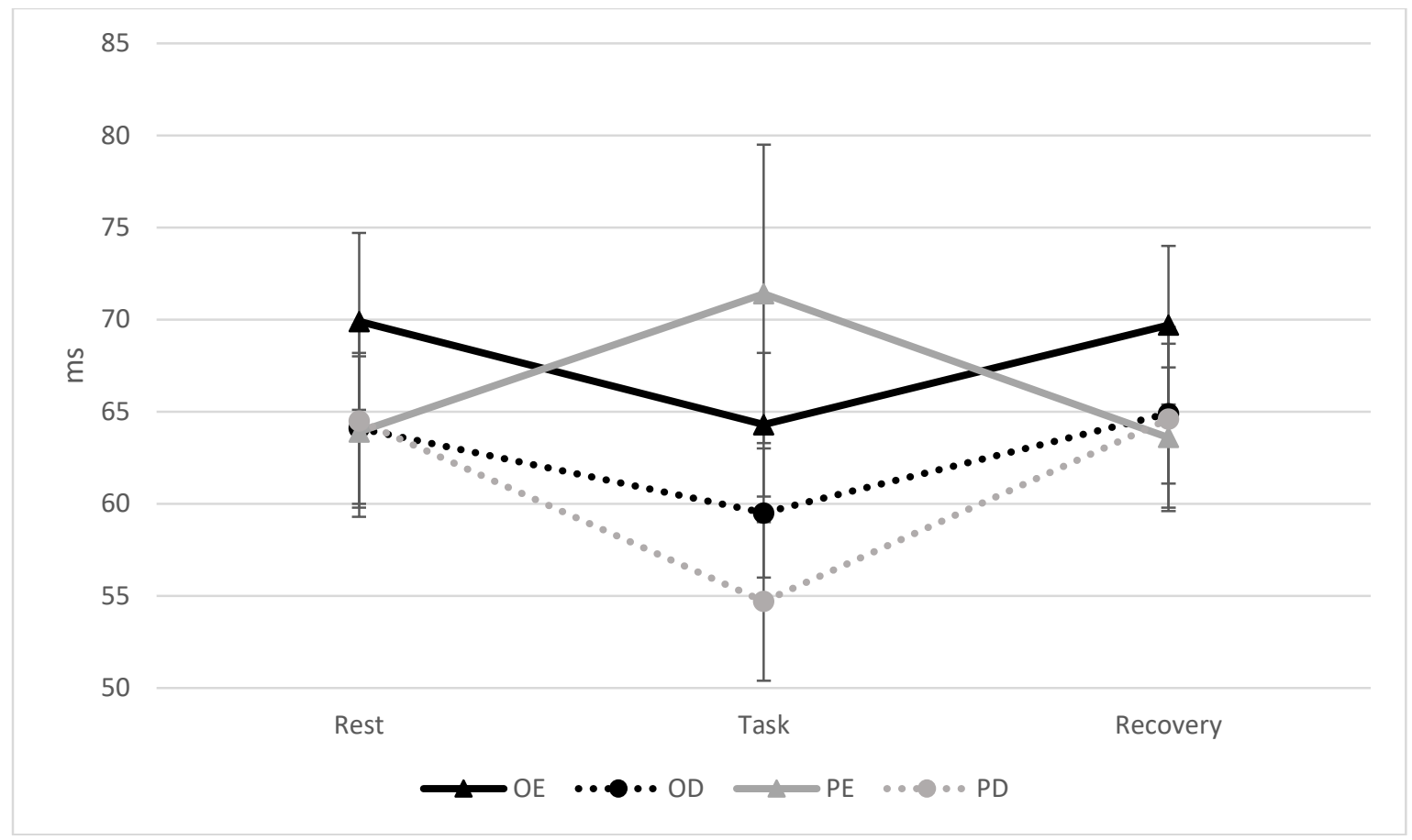


Figure 7: LF-HRV of optimist easy (OE), optimist difficult (OD), pessimist easy (PE), and pessimist difficult (PD) during rest, task period, and recovery.

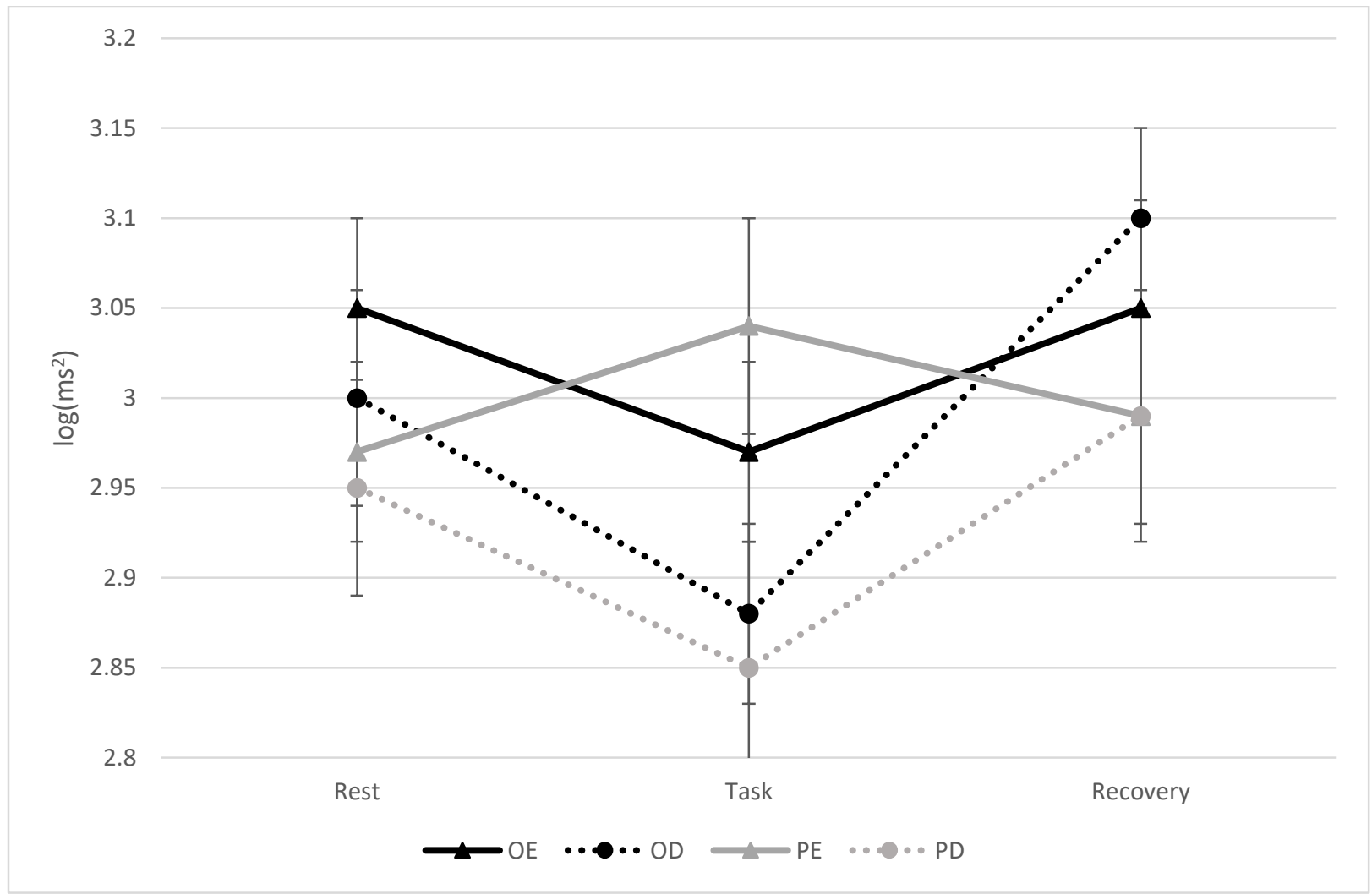


Appendix A

\section{Attachments}

1. Demographics Questionnaire

2. Self-Efficacy Questionnaire

3. Post-task Questionnaire 
Demographics Questionnaire

Participant \#:

Height(in.):
Date:

Weight(lbs):

Please provide your email address so that we can contact you for part 2 of the study:

\section{Your Information:}

Your age

Your sex
○ Male
○ Female

Are you Hispanic, Latino, or of Spanish origin?

- No, not of Hispanic, Latino, or Spanish origin

- Yes, Mexican, Mexican Am., Chicano

- Yes, Puerto Rican

○ Yes, Cuban

○ Yes, another Hispanic, Latino, or Spanish origin (please indicate)

Your race- check all that apply

$\circ$ White

- Black, African Am., or Negro

- American Indian or Alaska Native

- Asian Indian

- Chinese

$\circ \quad$ Filipino 
○ Japanese

○ Korean

○ Vietnamese

○ Native Hawaiian

- Guamanian or Chamorro

○ Samoan

○ Other Pacific Islander (please indicate)

- Other Asian (please indicate)

O Other race (please indicate)

Indicate the highest level of education you have completed:
$\circ$ High school
$\circ 1$ year college
$\circ 2$ years college
$\circ 3$ years college
○ 4 or more years college

Please describe any cardiovascular related illness that you may have, including high blood pressure

Please list any other medical or psychiatric problems that you have:

Please list any major surgeries and medical, or psychiatric illnesses you have had in the past. Females: Are you currently pregnant?
○ Yes
$\circ \mathrm{No}$

Females: Are you currently on birth control (contraceptives). 
○ Yes

$\circ$ No

What type of birth control are you taking?

Please list any drugs (legal or otherwise) that you are currently taking including; birth control (contraceptives), heart medications, cold or allergy medications, over the counter medications, asthma medications, Beta-Blockers (i.e. Inderal, Tenormin), psychoactive drugs (i.e. Adderall, Xanax, Haldol, Lithium, Prozac), or diet pills.

Do you currently smoke cigarettes (within the last month)?
○ Yes
○ No

Do you currently use smokeless tobacco (within the past month)?
○ Yes
$\circ$ No

How often do you drink alcohol?

$$
\begin{aligned}
& \text { o never } \\
& \text { o infrequently (a few drinks per year) } \\
& \text { occasionally (1-2 drinks per month) } \\
& \text { o weekly (1-3 drinks per week) } \\
& \text { o daily (7-14 drinks per week) } \\
& \text { o daily (more than } 14 \text { drinks per week) }
\end{aligned}
$$


How many cups of caffeinated coffee, tea, or soda do you have per day?

$$
\begin{aligned}
& \circ \text { none } \\
& \circ \text { 1-2 cups per day } \\
& \circ \text { 3-4 cups per day } \\
& \circ \text { 5-6 cups per day } \\
& \text { 7-8 cups per day } \\
& \circ \text { greater than eight cups per day }
\end{aligned}
$$

How many times per week do you engage in aerobic physical activity?

$$
\begin{aligned}
& \circ \text { never } \\
& \text { 1-2 times } \\
& \text { 3-6 times } \\
& \circ 7 \text { or more times }
\end{aligned}
$$

For how long do you typically exercise on each occasion?

$$
\begin{aligned}
& \text { 5-10 minutes } \\
& \text { 10-15 minutes } \\
& \text { o 15-30 minutes } \\
& \text { 30-60 minutes } \\
& \text { o more than } 60 \text { minutes }
\end{aligned}
$$

\section{Family Information:}

Imagine a ladder that represents where people stand in the United States.

At the top of the ladder are the people who are the best off - those who have the most money, the most education, and the most respected jobs. At the bottom are the people who are the worst off - who have the least money, least education, and the least respected jobs or no job. The 
higher up you are on this ladder, the closer you are to the people at the very top; the lower you are, the closer you are to the people at the very bottom.

On which rung of the ladder ( 1 being the lowest rung and 10 being the highest rung) would you place your family?

$1 \ldots \ldots \ldots .2 \ldots \ldots \ldots 3 \ldots \ldots \ldots 4 \ldots \ldots \ldots 5 \ldots \ldots \ldots 6 \ldots \ldots . \ldots \ldots \ldots . \ldots \ldots \ldots 9 \ldots \ldots 10$

Is your father currently living?

○ yes

$\circ$ no

Approximately how old is your father?

Did/does your father have high blood pressure (hypertension)?

$\circ$ yes

○ no

How certain are you that he did, or did not, have high blood pressure (hypertension)?

○ Absolutely $(100 \%)$ certain

○ Almost (75\%) certain

○ Not sure at all (25\%)

$\circ$ No information by which to judge $(0 \%)$

Did/does your father have any heart problems such as angina (chest pains), a heart attack, or coronary heart disease?

$\circ$ yes

$\circ$ no

If yes, please specify if you are able: 
How certain are you that he did, or did not, have a heart problem as indicated above?
○ Absolutely (100\%) certain
○ Almost (75\%) certain
$\circ$ Not sure at all $(25 \%)$
$\circ$ No information by which to judge $(0 \%)$

Is your mother currently living?

$$
\begin{aligned}
& \circ \text { yes } \\
& \circ \text { no }
\end{aligned}
$$

Approximately how old is your mother?

Did/does your mother have high blood pressure (hypertension)?

$$
\begin{aligned}
& \text { o yes } \\
& \text { ○ no }
\end{aligned}
$$

How certain are you that she did, or did not, have high blood pressure (hypertension)?

$$
\begin{aligned}
& \text { Absolutely }(100 \%) \text { certain } \\
& \text { Almost }(75 \%) \text { certain } \\
& \text { Not sure at all }(25 \%) \\
& \circ \text { No information by which to judge }(0 \%)
\end{aligned}
$$

Did/does your mother have any heart problems such as angina (chest pains), a heart attack, or coronary heart disease?

$$
\circ \text { yes }
$$


○ no

If yes, please specify if you are able:

How certain are you that she did, or did not, have a heart problem as indicated above?

○ Absolutely (100\%) certain

○ Almost (75\%) certain

$\circ$ Not sure at all $(25 \%)$

○ No information by which to judge ( $0 \%)$ 


\section{Self-Efficacy Questionnaire}

Below is a pattern with a piece missing. Look at the pattern. Think about what shape will complete the pattern correctly both across and down. You must choose which of the pieces below is the best one to complete the pattern.

Image of Raven's Matrice puzzle placed here.

How confident are you that you will be able to accurately complete all of the items during the task?

Not at all Somewhat unconfident

1
Somewhat confident

3
Very confident

4 


\section{Post Task Questionnaire}

\section{Instructions:}

Please select the response below each question that best represents your answer to the question.

1. How stressful was the task?

Not at all Minimally stressful Neutral Fairly stressful Extremely stressful

2. How difficult were the problems on this task?

Not at all Minimally difficult Neutral Fairly difficult Extremely difficult

3. How much effort did you put into completing the problems?

None Minimal effort Neutral Fair amount of effort A lot of effort

4. How well do you think you performed on the task?

Extremely poorly Somewhat poorly Unsure Somewhat well Extremely well

5. How persistent were you in completing the task?

Not at all Minimally persistent Neutral Fairly persistent Very persistent

6. How upset are you by your performance on the task?

Not at all Somewhat upset Neutral Fairly upset Extremely upset 
Appendix B: Statistical Tables

\section{Rest Period - Repeated Measures ANOVAs across Minute (Min 1, 3, and 5)}

1. SBP

\section{Tests of Within-Subjects Effects}

Measure: rest

\begin{tabular}{|c|c|c|c|c|c|c|c|}
\hline Source & & $\begin{array}{c}\text { Type III Sum } \\
\text { of Squares }\end{array}$ & $\mathrm{df}$ & Mean Square & $\mathrm{F}$ & Sig. & $\begin{array}{c}\text { Partial Eta } \\
\text { Squared } \\
\end{array}$ \\
\hline \multirow[t]{4}{*}{ SBPrest } & Sphericity Assumed & 65.837 & 2 & 32.918 & 1.922 & .148 & .013 \\
\hline & Greenhouse-Geisser & 65.837 & 1.945 & 33.855 & 1.922 & .149 & .013 \\
\hline & Huynh-Feldt & 65.837 & 1.970 & 33.425 & 1.922 & .149 & .013 \\
\hline & Lower-bound & 65.837 & 1.000 & 65.837 & 1.922 & .168 & .013 \\
\hline \multirow[t]{4}{*}{ Error(SBPrest) } & Sphericity Assumed & 5171.997 & 302 & 17.126 & & & \\
\hline & Greenhouse-Geisser & 5171.997 & 293.644 & 17.613 & & & \\
\hline & Huynh-Feldt & 5171.997 & 297.419 & 17.390 & & & \\
\hline & Lower-bound & 5171.997 & 151.000 & 34.252 & & & \\
\hline
\end{tabular}

2. DBP

Tests of Within-Subjects Effects

Measure: rest

\begin{tabular}{ll|r|r|r|r|r|r} 
Source & $\begin{array}{c}\text { Type III Sum } \\
\text { of Squares }\end{array}$ & df & Mean Square & F & Sig. & \multicolumn{2}{c}{$\begin{array}{c}\text { Partial Eta } \\
\text { Squared }\end{array}$} \\
\hline DBP & Sphericity Assumed & 43.543 & 2 & 21.771 & .835 & .435 & .006 \\
\hline & Greenhouse-Geisser & 43.543 & 1.991 & 21.871 & .835 & .434 & .006 \\
\cline { 2 - 10 } & Huynh-Feldt & 43.543 & 2.000 & 21.771 & .835 & .435 & .006 \\
\hline \multirow{2}{*}{ Error(DBP) } & Lower-bound & 43.543 & 1.000 & 43.543 & .835 & .362 & .006 \\
\hline & Sphericity Assumed & 7873.291 & 302 & 26.070 & & & \\
\hline & Greenhouse-Geisser & 7873.291 & 300.619 & 26.190 & & & \\
\hline & Huynh-Feldt & 7873.291 & 302.000 & 26.070 & & & \\
\hline
\end{tabular}




\section{MAP}

Tests of Within-Subjects Effects

Measure: rest

\begin{tabular}{|c|c|c|c|c|c|c|c|}
\hline Source & & $\begin{array}{c}\text { Type III Sum } \\
\text { of Squares }\end{array}$ & $\mathrm{df}$ & Mean Square & $\mathrm{F}$ & Sig. & $\begin{array}{c}\text { Partial Eta } \\
\text { Squared }\end{array}$ \\
\hline \multirow[t]{4}{*}{ MAP } & Sphericity Assumed & 8.678 & 2 & 4.339 & .315 & .730 & .002 \\
\hline & Greenhouse-Geisser & 8.678 & 1.993 & 4.354 & .315 & .729 & .002 \\
\hline & Huynh-Feldt & 8.678 & 2.000 & 4.339 & .315 & .730 & .002 \\
\hline & Lower-bound & 8.678 & 1.000 & 8.678 & .315 & .576 & .002 \\
\hline \multirow[t]{4}{*}{ Error(MAP) } & Sphericity Assumed & 4163.156 & 302 & 13.785 & & & \\
\hline & Greenhouse-Geisser & 4163.156 & 300.922 & 13.835 & & & \\
\hline & Huynh-Feldt & 4163.156 & 302.000 & 13.785 & & & \\
\hline & Lower-bound & 4163.156 & 151.000 & 27.571 & & & \\
\hline
\end{tabular}

\section{HR}

\section{Tests of Within-Subjects Effects}

Measure: rest

\begin{tabular}{ll|r|r|r|r|r|r} 
Source & \multicolumn{2}{c}{$\begin{array}{c}\text { Type III Sum } \\
\text { of Squares }\end{array}$} & \multicolumn{1}{c|}{ df } & Mean Square & F & Sig. & \multicolumn{2}{c}{$\begin{array}{c}\text { Partial Eta } \\
\text { Squared }\end{array}$} \\
\hline HR & Sphericity Assumed & 79.701 & 2 & 39.850 & 6.080 & .003 & .039 \\
\hline & Greenhouse-Geisser & 79.701 & 1.987 & 40.114 & 6.080 & .003 & .039 \\
\hline & Huynh-Feldt & 79.701 & 2.000 & 39.850 & 6.080 & .003 & .039 \\
\hline \multirow{2}{*}{ Error(HR) } & Lower-bound & 79.701 & 1.000 & 79.701 & 6.080 & .015 & .039 \\
\hline & Sphericity Assumed & 1953.273 & 298 & 6.555 & & & \\
\hline & Greenhouse-Geisser & 1953.273 & 296.043 & 6.598 & & & \\
& Huynh-Feldt & 1953.273 & 298.000 & 6.555 & & & \\
\hline & Lower-bound & 1953.273 & 149.000 & 13.109 & & & \\
\hline
\end{tabular}


5.

\section{Pairwise Comparisons}

Measure: rest

\begin{tabular}{|c|c|c|c|c|c|c|}
\hline \multirow[b]{2}{*}{ (I) HR } & \multirow[b]{2}{*}{ (J) HR } & \multirow{2}{*}{$\begin{array}{c}\text { Mean Difference } \\
(\mathrm{I}-\mathrm{J}) \\
\end{array}$} & \multirow[b]{2}{*}{ Std. Error } & \multirow[b]{2}{*}{ Sig. ${ }^{b}$} & \multicolumn{2}{|c|}{$\begin{array}{c}\text { 95\% Confidence Interval for } \\
\text { Difference }^{\mathrm{b}}\end{array}$} \\
\hline & & & & & Lower Bound & Upper Bound \\
\hline \multirow[t]{2}{*}{1} & 2 & -.676 & .307 & .088 & -1.420 & .068 \\
\hline & 3 & $-1.012^{*}$ & .291 & .002 & -1.717 & -.307 \\
\hline \multirow[t]{2}{*}{2} & 1 & .676 & .307 & .088 & -.068 & 1.420 \\
\hline & 3 & -.336 & .288 & .736 & -1.033 & .361 \\
\hline \multirow[t]{2}{*}{3} & 1 & $1.012^{*}$ & .291 & .002 & .307 & 1.717 \\
\hline & 2 & .336 & .288 & .736 & -.361 & 1.033 \\
\hline
\end{tabular}

6.

\section{Estimates}

Measure: rest

\begin{tabular}{lc|r|r|r} 
& & & \multicolumn{2}{|c}{$95 \%$ Confidence Interval } \\
HR & Mean & Std. Error & Lower Bound & Upper Bound \\
\hline 1 & 76.053 & .870 & 74.334 & 77.771 \\
\hline 2 & 76.729 & .879 & 74.992 & 78.466 \\
\hline 3 & 77.065 & .896 & 75.295 & 78.835 \\
\hline
\end{tabular}




\section{Task Period Reactivity - Group (Easy, Difficult) X Period (Rest, Task) ANOVAs}

7. SBP

Tests of Within-Subjects Effects

Measure: SBP

\begin{tabular}{|c|c|c|c|c|c|c|c|}
\hline Source & & $\begin{array}{c}\text { Type III Sum } \\
\text { of Squares }\end{array}$ & df & Mean Square & $\mathrm{F}$ & Sig. & $\begin{array}{c}\text { Partial Eta } \\
\text { Squared } \\
\end{array}$ \\
\hline \multirow[t]{4}{*}{ Period } & Sphericity Assumed & 3690.244 & 1 & 3690.244 & 149.180 & .000 & .499 \\
\hline & Greenhouse-Geisser & 3690.244 & 1.000 & 3690.244 & 149.180 & .000 & .499 \\
\hline & Huynh-Feldt & 3690.244 & 1.000 & 3690.244 & 149.180 & .000 & .499 \\
\hline & Lower-bound & 3690.244 & 1.000 & 3690.244 & 149.180 & .000 & .499 \\
\hline Period $*$ Task & Sphericity Assumed & 5.665 & 1 & 5.665 & .229 & .633 & .002 \\
\hline \multirow[t]{3}{*}{ Difficulty } & Greenhouse-Geisser & 5.665 & 1.000 & 5.665 & .229 & .633 & .002 \\
\hline & Huynh-Feldt & 5.665 & 1.000 & 5.665 & .229 & .633 & .002 \\
\hline & Lower-bound & 5.665 & 1.000 & 5.665 & .229 & .633 & .002 \\
\hline \multirow[t]{4}{*}{ Error(time) } & Sphericity Assumed & 3710.522 & 150 & 24.737 & & & \\
\hline & Greenhouse-Geisser & 3710.522 & 150.000 & 24.737 & & & \\
\hline & Huynh-Feldt & 3710.522 & 150.000 & 24.737 & & & \\
\hline & Lower-bound & 3710.522 & 150.000 & 24.737 & & & \\
\hline
\end{tabular}

8.

\section{Estimates}

Measure: SBP

\begin{tabular}{lc|r|r|r} 
& & & \multicolumn{2}{|c}{$95 \%$ Confidence Interval } \\
time & Mean & Std. Error & Lower Bound & Upper Bound \\
\hline 1 & 111.468 & .867 & 109.756 & 113.181 \\
\hline 2 & 118.436 & .966 & 116.528 & 120.345 \\
\hline
\end{tabular}




\section{DBP}

\section{Tests of Within-Subjects Effects}

Measure: DBP

\begin{tabular}{|c|c|c|c|c|c|c|c|}
\hline Source & & $\begin{array}{c}\text { Type III Sum } \\
\text { of Squares }\end{array}$ & $\mathrm{df}$ & $\begin{array}{c}\text { Mean } \\
\text { Square } \\
\end{array}$ & $\mathrm{F}$ & Sig. & $\begin{array}{c}\text { Partial Eta } \\
\text { Squared } \\
\end{array}$ \\
\hline \multirow[t]{4}{*}{ period } & Sphericity Assumed & 2479.320 & 1 & 2479.320 & 132.092 & .000 & .468 \\
\hline & $\begin{array}{l}\text { Greenhouse- } \\
\text { Geisser }\end{array}$ & 2479.320 & 1.000 & 2479.320 & 132.092 & .000 & .468 \\
\hline & Huynh-Feldt & 2479.320 & 1.000 & 2479.320 & 132.092 & .000 & .468 \\
\hline & Lower-bound & 2479.320 & 1.000 & 2479.320 & 132.092 & .000 & .468 \\
\hline period $*$ & Sphericity Assumed & 10.132 & 1 & 10.132 & .540 & .464 & .004 \\
\hline \multirow[t]{3}{*}{ TASK_difficult_easy } & $\begin{array}{l}\text { Greenhouse- } \\
\text { Geisser }\end{array}$ & 10.132 & 1.000 & 10.132 & .540 & .464 & .004 \\
\hline & Huynh-Feldt & 10.132 & 1.000 & 10.132 & .540 & .464 & .004 \\
\hline & Lower-bound & 10.132 & 1.000 & 10.132 & .540 & .464 & .004 \\
\hline \multirow[t]{4}{*}{ Error(time) } & Sphericity Assumed & 2815.450 & 150 & 18.770 & & & \\
\hline & $\begin{array}{l}\text { Greenhouse- } \\
\text { Geisser }\end{array}$ & 2815.450 & 150.000 & 18.770 & & & \\
\hline & Huynh-Feldt & 2815.450 & 150.000 & 18.770 & & & \\
\hline & Lower-bound & 2815.450 & 150.000 & 18.770 & & & \\
\hline
\end{tabular}

10.

\section{Estimates}

Measure: DBP

\begin{tabular}{lc|r|r|r} 
& & & \multicolumn{2}{|c}{$95 \%$ Confidence Interval } \\
time & Mean & \multicolumn{1}{c|}{ Std. Error } & Lower Bound & Upper Bound \\
\hline 1 & 65.411 & .716 & 63.997 & 66.825 \\
\hline 2 & 71.123 & .749 & 69.644 & 72.602 \\
\hline
\end{tabular}




\section{MAP}

Tests of Within-Subjects Effects

Measure: MAP

\begin{tabular}{|c|c|c|c|c|c|c|c|}
\hline Source & & $\begin{array}{c}\text { Type III Sum } \\
\text { of Squares } \\
\end{array}$ & $\mathrm{df}$ & $\begin{array}{l}\text { Mean } \\
\text { Square } \\
\end{array}$ & $\mathrm{F}$ & Sig. & $\begin{array}{c}\text { Partial Eta } \\
\text { Squared } \\
\end{array}$ \\
\hline \multirow[t]{4}{*}{ period } & Sphericity & 2856.294 & 1 & 2856.294 & 203.019 & .000 & .575 \\
\hline & $\begin{array}{l}\text { Greenhouse- } \\
\text { Geisser }\end{array}$ & 2856.294 & 1.000 & 2856.294 & 203.019 & .000 & .575 \\
\hline & Huynh-Feldt & 2856.294 & 1.000 & 2856.294 & 203.019 & .000 & .575 \\
\hline & Lower-bound & 2856.294 & 1.000 & 2856.294 & 203.019 & .000 & .575 \\
\hline \multirow[t]{4}{*}{$\begin{array}{l}\text { period * } \\
\text { TASK_difficult_easy }\end{array}$} & $\begin{array}{l}\text { Sphericity } \\
\text { Assumed }\end{array}$ & 1.765 & 1 & 1.765 & .125 & .724 & .001 \\
\hline & $\begin{array}{l}\text { Greenhouse- } \\
\text { Geisser }\end{array}$ & 1.765 & 1.000 & 1.765 & .125 & .724 & .001 \\
\hline & Huynh-Feldt & 1.765 & 1.000 & 1.765 & .125 & .724 & .001 \\
\hline & Lower-bound & 1.765 & 1.000 & 1.765 & .125 & .724 & .001 \\
\hline \multirow[t]{4}{*}{ Error(time) } & $\begin{array}{l}\text { Sphericity } \\
\text { Assumed }\end{array}$ & 2110.365 & 150 & 14.069 & & & \\
\hline & $\begin{array}{l}\text { Greenhouse- } \\
\text { Geisser }\end{array}$ & 2110.365 & 150.000 & 14.069 & & & \\
\hline & Huynh-Feldt & 2110.365 & 150.000 & 14.069 & & & \\
\hline & Lower-bound & 2110.365 & 150.000 & 14.069 & & & \\
\hline
\end{tabular}

12.

\section{Estimates}

Measure: MAP

\begin{tabular}{lc|r|r|r} 
& & & \multicolumn{2}{|c}{$95 \%$ Confidence Interval } \\
Time & Mean & Std. Error & Lower Bound & Upper Bound \\
\hline 1 & 80.764 & .641 & 79.497 & 82.030 \\
\hline 2 & 86.894 & .693 & 85.525 & 88.263 \\
\hline
\end{tabular}




\section{HR}

\section{Tests of Within-Subjects Effects}

Measure: HR

\begin{tabular}{|c|c|c|c|c|c|c|c|}
\hline Source & & $\begin{array}{l}\text { Type III Sum } \\
\text { of Squares }\end{array}$ & $\mathrm{df}$ & $\begin{array}{c}\text { Mean } \\
\text { Square } \\
\end{array}$ & $\mathrm{F}$ & Sig. & $\begin{array}{l}\text { Partial Eta } \\
\text { Squared } \\
\end{array}$ \\
\hline \multirow[t]{5}{*}{ Period } & Sphericity & 1117.173 & 1 & 1117.173 & 57.068 & .000 & .280 \\
\hline & Assumed & & & & & & \\
\hline & $\begin{array}{l}\text { Greenhouse- } \\
\text { Geisser }\end{array}$ & 1117.173 & 1.000 & 1117.173 & 57.068 & .000 & .280 \\
\hline & Huynh-Feldt & 1117.173 & 1.000 & 1117.173 & 57.068 & .000 & .280 \\
\hline & Lower-bound & 1117.173 & 1.000 & 1117.173 & 57.068 & .000 & .280 \\
\hline \multirow{5}{*}{$\begin{array}{l}\text { period } * \\
\text { TASK_difficult_easy }\end{array}$} & Sphericity & 14.631 & 1 & 14.631 & .747 & .389 & .005 \\
\hline & Assumed & & & & & & \\
\hline & $\begin{array}{l}\text { Greenhouse- } \\
\text { Geisser }\end{array}$ & 14.631 & 1.000 & 14.631 & .747 & .389 & .005 \\
\hline & Huynh-Feldt & 14.631 & 1.000 & 14.631 & .747 & .389 & .005 \\
\hline & Lower-bound & 14.631 & 1.000 & 14.631 & .747 & .389 & .005 \\
\hline \multirow[t]{5}{*}{ Error(time) } & Sphericity & 2877.717 & 147 & 19.576 & & & \\
\hline & Assumed & & & & & & \\
\hline & $\begin{array}{l}\text { Greenhouse- } \\
\text { Geisser }\end{array}$ & 2877.717 & 147.000 & 19.576 & & & \\
\hline & Huynh-Feldt & 2877.717 & 147.000 & 19.576 & & & \\
\hline & Lower-bound & 2877.717 & 147.000 & 19.576 & & & \\
\hline
\end{tabular}

14.

\section{Estimates}

Measure: HR

\begin{tabular}{lc|r|r|r} 
& & & \multicolumn{2}{|c}{$95 \%$ Confidence Interval } \\
Time & Mean & \multicolumn{1}{c|}{ Std. Error } & Lower Bound & Upper Bound \\
\hline 1 & 77.428 & .886 & 75.676 & 79.180 \\
\hline 2 & 81.301 & .912 & 79.499 & 83.102 \\
\hline
\end{tabular}




\section{SDNN}

\section{Tests of Within-Subjects Effects}

Measure: SDNN

\begin{tabular}{|c|c|c|c|c|c|c|c|}
\hline Source & & $\begin{array}{c}\text { Type III Sum } \\
\text { of Squares }\end{array}$ & df & Mean Square & $\mathrm{F}$ & Sig. & $\begin{array}{c}\text { Partial Eta } \\
\text { Squared } \\
\end{array}$ \\
\hline \multirow[t]{4}{*}{ period } & Sphericity Assumed & 766.708 & 1 & 766.708 & 2.457 & .119 & .016 \\
\hline & Greenhouse-Geisser & 766.708 & 1.000 & 766.708 & 2.457 & .119 & .016 \\
\hline & Huynh-Feldt & 766.708 & 1.000 & 766.708 & 2.457 & .119 & .016 \\
\hline & Lower-bound & 766.708 & 1.000 & 766.708 & 2.457 & .119 & .016 \\
\hline period $*$ & Sphericity Assumed & 1188.716 & 1 & 1188.716 & 3.810 & .053 & .025 \\
\hline \multirow[t]{3}{*}{ TASK_difficult_easy } & Greenhouse-Geisser & 1188.716 & 1.000 & 1188.716 & 3.810 & .053 & .025 \\
\hline & Huynh-Feldt & 1188.716 & 1.000 & 1188.716 & 3.810 & .053 & .025 \\
\hline & Lower-bound & 1188.716 & 1.000 & 1188.716 & 3.810 & .053 & .025 \\
\hline \multirow[t]{4}{*}{ Error(time) } & Sphericity Assumed & 45867.503 & 147 & 312.024 & & & \\
\hline & Greenhouse-Geisser & 45867.503 & 147.000 & 312.024 & & & \\
\hline & Huynh-Feldt & 45867.503 & 147.000 & 312.024 & & & \\
\hline & Lower-bound & 45867.503 & 147.000 & 312.024 & & & \\
\hline
\end{tabular}




\section{HF-HRV}

\section{Tests of Within-Subjects Effects}

Measure: $\mathrm{HF}$

\begin{tabular}{|c|c|c|c|c|c|c|c|}
\hline Source & & $\begin{array}{c}\text { Type III Sum } \\
\text { of Squares }\end{array}$ & $\mathrm{df}$ & $\begin{array}{l}\text { Mean } \\
\text { Square } \\
\end{array}$ & $\mathrm{F}$ & Sig. & $\begin{array}{c}\text { Partial Eta } \\
\text { Squared } \\
\end{array}$ \\
\hline \multirow[t]{5}{*}{ period } & Sphericity & .708 & 1 & .708 & 8.488 & .004 & .055 \\
\hline & Assumed & & & & & & \\
\hline & $\begin{array}{l}\text { Greenhouse- } \\
\text { Geisser }\end{array}$ & .708 & 1.000 & .708 & 8.488 & .004 & .055 \\
\hline & Huynh-Feldt & .708 & 1.000 & .708 & 8.488 & .004 & .055 \\
\hline & Lower-bound & .708 & 1.000 & .708 & 8.488 & .004 & .055 \\
\hline \multirow{5}{*}{$\begin{array}{l}\text { period * } \\
\text { TASK_difficult_easy }\end{array}$} & Sphericity & .042 & 1 & .042 & .501 & .480 & .003 \\
\hline & Assumed & & & & & & \\
\hline & $\begin{array}{l}\text { Greenhouse- } \\
\text { Geisser }\end{array}$ & .042 & 1.000 & .042 & .501 & .480 & .003 \\
\hline & Huynh-Feldt & .042 & 1.000 & .042 & .501 & .480 & .003 \\
\hline & Lower-bound & .042 & 1.000 & .042 & .501 & .480 & .003 \\
\hline \multirow[t]{5}{*}{ Error(time) } & Sphericity & 12.268 & 147 & .083 & & & \\
\hline & Assumed & & & & & & \\
\hline & $\begin{array}{l}\text { Greenhouse- } \\
\text { Geisser }\end{array}$ & 12.268 & 147.000 & .083 & & & \\
\hline & Huynh-Feldt & 12.268 & 147.000 & .083 & & & \\
\hline & Lower-bound & 12.268 & 147.000 & .083 & & & \\
\hline
\end{tabular}

17.

\section{Estimates}

Measure: HF

\begin{tabular}{ll|r|r|r} 
& & & \multicolumn{2}{|c}{$95 \%$ Confidence Interval } \\
time & Mean & Std. Error & \multicolumn{1}{c}{ Lower Bound } & \multicolumn{1}{c}{ Upper Bound } \\
\hline 1 & 2370.357 & 910.486 & 571.025 & 4169.689 \\
\hline 2 & 1334.617 & 223.182 & 893.558 & 1775.676 \\
\hline
\end{tabular}




\section{LF-HRV}

\section{Tests of Within-Subjects Effects}

Measure: LF

\begin{tabular}{|c|c|c|c|c|c|c|c|}
\hline Source & & $\begin{array}{c}\text { Type III Sum } \\
\text { of Squares }\end{array}$ & $\mathrm{df}$ & Mean Square & $\mathrm{F}$ & Sig. & $\begin{array}{c}\text { Partial Eta } \\
\text { Squared } \\
\end{array}$ \\
\hline \multirow[t]{4}{*}{ period } & Sphericity Assumed & .221 & 1 & .221 & 4.989 & .027 & .033 \\
\hline & Greenhouse-Geisser & .221 & 1.000 & .221 & 4.989 & .027 & .033 \\
\hline & Huynh-Feldt & .221 & 1.000 & .221 & 4.989 & .027 & .033 \\
\hline & Lower-bound & .221 & 1.000 & .221 & 4.989 & .027 & .033 \\
\hline period $*$ & Sphericity Assumed & .228 & 1 & .228 & 5.158 & .025 & .034 \\
\hline \multirow[t]{3}{*}{ TASK_difficult_easy } & Greenhouse-Geisser & .228 & 1.000 & .228 & 5.158 & .025 & .034 \\
\hline & Huynh-Feldt & .228 & 1.000 & .228 & 5.158 & .025 & .034 \\
\hline & Lower-bound & .228 & 1.000 & .228 & 5.158 & .025 & .034 \\
\hline \multirow[t]{4}{*}{ Error(time) } & Sphericity Assumed & 6.498 & 147 & .044 & & & \\
\hline & Greenhouse-Geisser & 6.498 & 147.000 & .044 & & & \\
\hline & Huynh-Feldt & 6.498 & 147.000 & .044 & & & \\
\hline & Lower-bound & 6.498 & 147.000 & .044 & & & \\
\hline
\end{tabular}

19.

\section{TASK_difficult_easy $*$ time}

Measure: LF

\begin{tabular}{lll|r|r|r} 
& & & & \multicolumn{2}{|c}{$95 \%$ Confidence Interval } \\
TASK_difficult_easy & time & \multicolumn{1}{c}{ Mean } & Std. Error & Lower Bound & \multicolumn{1}{c}{ Upper Bound } \\
\hline 1.00 & 1 & 1379.787 & 134.187 & 1114.602 & 1644.971 \\
\hline 2 & 998.693 & 132.049 & 737.733 & 1259.654 \\
\hline 2.00 & 1 & 1303.108 & 135.090 & 1036.138 & 1570.078 \\
\hline & 2 & 1401.122 & 132.939 & 1138.404 & 1663.839 \\
\hline
\end{tabular}




\section{Group X Period Mixed factors ANOVAs for task period}

20. SBP

\section{Tests of Within-Subjects Effects}

Measure: task

\begin{tabular}{|c|c|c|c|c|c|c|c|}
\hline Source & & $\begin{array}{c}\text { Type III Sum } \\
\text { of Squares } \\
\end{array}$ & df & Mean Square & $\mathrm{F}$ & Sig. & $\begin{array}{c}\text { Partial Eta } \\
\text { Squared } \\
\end{array}$ \\
\hline \multirow[t]{4}{*}{ SBP } & Sphericity Assumed & 1924.041 & 2 & 962.020 & 41.848 & .000 & .218 \\
\hline & Greenhouse-Geisser & 1924.041 & 1.939 & 992.209 & 41.848 & .000 & .218 \\
\hline & Huynh-Feldt & 1924.041 & 1.977 & 973.099 & 41.848 & .000 & .218 \\
\hline & Lower-bound & 1924.041 & 1.000 & 1924.041 & 41.848 & .000 & .218 \\
\hline $\mathrm{SBP} *$ & Sphericity Assumed & 54.378 & 2 & 27.189 & 1.183 & .308 & .008 \\
\hline \multirow[t]{3}{*}{ TASK_difficult_easy } & Greenhouse-Geisser & 54.378 & 1.939 & 28.042 & 1.183 & .307 & .008 \\
\hline & Huynh-Feldt & 54.378 & 1.977 & 27.502 & 1.183 & .308 & .008 \\
\hline & Lower-bound & 54.378 & 1.000 & 54.378 & 1.183 & .279 & .008 \\
\hline \multirow[t]{4}{*}{ Error(SBP) } & Sphericity Assumed & 6896.581 & 300 & 22.989 & & & \\
\hline & Greenhouse-Geisser & 6896.581 & 290.872 & 23.710 & & & \\
\hline & Huynh-Feldt & 6896.581 & 296.585 & 23.253 & & & \\
\hline & Lower-bound & 6896.581 & 150.000 & 45.977 & & & \\
\hline
\end{tabular}

21.

Pairwise Comparisons

Measure: task

\begin{tabular}{|c|c|c|c|c|c|c|}
\hline \multirow[b]{2}{*}{ (I) SBP } & \multirow[b]{2}{*}{ (J) SBP } & \multirow{2}{*}{$\begin{array}{c}\text { Mean Difference } \\
(\mathrm{I}-\mathrm{J}) \\
\end{array}$} & \multirow[b]{2}{*}{ Std. Error } & \multirow[b]{2}{*}{ Sig. ${ }^{b}$} & \multicolumn{2}{|c|}{$\begin{array}{l}\text { 95\% Confidence Interval for } \\
\text { Difference }\end{array}$} \\
\hline & & & & & Lower Bound & Upper Bound \\
\hline \multirow[t]{2}{*}{1} & $\underline{2}$ & $2.171^{*}$ & .556 & .000 & .825 & 3.517 \\
\hline & 3 & $5.016^{*}$ & .588 & .000 & 3.594 & 6.439 \\
\hline \multirow[t]{2}{*}{2} & 1 & $-2.171^{*}$ & .556 & .000 & -3.517 & -.825 \\
\hline & 3 & $2.845^{*}$ & .503 & .000 & 1.627 & 4.064 \\
\hline \multirow[t]{2}{*}{3} & 1 & $-5.016^{*}$ & .588 & .000 & -6.439 & -3.594 \\
\hline & 2 & $-2.845^{*}$ & .503 & .000 & -4.064 & -1.627 \\
\hline
\end{tabular}

Based on estimated marginal means 
22.

\section{Estimates}

Measure: task

\begin{tabular}{ll|r|r|r} 
& & & \multicolumn{2}{|c}{$95 \%$ Confidence Interval } \\
SBP & Mean & Std. Error & \multicolumn{1}{c}{ Lower Bound } & Upper Bound \\
\hline 1 & 120.832 & 1.042 & 118.773 & 122.892 \\
\hline 2 & 118.661 & 1.068 & 116.551 & 120.771 \\
\hline 3 & 115.816 & .935 & 113.968 & 117.664 \\
\hline
\end{tabular}

\section{DBP}

\section{Tests of Within-Subjects Effects}

Measure: easy_hardtask

\begin{tabular}{|c|c|c|c|c|c|c|c|}
\hline Source & & $\begin{array}{c}\text { Type III Sum } \\
\text { of Squares }\end{array}$ & $\mathrm{df}$ & Mean Square & $\mathrm{F}$ & Sig. & $\begin{array}{c}\text { Partial Eta } \\
\text { Squared } \\
\end{array}$ \\
\hline \multirow[t]{4}{*}{ period } & Sphericity Assumed & 881.478 & 2 & 440.739 & 12.013 & .000 & .074 \\
\hline & Greenhouse-Geisser & 881.478 & 1.808 & 487.663 & 12.013 & .000 & .074 \\
\hline & Huynh-Feldt & 881.478 & 1.841 & 478.933 & 12.013 & .000 & .074 \\
\hline & Lower-bound & 881.478 & 1.000 & 881.478 & 12.013 & .001 & .074 \\
\hline period $*$ & Sphericity Assumed & 66.373 & 2 & 33.186 & .905 & .406 & .006 \\
\hline \multirow[t]{3}{*}{ TASK_difficult_easy } & Greenhouse-Geisser & 66.373 & 1.808 & 36.720 & .905 & .397 & .006 \\
\hline & Huynh-Feldt & 66.373 & 1.841 & 36.062 & .905 & .399 & .006 \\
\hline & Lower-bound & 66.373 & 1.000 & 66.373 & .905 & .343 & .006 \\
\hline \multirow[t]{4}{*}{ Error(period) } & Sphericity Assumed & 11006.149 & 300 & 36.687 & & & \\
\hline & Greenhouse-Geisser & 11006.149 & 271.133 & 40.593 & & & \\
\hline & Huynh-Feldt & 11006.149 & 276.075 & 39.866 & & & \\
\hline & Lower-bound & 11006.149 & 150.000 & 73.374 & & & \\
\hline
\end{tabular}


24.

\section{Pairwise Comparisons}

Measure: easy_hardtask

\begin{tabular}{|c|c|c|c|c|c|c|}
\hline \multirow[b]{2}{*}{ (I) period } & \multirow[b]{2}{*}{ (J) period } & \multirow{2}{*}{$\begin{array}{c}\text { Mean Difference } \\
(\mathrm{I}-\mathrm{J}) \\
\end{array}$} & \multirow[b]{2}{*}{ Std. Error } & \multirow[b]{2}{*}{ Sig. ${ }^{b}$} & \multicolumn{2}{|c|}{$\begin{array}{c}\text { 95\% Confidence Interval for } \\
\text { Difference }^{\mathrm{b}}\end{array}$} \\
\hline & & & & & Lower Bound & Upper Bound \\
\hline \multirow[t]{2}{*}{1} & $\underline{2}$ & $2.842^{*}$ & .771 & .001 & .976 & 4.709 \\
\hline & 3 & $3.046^{*}$ & .723 & .000 & 1.295 & 4.797 \\
\hline \multirow[t]{2}{*}{2} & $\underline{1}$ & $-2.842^{*}$ & .771 & .001 & -4.709 & -.976 \\
\hline & 3 & .204 & .575 & 1.000 & -1.188 & 1.596 \\
\hline \multirow[t]{2}{*}{3} & 1 & $-3.046^{*}$ & .723 & .000 & -4.797 & -1.295 \\
\hline & 2 & -.204 & .575 & 1.000 & -1.596 & 1.188 \\
\hline
\end{tabular}

Based on estimated marginal means

*. The mean difference is significant at the .05 level.

b. Adjustment for multiple comparisons: Bonferroni.

25.

\section{Estimates}

Measure: easy_hardtask

\begin{tabular}{lc|r|r|r} 
& & \multicolumn{3}{c}{$95 \%$ Confidence Interval } \\
period & Mean & Std. Error & Lower Bound & Upper Bound \\
\hline 1 & 73.086 & .804 & 71.496 & 74.675 \\
\hline 2 & 70.243 & .877 & 68.510 & 71.977 \\
\hline 3 & 70.039 & .865 & 68.331 & 71.748 \\
\hline
\end{tabular}




\section{MAP}

\section{Tests of Within-Subjects Effects}

Measure: easy_hardtask

\begin{tabular}{|c|c|c|c|c|c|c|c|}
\hline Source & & $\begin{array}{l}\text { Type III Sum } \\
\text { of Squares }\end{array}$ & df & Mean Square & $\mathrm{F}$ & Sig. & $\begin{array}{c}\text { Partial Eta } \\
\text { Squared } \\
\end{array}$ \\
\hline \multirow[t]{4}{*}{ period } & Sphericity Assumed & 1101.657 & 2 & 550.828 & 27.500 & .000 & .155 \\
\hline & Greenhouse-Geisser & 1101.657 & 1.783 & 617.724 & 27.500 & .000 & .155 \\
\hline & Huynh-Feldt & 1101.657 & 1.815 & 606.825 & 27.500 & .000 & .155 \\
\hline & Lower-bound & 1101.657 & 1.000 & 1101.657 & 27.500 & .000 & .155 \\
\hline \multirow{4}{*}{$\begin{array}{l}\text { period * } \\
\text { TASK_difficult_easy }\end{array}$} & Sphericity Assumed & 61.041 & 2 & 30.521 & 1.524 & .220 & .010 \\
\hline & Greenhouse-Geisser & 61.041 & 1.783 & 34.227 & 1.524 & .221 & .010 \\
\hline & Huynh-Feldt & 61.041 & 1.815 & 33.623 & 1.524 & .221 & .010 \\
\hline & Lower-bound & 61.041 & 1.000 & 61.041 & 1.524 & .219 & .010 \\
\hline \multirow[t]{4}{*}{ Error(period) } & Sphericity Assumed & 6008.969 & 300 & 20.030 & & & \\
\hline & Greenhouse-Geisser & 6008.969 & 267.512 & 22.462 & & & \\
\hline & Huynh-Feldt & 6008.969 & 272.316 & 22.066 & & & \\
\hline & Lower-bound & 6008.969 & 150.000 & 40.060 & & & \\
\hline
\end{tabular}


27.

\section{Pairwise Comparisons}

Measure: easy_hardtask

\begin{tabular}{|c|c|c|c|c|c|c|}
\hline \multirow[b]{2}{*}{ (I) period } & \multirow[b]{2}{*}{ (J) period } & \multirow{2}{*}{$\begin{array}{c}\text { Mean Difference } \\
(\mathrm{I}-\mathrm{J}) \\
\end{array}$} & \multirow[b]{2}{*}{ Std. Error } & \multirow[b]{2}{*}{ Sig. ${ }^{b}$} & \multicolumn{2}{|c|}{$\begin{array}{c}\text { 95\% Confidence Interval for } \\
\text { Difference }^{\mathrm{b}}\end{array}$} \\
\hline & & & & & Lower Bound & Upper Bound \\
\hline \multirow[t]{2}{*}{1} & $\underline{2}$ & $2.618^{*}$ & .572 & .000 & 1.235 & 4.002 \\
\hline & 3 & $3.703^{*}$ & .538 & .000 & 2.400 & 5.006 \\
\hline \multirow[t]{2}{*}{2} & 1 & $-2.618^{*}$ & .572 & .000 & -4.002 & -1.235 \\
\hline & 3 & $1.084^{*}$ & .417 & .031 & .074 & 2.095 \\
\hline \multirow[t]{2}{*}{3} & 1 & $-3.703^{*}$ & .538 & .000 & -5.006 & -2.400 \\
\hline & 2 & $-1.084^{*}$ & .417 & .031 & -2.095 & -.074 \\
\hline
\end{tabular}

28. HR

Tests of Within-Subjects Effects

Measure: easy_hardtask

\begin{tabular}{|c|c|c|c|c|c|c|c|}
\hline Source & & $\begin{array}{c}\text { Type III Sum } \\
\text { of Squares }\end{array}$ & df & Mean Square & $\mathrm{F}$ & Sig. & $\begin{array}{c}\text { Partial Eta } \\
\text { Squared }\end{array}$ \\
\hline \multirow[t]{4}{*}{ period } & Sphericity Assumed & 574.799 & 2 & 287.400 & 19.511 & .000 & .117 \\
\hline & Greenhouse-Geisser & 574.799 & 1.783 & 322.320 & 19.511 & .000 & .117 \\
\hline & Huynh-Feldt & 574.799 & 1.816 & 316.519 & 19.511 & .000 & .117 \\
\hline & Lower-bound & 574.799 & 1.000 & 574.799 & 19.511 & .000 & .117 \\
\hline period * & Sphericity Assumed & 129.993 & 2 & 64.997 & 4.413 & .013 & .029 \\
\hline \multirow[t]{3}{*}{ TASK_difficult_easy } & Greenhouse-Geisser & 129.993 & 1.783 & 72.894 & 4.413 & .016 & .029 \\
\hline & Huynh-Feldt & 129.993 & 1.816 & 71.582 & 4.413 & .016 & .029 \\
\hline & Lower-bound & 129.993 & 1.000 & 129.993 & 4.413 & .037 & .029 \\
\hline \multirow[t]{4}{*}{ Error(period) } & Sphericity Assumed & 4330.619 & 294 & 14.730 & & & \\
\hline & Greenhouse-Geisser & 4330.619 & 262.148 & 16.520 & & & \\
\hline & Huynh-Feldt & 4330.619 & 266.953 & 16.222 & & & \\
\hline & Lower-bound & 4330.619 & 147.000 & 29.460 & & & \\
\hline
\end{tabular}


29.

\section{TASK_difficult_easy * period}

Measure: easy_hardtask

\begin{tabular}{llr|r|r|r} 
& & & & \multicolumn{2}{|c}{$95 \%$ Confidence Interval } \\
TASK_difficult_easy & period & \multicolumn{1}{l|}{ Mean } & Std. Error & Lower Bound & Upper Bound \\
\hline 1.00 & 1 & 82.411 & 1.488 & 79.471 & 85.350 \\
\hline 2 & 81.439 & 1.332 & 78.805 & 84.072 \\
\hline 2.00 & 3 & 80.488 & 1.231 & 78.055 & 82.921 \\
\hline & 1 & 83.401 & 1.498 & 80.442 & 86.361 \\
\hline & 2 & 79.793 & 1.341 & 77.142 & 82.444 \\
\hline
\end{tabular}




\section{Consideration of covariates}

30.

\begin{tabular}{|c|c|c|c|c|c|c|c|c|}
\hline & & & & rrelations & & & & \\
\hline & & & LOTR_t & STAI_tot & Negative_e & digitspan_sc & SysRest_A & SysStress_A \\
\hline & & BMI & ot & al & motionality & ore & VER & VER \\
\hline BMI & Pearson & 1 & .039 & -.001 & -.013 & -.067 & $.412^{* *}$ & $.350^{* *}$ \\
\hline & Correlation & & & & & & & \\
\hline & Sig. (2-tailed) & & .631 & .992 & .875 & .414 & .000 & .000 \\
\hline & $\mathrm{N}$ & 151 & 151 & 151 & 151 & 151 & 151 & 151 \\
\hline LOTR_tot & Pearson & .039 & 1 & $-.777^{* *}$ & $-.660^{* *}$ & .125 & .036 & .031 \\
\hline & Correlation & & & & & & & \\
\hline & Sig. (2-tailed) & .631 & & .000 & .000 & .124 & .657 & .708 \\
\hline & $\mathrm{N}$ & 151 & 152 & 152 & 152 & 152 & 152 & 152 \\
\hline STAI_total & Pearson & -.001 & $-.777^{* *}$ & 1 & $.839^{* *}$ & -.100 & .041 & .025 \\
\hline & Correlation & & & & & & & \\
\hline & Sig. (2-tailed) & .992 & .000 & & .000 & .221 & .613 & .761 \\
\hline & $\mathrm{N}$ & 151 & 152 & 152 & 152 & 152 & 152 & 152 \\
\hline Negative_emotion & Pearson & -.013 & $-.660^{* *}$ & $.839^{* *}$ & 1 & .019 & -.003 & -.022 \\
\hline ality & Correlation & & & & & & & \\
\hline & Sig. (2-tailed) & .875 & .000 & .000 & & .813 & .969 & .790 \\
\hline & $\mathrm{N}$ & 151 & 152 & 152 & 152 & 152 & 152 & 152 \\
\hline digitspan_score & Pearson & -.067 & .125 & -.100 & .019 & 1 & -.003 & .038 \\
\hline & Correlation & & & & & & & \\
\hline & Sig. (2-tailed) & .414 & .124 & .221 & .813 & & .971 & .645 \\
\hline & $\mathrm{N}$ & 151 & 152 & 152 & 152 & 152 & 152 & 152 \\
\hline SysRest_AVER & Pearson & $.412^{* *}$ & .036 & .041 & -.003 & -.003 & 1 & $.811^{* *}$ \\
\hline & Correlation & & & & & & & \\
\hline & Sig. (2-tailed) & .000 & .657 & .613 & .969 & .971 & & .000 \\
\hline & $\mathrm{N}$ & 151 & 152 & 152 & 152 & 152 & 152 & 152 \\
\hline SysStress_AVER & Pearson & $.350^{* *}$ & .031 & .025 & -.022 & .038 & $.811^{* *}$ & 1 \\
\hline & Correlation & & & & & & & \\
\hline & Sig. (2-tailed) & .000 & .708 & .761 & .790 & .645 & .000 & \\
\hline & $\mathrm{N}$ & 151 & 152 & 152 & 152 & 152 & 152 & 152 \\
\hline
\end{tabular}

**. Correlation is significant at the 0.01 level (2-tailed). 
31.

\begin{tabular}{|c|c|c|c|c|c|c|c|c|}
\hline & & & Cor & rrelations & & & & \\
\hline & & BMI & $\begin{array}{c}\text { LOTR_t } \\
\text { ot }\end{array}$ & $\begin{array}{c}\text { STAI_tot } \\
\text { al }\end{array}$ & $\begin{array}{l}\text { Negative_e } \\
\text { motionality }\end{array}$ & $\begin{array}{c}\text { digitspan_sc } \\
\text { ore }\end{array}$ & $\begin{array}{c}\text { DiaRest_A } \\
\text { VER }\end{array}$ & $\begin{array}{c}\text { DiaStress_A } \\
\text { VER }\end{array}$ \\
\hline BMI & Pearson & 1 & .039 & -.001 & -.013 & -.067 & $.261^{* *}$ & $.253^{* *}$ \\
\hline & Correlation & & & & & & & \\
\hline & Sig. (2-tailed) & & .631 & .992 & .875 & .414 & .001 & .002 \\
\hline & $\mathrm{N}$ & 151 & 151 & 151 & 151 & 151 & 151 & 151 \\
\hline LOTR_tot & Pearson & .039 & 1 & $-.777^{* *}$ & $-.660^{* *}$ & .125 & .006 & .089 \\
\hline & Correlation & & & & & & & \\
\hline & Sig. (2-tailed) & .631 & & .000 & .000 & .124 & .939 & .274 \\
\hline & $\mathrm{N}$ & 151 & 152 & 152 & 152 & 152 & 152 & 152 \\
\hline STAI_total & Pearson & -.001 & $-.777^{* *}$ & 1 & $.839^{* *}$ & -.100 & .027 & .015 \\
\hline & Correlation & & & & & & & \\
\hline & Sig. (2-tailed) & .992 & .000 & & .000 & .221 & .737 & .856 \\
\hline & $\mathrm{N}$ & 151 & 152 & 152 & 152 & 152 & 152 & 152 \\
\hline Negative_emotion & Pearson & -.013 & $-.660^{* *}$ & $.839^{* *}$ & 1 & .019 & -.069 & -.078 \\
\hline ality & Correlation & & & & & & & \\
\hline & Sig. (2-tailed) & .875 & .000 & .000 & & .813 & .397 & .339 \\
\hline & $\mathrm{N}$ & 151 & 152 & 152 & 152 & 152 & 152 & 152 \\
\hline digitspan_score & Pearson & -.067 & .125 & -.100 & .019 & 1 & .092 & .113 \\
\hline & Correlation & & & & & & & \\
\hline & Sig. (2-tailed) & .414 & .124 & .221 & .813 & & .258 & .165 \\
\hline & $\mathrm{N}$ & 151 & 152 & 152 & 152 & 152 & 152 & 152 \\
\hline DiaRest_AVER & Pearson & $.261^{* *}$ & .006 & .027 & -.069 & .092 & 1 & $.770^{* * *}$ \\
\hline & Correlation & & & & & & & \\
\hline & Sig. (2-tailed) & .001 & .939 & .737 & .397 & .258 & & .000 \\
\hline & $\mathrm{N}$ & 151 & 152 & 152 & 152 & 152 & 152 & 152 \\
\hline DiaStress_AVER & Pearson & $.253^{* *}$ & .089 & .015 & -.078 & .113 & $.770^{* *}$ & 1 \\
\hline & Correlation & & & & & & & \\
\hline & Sig. (2-tailed) & .002 & .274 & .856 & .339 & .165 & .000 & \\
\hline & $\mathrm{N}$ & 151 & 152 & 152 & 152 & 152 & 152 & 152 \\
\hline
\end{tabular}

**. Correlation is significant at the 0.01 level (2-tailed). 
32.

\begin{tabular}{|c|c|c|c|c|c|c|c|c|}
\hline & & & & rrelations & & & & \\
\hline & & BMI & $\begin{array}{c}\text { LOTR_t } \\
\text { ot }\end{array}$ & $\begin{array}{c}\text { STAI_to } \\
\text { tal }\end{array}$ & $\begin{array}{l}\text { Negative_e } \\
\text { motionality }\end{array}$ & $\begin{array}{c}\text { MAP_Rest_ } \\
\text { AVER }\end{array}$ & $\begin{array}{c}\text { MAPTask_ } \\
\text { AVER }\end{array}$ & $\begin{array}{c}\text { digitspan_sc } \\
\text { ore }\end{array}$ \\
\hline BMI & Pearson & 1 & .039 & -.001 & -.013 & $.382^{* *}$ & $.347^{* *}$ & -.067 \\
\hline & Correlation & & & & & & & \\
\hline & Sig. (2-tailed) & & .631 & .992 & .875 & .000 & .000 & .414 \\
\hline & $\mathrm{N}$ & 151 & 151 & 151 & 151 & 151 & 151 & 151 \\
\hline LOTR_tot & Pearson & .039 & 1 & $-.777^{* *}$ & $-.660^{* *}$ & .021 & .079 & .125 \\
\hline & Correlation & & & & & & & \\
\hline & Sig. (2-tailed) & .631 & & .000 & .000 & .797 & .336 & .124 \\
\hline & $\mathrm{N}$ & 151 & 152 & 152 & 152 & 152 & 152 & 152 \\
\hline STAI_total & Pearson & -.001 & $-.777^{* *}$ & 1 & $.839^{* *}$ & .039 & .022 & -.100 \\
\hline & Correlation & & & & & & & \\
\hline & Sig. (2-tailed) & .992 & .000 & & .000 & .632 & .786 & .221 \\
\hline & $\mathrm{N}$ & 151 & 152 & 152 & 152 & 152 & 152 & 152 \\
\hline Negative_emotion & Pearson & -.013 & $-.660^{* *}$ & $.839^{* *}$ & 1 & -.053 & -.066 & .019 \\
\hline ality & Correlation & & & & & & & \\
\hline & Sig. (2-tailed) & .875 & .000 & .000 & & .517 & .417 & .813 \\
\hline & $\mathrm{N}$ & 151 & 152 & 152 & 152 & 152 & 152 & 152 \\
\hline MAP_Rest_AVE & Pearson & $.382^{* *}$ & .021 & .039 & -.053 & 1 & $.795^{* *}$ & .067 \\
\hline $\mathrm{R}$ & Correlation & & & & & & & \\
\hline & Sig. (2-tailed) & .000 & .797 & .632 & .517 & & .000 & .409 \\
\hline & $\mathrm{N}$ & 151 & 152 & 152 & 152 & 152 & 152 & 152 \\
\hline MAPTask_AVER & Pearson & $.347^{* *}$ & .079 & .022 & -.066 & $.795^{* *}$ & 1 & .099 \\
\hline & Correlation & & & & & & & \\
\hline & Sig. (2-tailed) & .000 & .336 & .786 & .417 & .000 & & .225 \\
\hline & $\mathrm{N}$ & 151 & 152 & 152 & 152 & 152 & 152 & 152 \\
\hline digitspan_score & Pearson & -.067 & .125 & -.100 & .019 & .067 & .099 & 1 \\
\hline & Correlation & & & & & & & \\
\hline & Sig. (2-tailed) & .414 & .124 & .221 & .813 & .409 & .225 & \\
\hline & $\mathrm{N}$ & 151 & 152 & 152 & 152 & 152 & 152 & 152 \\
\hline
\end{tabular}

**. Correlation is significant at the 0.01 level (2-tailed). 
33.

\begin{tabular}{|c|c|c|c|c|c|c|c|}
\hline & & & Correlati & ons & & & \\
\hline & & & digitspan_sco & HRRest_AV & HRTask_AV & & SDNN_Tas \\
\hline & & BMI & re & ER & ER & SDNN_Rest & $\mathrm{k}$ \\
\hline BMI & Pearson & 1 & -.067 & .006 & .023 & .029 & .035 \\
\hline & Correlation & & & & & & \\
\hline & Sig. (2-tailed) & & .414 & .943 & .779 & .726 & .670 \\
\hline & $\mathrm{N}$ & 151 & 151 & 149 & 148 & 149 & 148 \\
\hline digitspan_score & Pearson & -.067 & 1 & .026 & .032 & -.006 & .052 \\
\hline & Correlation & & & & & & \\
\hline & Sig. (2-tailed) & .414 & & .753 & .695 & .944 & .525 \\
\hline & $\mathrm{N}$ & 151 & 152 & 150 & 149 & 150 & 149 \\
\hline HRRest_AVER & Pearson & .006 & .026 & 1 & $.837^{* *}$ & $-.627^{* *}$ & $-.479^{* *}$ \\
\hline & Correlation & & & & & & \\
\hline & Sig. (2-tailed) & .943 & .753 & & .000 & .000 & .000 \\
\hline & $\mathrm{N}$ & 149 & 150 & 150 & 149 & 150 & 149 \\
\hline HRTask_AVE & Pearson & .023 & .032 & $.837^{* *}$ & 1 & $-.566^{* *}$ & $-.552^{* *}$ \\
\hline $\mathrm{R}$ & Correlation & & & & & & \\
\hline & Sig. (2-tailed) & .779 & .695 & .000 & & .000 & .000 \\
\hline & $\mathrm{N}$ & 148 & 149 & 149 & 149 & 149 & 149 \\
\hline SDNN_Rest & Pearson & .029 & -.006 & $-.627^{* *}$ & $-.566^{* *}$ & 1 & $.664^{* *}$ \\
\hline & Correlation & & & & & & \\
\hline & Sig. (2-tailed) & .726 & .944 & .000 & .000 & & .000 \\
\hline & $\mathrm{N}$ & 149 & 150 & 150 & 149 & 150 & 149 \\
\hline SDNN_Task & Pearson & .035 & .052 & $-.479^{* *}$ & $-.552^{* *}$ & $.664^{* *}$ & 1 \\
\hline & Correlation & & & & & & \\
\hline & Sig. (2-tailed) & .670 & .525 & .000 & .000 & .000 & \\
\hline & $\mathrm{N}$ & 148 & 149 & 149 & 149 & 149 & 149 \\
\hline
\end{tabular}

**. Correlation is significant at the 0.01 level (2-tailed). 
34.

\begin{tabular}{|c|c|c|c|c|c|c|c|}
\hline \multicolumn{8}{|c|}{ Correlations } \\
\hline & & BMI & digitspan_score & HF_Rest & HF_Task & LF_Rest & LF_Task \\
\hline \multirow[t]{3}{*}{ BMI } & Pearson Correlation & 1 & -.067 & .082 & -.020 & .065 & .022 \\
\hline & Sig. (2-tailed) & & .414 & .321 & .809 & .431 & .790 \\
\hline & $\mathrm{N}$ & 151 & 151 & 149 & 148 & 149 & 148 \\
\hline \multirow[t]{3}{*}{ digitspan_score } & Pearson Correlation & -.067 & 1 & -.064 & -.036 & -.038 & .025 \\
\hline & Sig. (2-tailed) & .414 & & .436 & .662 & .640 & .762 \\
\hline & $\mathrm{N}$ & 151 & 152 & 150 & 149 & 150 & 149 \\
\hline \multirow[t]{3}{*}{ HF_Rest } & Pearson Correlation & .082 & -.064 & 1 & .053 & $.513^{* *}$ & .079 \\
\hline & Sig. (2-tailed) & .321 & .436 & & .520 & .000 & .338 \\
\hline & $\mathrm{N}$ & 149 & 150 & 150 & 149 & 150 & 149 \\
\hline \multirow[t]{3}{*}{ HF_Task } & Pearson Correlation & -.020 & -.036 & .053 & 1 & $.246^{* *}$ & $.496^{* *}$ \\
\hline & Sig. (2-tailed) & .809 & .662 & .520 & & .002 & .000 \\
\hline & $\mathrm{N}$ & 148 & 149 & 149 & 149 & 149 & 149 \\
\hline \multirow[t]{3}{*}{ LF_Rest } & Pearson Correlation & .065 & -.038 & $.513^{* *}$ & $.246^{* *}$ & 1 & $.458^{* *}$ \\
\hline & Sig. (2-tailed) & .431 & .640 & .000 & .002 & & .000 \\
\hline & $\mathrm{N}$ & 149 & 150 & 150 & 149 & 150 & 149 \\
\hline \multirow[t]{3}{*}{ LF_Task } & Pearson Correlation & .022 & .025 & .079 & $.496^{* *}$ & $.458^{* *}$ & 1 \\
\hline & Sig. (2-tailed) & .790 & .762 & .338 & .000 & .000 & \\
\hline & $\mathrm{N}$ & 148 & 149 & 149 & 149 & 149 & 149 \\
\hline
\end{tabular}

**. Correlation is significant at the 0.01 level (2-tailed). 


\section{Cardiovascular Measures at Rest: Group X Task ANCOVAs for resting levels} 35. SBP

\section{Tests of Between-Subjects Effects}

Dependent Variable: SysRest_AVER

\begin{tabular}{|c|c|c|c|c|c|c|}
\hline Source & $\begin{array}{l}\text { Type III Sum of } \\
\text { Squares } \\
\end{array}$ & df & Mean Square & $\mathrm{F}$ & Sig. & $\begin{array}{c}\text { Partial Eta } \\
\text { Squared } \\
\end{array}$ \\
\hline Corrected Model & $3108.184^{\mathrm{a}}$ & 6 & 518.031 & 5.338 & .000 & .182 \\
\hline Intercept & 19549.968 & 1 & 19549.968 & 201.465 & .000 & .583 \\
\hline BMI & 2887.340 & 1 & 2887.340 & 29.754 & .000 & .171 \\
\hline Negative_emotionality & 74.931 & 1 & 74.931 & .772 & .381 & .005 \\
\hline STAI_total & 151.801 & 1 & 151.801 & 1.564 & .213 & .011 \\
\hline Opt_Pess & 49.130 & 1 & 49.130 & .506 & .478 & .004 \\
\hline TASK_difficult_easy & 24.331 & 1 & 24.331 & .251 & .617 & .002 \\
\hline $\begin{array}{l}\text { Opt_Pess * } \\
\text { TASK_difficult_easy }\end{array}$ & 60.149 & 1 & 60.149 & .620 & .432 & .004 \\
\hline Error & 13973.604 & 144 & 97.039 & & & \\
\hline Total & 1891008.028 & 151 & & & & \\
\hline Corrected Total & 17081.788 & 150 & & & & \\
\hline
\end{tabular}

a. R Squared $=.182($ Adjusted R Squared $=.148)$

\section{DBP}

\section{Tests of Between-Subjects Effects}

Dependent Variable: DiaRest_AVER

\begin{tabular}{|c|c|c|c|c|c|c|}
\hline Source & $\begin{array}{c}\text { Type III Sum of } \\
\text { Squares } \\
\end{array}$ & $\mathrm{df}$ & Mean Square & $\mathrm{F}$ & Sig. & $\begin{array}{c}\text { Partial Eta } \\
\text { Squared } \\
\end{array}$ \\
\hline Corrected Model & $1078.222^{\mathrm{a}}$ & 6 & 179.704 & 2.508 & .024 & .095 \\
\hline Intercept & 8077.712 & 1 & 8077.712 & 112.735 & .000 & .439 \\
\hline BMI & 718.264 & 1 & 718.264 & 10.024 & .002 & .065 \\
\hline Negative_emotionality & 250.637 & 1 & 250.637 & 3.498 & .063 & .024 \\
\hline STAI_total & 131.669 & 1 & 131.669 & 1.838 & .177 & .013 \\
\hline Opt_Pess & 1.646 & 1 & 1.646 & .023 & .880 & .000 \\
\hline TASK_difficult_easy & 6.043 & 1 & 6.043 & .084 & .772 & .001 \\
\hline $\begin{array}{l}\text { Opt_Pess * } \\
\text { TASK_difficult_easy }\end{array}$ & 9.539 & 1 & 9.539 & .133 & .716 & .001 \\
\hline Error & 10317.873 & 144 & 71.652 & & & \\
\hline Total & 655299.806 & 151 & & & & \\
\hline Corrected Total & 11396.095 & 150 & & & & \\
\hline
\end{tabular}




\section{MAP}

\section{Tests of Between-Subjects Effects}

Dependent Variable: MAP_Rest_AVER

\begin{tabular}{|c|c|c|c|c|c|c|}
\hline Source & $\begin{array}{c}\text { Type III Sum of } \\
\text { Squares } \\
\end{array}$ & $\mathrm{df}$ & Mean Square & $\mathrm{F}$ & Sig. & $\begin{array}{c}\text { Partial Eta } \\
\text { Squared }\end{array}$ \\
\hline Corrected Model & $1532.792^{\mathrm{a}}$ & 6 & 255.465 & 4.822 & .000 & .167 \\
\hline Intercept & 11347.461 & 1 & 11347.461 & 214.177 & .000 & .598 \\
\hline BMI & 1280.086 & 1 & 1280.086 & 24.161 & .000 & .144 \\
\hline Negative_emotionality & 180.627 & 1 & 180.627 & 3.409 & .067 & .023 \\
\hline STAI_total & 138.221 & 1 & 138.221 & 2.609 & .108 & .018 \\
\hline Opt_Pess & 2.194 & 1 & 2.194 & .041 & .839 & .000 \\
\hline TASK_difficult_easy & $2.945 \mathrm{E}-5$ & 1 & $2.945 \mathrm{E}-5$ & .000 & .999 & .000 \\
\hline $\begin{array}{l}\text { Opt_Pess * } \\
\text { TASK_difficult_easy }\end{array}$ & .277 & 1 & .277 & .005 & .942 & .000 \\
\hline Error & 7629.371 & 144 & 52.982 & & & \\
\hline Total & 991762.830 & 151 & & & & \\
\hline Corrected Total & 9162.163 & 150 & & & & \\
\hline
\end{tabular}

a. R Squared $=.167$ (Adjusted R Squared $=.133)$ 


\section{HR}

\section{Tests of Between-Subjects Effects}

Dependent Variable: HRRest_AVER

\begin{tabular}{|c|c|c|c|c|c|c|}
\hline Source & $\begin{array}{c}\text { Type III Sum of } \\
\text { Squares } \\
\end{array}$ & $\mathrm{df}$ & Mean Square & $\mathrm{F}$ & Sig. & $\begin{array}{c}\text { Partial Eta } \\
\text { Squared } \\
\end{array}$ \\
\hline Corrected Model & $349.700^{\mathrm{a}}$ & 6 & 58.283 & .491 & .814 & .020 \\
\hline Intercept & 13974.132 & 1 & 13974.132 & 117.674 & .000 & .453 \\
\hline BMI & .077 & 1 & .077 & .001 & .980 & .000 \\
\hline Negative_emotionality & 55.324 & 1 & 55.324 & .466 & .496 & .003 \\
\hline STAI_total & 177.635 & 1 & 177.635 & 1.496 & .223 & .010 \\
\hline Opt_Pess & 186.808 & 1 & 186.808 & 1.573 & .212 & .011 \\
\hline TASK_difficult_easy & 131.401 & 1 & 131.401 & 1.107 & .295 & .008 \\
\hline $\begin{array}{l}\text { Opt_Pess * } \\
\text { TASK_difficult_easy }\end{array}$ & .006 & 1 & .006 & .000 & .994 & .000 \\
\hline Error & 16862.980 & 142 & 118.753 & & & \\
\hline Total & 913153.264 & 149 & & & & \\
\hline Corrected Total & 17212.680 & 148 & & & & \\
\hline
\end{tabular}

a. R Squared $=.020$ (Adjusted R Squared $=-.021$ )

\section{HF-HRV}

\section{Tests of Between-Subjects Effects}

Dependent Variable: HFRest_transformed

\begin{tabular}{|c|c|c|c|c|c|c|}
\hline Source & $\begin{array}{c}\text { Type III Sum of } \\
\text { Squares } \\
\end{array}$ & df & Mean Square & $\mathrm{F}$ & Sig. & $\begin{array}{c}\text { Partial Eta } \\
\text { Squared }\end{array}$ \\
\hline Corrected Model & $1.149^{\mathrm{a}}$ & 6 & .191 & .622 & .713 & .026 \\
\hline Intercept & 26.346 & 1 & 26.346 & 85.552 & .000 & .376 \\
\hline BMI & .010 & 1 & .010 & .033 & .856 & .000 \\
\hline Negative_emotionality & .004 & 1 & .004 & .012 & .913 & .000 \\
\hline STAI_total & .143 & 1 & .143 & .464 & .497 & .003 \\
\hline Opt_Pess & .106 & 1 & .106 & .343 & .559 & .002 \\
\hline TASK_difficult_easy & .798 & 1 & .798 & 2.591 & .110 & .018 \\
\hline $\begin{array}{l}\text { Opt_Pess * } \\
\text { TASK_difficult_easy }\end{array}$ & .045 & 1 & .045 & .147 & .702 & .001 \\
\hline Error & 43.729 & 142 & .308 & & & \\
\hline Total & 1307.259 & 149 & & & & \\
\hline Corrected Total & 44.878 & 148 & & & & \\
\hline
\end{tabular}




\section{SDNN}

\section{Tests of Between-Subjects Effects}

Dependent Variable: SDNN_Rest

\begin{tabular}{|c|c|c|c|c|c|c|}
\hline Source & $\begin{array}{c}\text { Type III Sum of } \\
\text { Squares } \\
\end{array}$ & $\mathrm{df}$ & Mean Square & $\mathrm{F}$ & Sig. & $\begin{array}{c}\text { Partial Eta } \\
\text { Squared } \\
\end{array}$ \\
\hline Corrected Model & $2251.279^{\mathrm{a}}$ & 5 & 450.256 & .567 & .725 & .019 \\
\hline Intercept & 31468.797 & 1 & 31468.797 & 39.641 & .000 & .216 \\
\hline Negative_emotionality & 78.597 & 1 & 78.597 & .099 & .753 & .001 \\
\hline STAI_total & 306.398 & 1 & 306.398 & .386 & .535 & .003 \\
\hline Opt_Pess & 195.213 & 1 & 195.213 & .246 & .621 & .002 \\
\hline TASK_difficult_easy & 412.475 & 1 & 412.475 & .520 & .472 & .004 \\
\hline $\begin{array}{l}\text { Opt_Pess * } \\
\text { TASK_difficult_easy }\end{array}$ & 335.116 & 1 & 335.116 & .422 & .517 & .003 \\
\hline Error & 114314.434 & 144 & 793.850 & & & \\
\hline Total & 761164.750 & 150 & & & & \\
\hline Corrected Total & 116565.713 & 149 & & & & \\
\hline
\end{tabular}

a. R Squared $=.019($ Adjusted R Squared $=-.015)$

\section{LF-HRV}

\section{Tests of Between-Subjects Effects}

Dependent Variable: LFRest_transformed

\begin{tabular}{|c|c|c|c|c|c|c|}
\hline Source & $\begin{array}{c}\text { Type III Sum of } \\
\text { Squares } \\
\end{array}$ & df & Mean Square & $\mathrm{F}$ & Sig. & $\begin{array}{c}\text { Partial Eta } \\
\text { Squared } \\
\end{array}$ \\
\hline Corrected Model & $.304^{\mathrm{a}}$ & 5 & .061 & .478 & .792 & .016 \\
\hline Intercept & 45.792 & 1 & 45.792 & 359.983 & .000 & .714 \\
\hline Negative_emotionality & .000 & 1 & .000 & .004 & .951 & .000 \\
\hline STAI_total & .037 & 1 & .037 & .291 & .591 & .002 \\
\hline Opt_Pess & .003 & 1 & .003 & .022 & .882 & .000 \\
\hline TASK_difficult_easy & .053 & 1 & .053 & .419 & .518 & .003 \\
\hline $\begin{array}{l}\text { Opt_Pess * } \\
\text { TASK_difficult_easy }\end{array}$ & .003 & 1 & .003 & .026 & .873 & .000 \\
\hline Error & 18.318 & 144 & .127 & & & \\
\hline Total & 1359.730 & 150 & & & & \\
\hline Corrected Total & 18.622 & 149 & & & & \\
\hline
\end{tabular}

a. R Squared $=.016$ (Adjusted R Squared $=-.018$ ) 


\section{Primary Analyses: Cardiovascular Reactivity to the Task \\ 42. SBP task}

\section{Tests of Between-Subjects Effects}

Dependent Variable: SysStress_AVER

\begin{tabular}{|c|c|c|c|c|c|c|}
\hline Source & $\begin{array}{l}\text { Type III Sum of } \\
\text { Squares } \\
\end{array}$ & $\mathrm{df}$ & Mean Square & $\mathrm{F}$ & Sig. & $\begin{array}{l}\text { Partial Eta } \\
\text { Squared }\end{array}$ \\
\hline Corrected Model & $13947.042^{\mathrm{a}}$ & 7 & 1992.435 & 41.210 & .000 & .669 \\
\hline Intercept & 566.226 & 1 & 566.226 & 11.711 & .001 & .076 \\
\hline SysRest_AVER & 11124.763 & 1 & 11124.763 & 230.095 & .000 & .617 \\
\hline BMI & 11.312 & 1 & 11.312 & .234 & .629 & .002 \\
\hline STAI_total & 29.304 & 1 & 29.304 & .606 & .438 & .004 \\
\hline Negative_emotionality & 8.693 & 1 & 8.693 & .180 & .672 & .001 \\
\hline Opt_Pess & 174.815 & 1 & 174.815 & 3.616 & .059 & .025 \\
\hline TASK_difficult_easy & 30.125 & 1 & 30.125 & .623 & .431 & .004 \\
\hline $\begin{array}{l}\text { Opt_Pess * } \\
\text { TASK_difficult_easy }\end{array}$ & 15.891 & 1 & 15.891 & .329 & .567 & .002 \\
\hline Error & 6913.848 & 143 & 48.349 & & & \\
\hline Total & 2134097.167 & 151 & & & & \\
\hline Corrected Total & 20860.890 & 150 & & & & \\
\hline
\end{tabular}

a. R Squared $=.669($ Adjusted R Squared $=.652)$ 


\section{DBP task}

\section{Tests of Between-Subjects Effects}

Dependent Variable: DiaStress_AVER

\begin{tabular}{|c|c|c|c|c|c|c|}
\hline Source & $\begin{array}{c}\text { Type III Sum of } \\
\text { Squares } \\
\end{array}$ & df & Mean Square & $\mathrm{F}$ & Sig. & $\begin{array}{c}\text { Partial Eta } \\
\text { Squared } \\
\end{array}$ \\
\hline Corrected Model & $7487.447^{\mathrm{a}}$ & 7 & 1069.635 & 31.347 & .000 & .605 \\
\hline Intercept & 265.467 & 1 & 265.467 & 7.780 & .006 & .052 \\
\hline BMI & 36.481 & 1 & 36.481 & 1.069 & .303 & .007 \\
\hline STAI_total & 105.411 & 1 & 105.411 & 3.089 & .081 & .021 \\
\hline Negative_emotionality & 22.902 & 1 & 22.902 & .671 & .414 & .005 \\
\hline DiaRest_AVER & 6234.647 & 1 & 6234.647 & 182.714 & .000 & .561 \\
\hline Opt_Pess & 198.494 & 1 & 198.494 & 5.817 & .017 & .039 \\
\hline TASK_difficult_easy & 23.413 & 1 & 23.413 & .686 & .409 & .005 \\
\hline $\begin{array}{l}\text { Opt_Pess * } \\
\text { TASK_difficult_easy }\end{array}$ & 15.598 & 1 & 15.598 & .457 & .500 & .003 \\
\hline Error & 4879.517 & 143 & 34.122 & & & \\
\hline Total & 773226.667 & 151 & & & & \\
\hline Corrected Total & 12366.964 & 150 & & & & \\
\hline
\end{tabular}

a. R Squared $=.605$ (Adjusted R Squared $=.586)$

44.

Estimates

Dependent Variable: DiaStress_AVER

95\% Confidence Interval

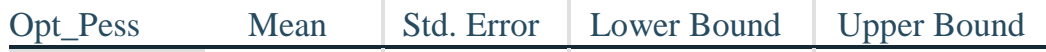

\begin{tabular}{ll|l|l|l}
\hline 1.00 & $72.757^{\mathrm{a}}$ & .875 & 71.027 & 74.488 \\
\hline 2.00 & $69.326^{\mathrm{a}}$ & .836 & 67.674 & 70.978 \\
\hline
\end{tabular}

a. Covariates appearing in the model are evaluated at the following values: BMI $=25.4503$, STAI_total $=44.9404$, Negative_emotionality $=37.3179$, DiaRest_AVER $=65.3013$. 


\section{MAP task}

\section{Tests of Between-Subjects Effects}

Dependent Variable: MAPTask_AVER

\begin{tabular}{|c|c|c|c|c|c|c|}
\hline Source & $\begin{array}{c}\text { Type III Sum of } \\
\text { Squares } \\
\end{array}$ & $\mathrm{df}$ & Mean Square & $\mathrm{F}$ & Sig. & $\begin{array}{c}\text { Partial Eta } \\
\text { Squared } \\
\end{array}$ \\
\hline Corrected Model & $6644.461^{\mathrm{a}}$ & 7 & 949.209 & 34.926 & .000 & .631 \\
\hline Intercept & 310.369 & 1 & 310.369 & 11.420 & .001 & .074 \\
\hline BMI & 30.723 & 1 & 30.723 & 1.130 & .289 & .008 \\
\hline STAI_total & 25.195 & 1 & 25.195 & .927 & .337 & .006 \\
\hline Negative_emotionality & 15.597 & 1 & 15.597 & .574 & .450 & .004 \\
\hline MAP_Rest_AVER & 5108.408 & 1 & 5108.408 & 187.961 & .000 & .568 \\
\hline Opt_Pess & 26.889 & 1 & 26.889 & .989 & .322 & .007 \\
\hline TASK_difficult_easy & 2.510 & 1 & 2.510 & .092 & .762 & .001 \\
\hline $\begin{array}{l}\text { Opt_Pess * } \\
\text { TASK_difficult_easy }\end{array}$ & 17.989 & 1 & 17.989 & .662 & .417 & .005 \\
\hline Error & 3886.451 & 143 & 27.178 & & & \\
\hline Total & 1147059.537 & 151 & & & & \\
\hline Corrected Total & 10530.913 & 150 & & & & \\
\hline
\end{tabular}

a. R Squared $=.631($ Adjusted R Squared $=.613)$ 
46. HR task

\section{Tests of Between-Subjects Effects}

Dependent Variable: HRTask_AVER

\begin{tabular}{|c|c|c|c|c|c|c|}
\hline Source & $\begin{array}{c}\text { Type III Sum of } \\
\text { Squares } \\
\end{array}$ & $\mathrm{df}$ & Mean Square & $\mathrm{F}$ & Sig. & $\begin{array}{c}\text { Partial Eta } \\
\text { Squared } \\
\end{array}$ \\
\hline Corrected Model & $12799.893^{\mathrm{a}}$ & 7 & 1828.556 & 47.885 & .000 & .705 \\
\hline Intercept & 353.095 & 1 & 353.095 & 9.247 & .003 & .062 \\
\hline BMI & 14.438 & 1 & 14.438 & .378 & .540 & .003 \\
\hline STAI_total & 32.926 & 1 & 32.926 & .862 & .355 & .006 \\
\hline Negative_emotionality & 1.836 & 1 & 1.836 & .048 & .827 & .000 \\
\hline HRRest_AVER & 12672.739 & 1 & 12672.739 & 331.865 & .000 & .703 \\
\hline Opt_Pess & 23.962 & 1 & 23.962 & .628 & .430 & .004 \\
\hline TASK_difficult_easy & 27.625 & 1 & 27.625 & .723 & .396 & .005 \\
\hline $\begin{array}{l}\text { Opt_Pess * } \\
\text { TASK_difficult_easy }\end{array}$ & 12.979 & 1 & 12.979 & .340 & .561 & .002 \\
\hline Error & 5346.097 & 140 & 38.186 & & & \\
\hline Total & 997887.993 & 148 & & & & \\
\hline Corrected Total & 18145.990 & 147 & & & & \\
\hline
\end{tabular}

a. R Squared $=.705$ (Adjusted R Squared $=.691)$ 


\section{HF-HRV}

\section{Tests of Between-Subjects Effects}

Dependent Variable: HFTask_transformed

\begin{tabular}{|c|c|c|c|c|c|c|}
\hline Source & $\begin{array}{l}\text { Type III Sum of } \\
\text { Squares } \\
\end{array}$ & $\mathrm{df}$ & Mean Square & $\mathrm{F}$ & Sig. & $\begin{array}{c}\text { Partial Eta } \\
\text { Squared }\end{array}$ \\
\hline Corrected Model & $19.263^{\mathrm{a}}$ & 7 & 2.752 & 21.768 & .000 & .521 \\
\hline Intercept & 1.315 & 1 & 1.315 & 10.399 & .002 & .069 \\
\hline BMI & .075 & 1 & .075 & .591 & .443 & .004 \\
\hline STAI_total & .059 & 1 & .059 & .468 & .495 & .003 \\
\hline Negative_emotionality & .415 & 1 & .415 & 3.283 & .072 & .023 \\
\hline HFRest_transformed & 17.481 & 1 & 17.481 & 138.281 & .000 & .497 \\
\hline Opt_Pess & .001 & 1 & .001 & .005 & .945 & .000 \\
\hline TASK_difficult_easy & .265 & 1 & .265 & 2.095 & .150 & .015 \\
\hline $\begin{array}{l}\text { Opt_Pess * } \\
\text { TASK_difficult_easy }\end{array}$ & .001 & 1 & .001 & .010 & .922 & .000 \\
\hline Error & 17.698 & 140 & .126 & & & \\
\hline Total & 1210.823 & 148 & & & & \\
\hline Corrected Total & 36.962 & 147 & & & & \\
\hline
\end{tabular}

a. R Squared $=.521($ Adjusted R Squared $=.497)$

\section{SDNN}

\section{Tests of Between-Subjects Effects}

Dependent Variable: SDNN_Task

\begin{tabular}{lr|r|r|r|r|r} 
Source & $\begin{array}{c}\text { Type III Sum of } \\
\text { Squares }\end{array}$ & df & Mean Square & F & Sig. & $\begin{array}{c}\text { Partial Eta } \\
\text { Squared }\end{array}$ \\
\hline Corrected Model & $75853.425^{2}$ & 7 & 10836.204 & 18.541 & .000 & .481 \\
\hline Intercept & 400.189 & 1 & 400.189 & .685 & .409 & .005 \\
\hline BMI & 3.512 & 1 & 3.512 & .006 & .938 & .000 \\
\hline STAI_total & 219.852 & 1 & 219.852 & .376 & .541 & .003 \\
\hline Negative_emotionality & 521.283 & 1 & 521.283 & .892 & .347 & .006 \\
\hline SDNN_Rest & 68271.791 & 1 & 68271.791 & 116.816 & .000 & .455 \\
\hline Opt_Pess & 216.274 & 1 & 216.274 & .370 & .544 & .003 \\
\hline TASK_difficult_easy & 2905.690 & 1 & 2905.690 & 4.972 & .027 & .034 \\
\hline Opt_Pess* & 1905.922 & 1 & 1905.922 & 3.261 & .073 & .023 \\
TASK_difficult_easy & & & & & & \\
\hline Error & 81821.618 & 140 & 584.440 & & & \\
\hline Total & 735125.240 & 148 & & & & \\
\hline Corrected Total & 157675.043 & 147 & & & & \\
\hline
\end{tabular}


49.

Estimates

Dependent Variable: SDNN_Task

\begin{tabular}{l|l|l|l|l}
\hline 1.00 & $57.996^{\mathrm{a}}$ & 2.834 & 52.392 & 63.599 \\
\hline 2.00 & $66.983^{\mathrm{a}}$ & 2.827 & 61.394 & 72.572 \\
\hline
\end{tabular}

a. Covariates appearing in the model are evaluated at the following values: $\mathrm{BMI}=$ 25.4595, STAI_total $=44.6892$, Negative_emotionality $=37.0946$, SDNN_Rest $=$ 65.7845

\section{LF-HRV}

\section{Tests of Between-Subjects Effects}

Dependent Variable: LFTask_transformed

\begin{tabular}{|c|c|c|c|c|c|c|}
\hline Source & $\begin{array}{l}\text { Type III Sum of } \\
\text { Squares } \\
\end{array}$ & df & Mean Square & $\mathrm{F}$ & Sig. & $\begin{array}{c}\text { Partial Eta } \\
\text { Squared } \\
\end{array}$ \\
\hline Corrected Model & $8.728^{a}$ & 7 & 1.247 & 17.416 & .000 & .465 \\
\hline Intercept & 1.390 & 1 & 1.390 & 19.422 & .000 & .122 \\
\hline BMI & .029 & 1 & .029 & .404 & .526 & .003 \\
\hline STAI_total & .054 & 1 & .054 & .755 & .386 & .005 \\
\hline Negative_emotionality & .142 & 1 & .142 & 1.983 & .161 & .014 \\
\hline LFRest_transformed & 7.641 & 1 & 7.641 & 106.735 & .000 & .433 \\
\hline Opt_Pess & .078 & 1 & .078 & 1.091 & .298 & .008 \\
\hline TASK_difficult_easy & .585 & 1 & .585 & 8.165 & .005 & .055 \\
\hline $\begin{array}{l}\text { Opt_Pess } * \\
\text { TASK_difficult_easy }\end{array}$ & .091 & 1 & .091 & 1.272 & .261 & .009 \\
\hline Error & 10.023 & 140 & .072 & & & \\
\hline Total & 1293.237 & 148 & & & & \\
\hline Corrected Total & 18.751 & 147 & & & & \\
\hline
\end{tabular}

a. R Squared $=.465$ (Adjusted R Squared $=.439)$

51.

\section{Estimates}

Dependent Variable: LF_Task

\begin{tabular}{lc|r|r|r} 
& & & \multicolumn{2}{|c}{$95 \%$ Confidence Interval } \\
TASK_difficult_easy & \multicolumn{1}{c|}{ Mean } & Std. Error & \multicolumn{1}{c}{ Lower Bound } & \multicolumn{1}{c}{ Upper Bound } \\
\hline 1.00 & $969.945^{\mathrm{a}}$ & 118.068 & 736.518 & 1203.373 \\
\hline 2.00 & $1427.468^{\mathrm{a}}$ & 117.781 & 1194.608 & 1660.328 \\
\hline
\end{tabular}




\section{Comparisons of Reactivity during the first minute of the task}

\section{SBP}

Tests of Between-Subjects Effects

Dependent Variable: SysStress_0min

\begin{tabular}{|c|c|c|c|c|c|c|}
\hline Source & $\begin{array}{c}\text { Type III Sum of } \\
\text { Squares } \\
\end{array}$ & $\mathrm{df}$ & Mean Square & $\mathrm{F}$ & Sig. & $\begin{array}{c}\text { Partial Eta } \\
\text { Squared } \\
\end{array}$ \\
\hline Corrected Model & $13482.590^{\mathrm{a}}$ & 7 & 1926.084 & 25.024 & .000 & .551 \\
\hline Intercept & 959.109 & 1 & 959.109 & 12.461 & .001 & .080 \\
\hline BMI & 47.379 & 1 & 47.379 & .616 & .434 & .004 \\
\hline STAI_total & 62.911 & 1 & 62.911 & .817 & .367 & .006 \\
\hline Negative_emotionality & 13.789 & 1 & 13.789 & .179 & 673 & .001 \\
\hline SysRest_AVER & 10275.767 & 1 & 10275.767 & 133.506 & .000 & .483 \\
\hline Opt_Pess & 276.424 & 1 & 276.424 & 3.591 & .060 & .024 \\
\hline TASK_difficult_easy & .213 & 1 & .213 & .003 & .958 & .000 \\
\hline $\begin{array}{l}\text { Opt_Pess } * \\
\text { TASK_difficult_easy }\end{array}$ & 17.110 & 1 & 17.110 & .222 & .638 & .002 \\
\hline Error & 11006.545 & 143 & 76.969 & & & \\
\hline Total & 2224524.250 & 151 & & & & \\
\hline Corrected Total & 24489.136 & 150 & & & & \\
\hline
\end{tabular}

a. R Squared $=.551($ Adjusted R Squared $=.529)$ 
53. DBP

\section{Tests of Between-Subjects Effects}

Dependent Variable: DiaStress_0min

\begin{tabular}{|c|c|c|c|c|c|c|}
\hline Source & $\begin{array}{c}\text { Type III Sum of } \\
\text { Squares } \\
\end{array}$ & $\mathrm{df}$ & Mean Square & $\mathrm{F}$ & Sig. & $\begin{array}{c}\text { Partial Eta } \\
\text { Squared } \\
\end{array}$ \\
\hline Corrected Model & $6088.586^{\mathrm{a}}$ & 7 & 869.798 & 14.874 & .000 & .421 \\
\hline Intercept & 624.387 & 1 & 624.387 & 10.678 & .001 & .069 \\
\hline BMI & 87.460 & 1 & 87.460 & 1.496 & .223 & .010 \\
\hline STAI_total & 35.956 & 1 & 35.956 & .615 & .434 & .004 \\
\hline Negative_emotionality & .012 & 1 & .012 & .000 & .989 & .000 \\
\hline DiaRest_AVER & 4775.095 & 1 & 4775.095 & 81.659 & .000 & .363 \\
\hline Opt_Pess & 141.745 & 1 & 141.745 & 2.424 & .122 & .017 \\
\hline TASK_difficult_easy & 93.317 & 1 & 93.317 & 1.596 & .209 & .011 \\
\hline $\begin{array}{l}\text { Opt_Pess * } \\
\text { TASK_difficult_easy }\end{array}$ & 30.990 & 1 & 30.990 & .530 & .468 & .004 \\
\hline Error & 8362.089 & 143 & 58.476 & & & \\
\hline Total & 818108.000 & 151 & & & & \\
\hline Corrected Total & 14450.676 & 150 & & & & \\
\hline
\end{tabular}

a. R Squared $=.421($ Adjusted R Squared $=.393)$ 


\section{MAP}

\section{Tests of Between-Subjects Effects}

Dependent Variable: MAPTask_0

\begin{tabular}{|c|c|c|c|c|c|c|}
\hline Source & $\begin{array}{c}\text { Type III Sum of } \\
\text { Squares } \\
\end{array}$ & $\mathrm{df}$ & Mean Square & $\mathrm{F}$ & Sig. & $\begin{array}{c}\text { Partial Eta } \\
\text { Squared } \\
\end{array}$ \\
\hline Corrected Model & $5581.146^{\mathrm{a}}$ & 7 & 797.307 & 19.207 & .000 & .485 \\
\hline Intercept & 738.622 & 1 & 738.622 & 17.793 & .000 & .111 \\
\hline BMI & 102.180 & 1 & 102.180 & 2.461 & .119 & .017 \\
\hline STAI_total & 2.812 & 1 & 2.812 & .068 & .795 & .000 \\
\hline Negative_emotionality & 1.457 & 1 & 1.457 & .035 & .852 & .000 \\
\hline MAP_Rest_AVER & 3893.542 & 1 & 3893.542 & 93.794 & .000 & .396 \\
\hline Opt_Pess & 7.558 & 1 & 7.558 & .182 & .670 & .001 \\
\hline TASK_difficult_easy & 43.285 & 1 & 43.285 & 1.043 & .309 & .007 \\
\hline $\begin{array}{l}\text { Opt_Pess * } \\
\text { TASK_difficult_easy }\end{array}$ & 21.663 & 1 & 21.663 & .522 & .471 & .004 \\
\hline Error & 5936.142 & 143 & 41.511 & & & \\
\hline Total & 1204119.806 & 151 & & & & \\
\hline Corrected Total & 11517.287 & 150 & & & & \\
\hline
\end{tabular}

a. R Squared $=.485$ (Adjusted R Squared $=.459)$

\section{HR}

\section{Tests of Between-Subjects Effects}

Dependent Variable: HRTask_0

\begin{tabular}{|c|c|c|c|c|c|c|}
\hline Source & $\begin{array}{c}\text { Type III Sum of } \\
\text { Squares } \\
\end{array}$ & $\mathrm{df}$ & Mean Square & $\mathrm{F}$ & Sig. & $\begin{array}{c}\text { Partial Eta } \\
\text { Squared } \\
\end{array}$ \\
\hline Corrected Model & $13940.351^{\mathrm{a}}$ & 6 & 2323.392 & 31.439 & .000 & .571 \\
\hline Intercept & 661.270 & 1 & 661.270 & 8.948 & .003 & .059 \\
\hline STAI_total & 99.533 & 1 & 99.533 & 1.347 & .248 & .009 \\
\hline Negative_emotionality & 4.365 & 1 & 4.365 & .059 & .808 & .000 \\
\hline HRRest_AVER & 13806.696 & 1 & 13806.696 & 186.826 & .000 & .568 \\
\hline Opt_Pess & 107.170 & 1 & 107.170 & 1.450 & .231 & .010 \\
\hline TASK_difficult_easy & 258.865 & 1 & 258.865 & 3.503 & .063 & .024 \\
\hline $\begin{array}{l}\text { Opt_Pess * } \\
\text { TASK_difficult_easy }\end{array}$ & 32.669 & 1 & 32.669 & .442 & .507 & .003 \\
\hline Error & 10494.018 & 142 & 73.902 & & & \\
\hline Total & 1048488.122 & 149 & & & & \\
\hline Corrected Total & 24434.369 & 148 & & & & \\
\hline
\end{tabular}




\section{Comparisons of Reactivity between "true pessimists" and "slight pessimists."}

56. SBP

\section{Tests of Between-Subjects Effects ${ }^{\mathrm{a}}$}

Dependent Variable: SysStress_AVER

\begin{tabular}{|c|c|c|c|c|c|c|}
\hline Source & $\begin{array}{c}\text { Type III Sum of } \\
\text { Squares }\end{array}$ & $\mathrm{df}$ & Mean Square & $\mathrm{F}$ & Sig. & $\begin{array}{c}\text { Partial Eta } \\
\text { Squared } \\
\end{array}$ \\
\hline Corrected Model & $7129.241^{b}$ & 5 & 1425.848 & 26.384 & .000 & .647 \\
\hline Intercept & 325.632 & 1 & 325.632 & 6.026 & .017 & .077 \\
\hline BMI & 17.441 & 1 & 17.441 & .323 & .572 & .004 \\
\hline STAI_total & 11.200 & 1 & 11.200 & .207 & 650 & .003 \\
\hline Negative_emotionality & 127.120 & 1 & 127.120 & 2.352 & .129 & .032 \\
\hline SysRest_AVER & 5468.712 & 1 & 5468.712 & 101.194 & .000 & .584 \\
\hline true_Pessimist & 292.502 & 1 & 292.502 & 5.413 & .023 & .070 \\
\hline Error & 3890.998 & 72 & 54.042 & & & \\
\hline Total & 1111535.944 & 78 & & & & \\
\hline Corrected Total & 11020.239 & 77 & & & & \\
\hline
\end{tabular}

a. Opt_Pess $=2.00$

b. $\mathrm{R}$ Squared $=.647$ (Adjusted R Squared $=.622$ )

57.

\section{Estimates $^{\text {a }}$}

Dependent Variable: SysStress_AVER

\begin{tabular}{ll|r|r|r} 
& & \multicolumn{2}{|c}{$95 \%$ Confidence Interval } \\
true_Pessimist & Mean & Std. Error & Lower Bound & Upper Bound \\
\hline true pessimist (under 12) & $116.101^{\mathrm{b}}$ & 1.421 & 113.268 & 118.935 \\
\hline slight pessimist (13-17) & $120.283^{\mathrm{b}}$ & 1.053 & 118.184 & 122.383 \\
\hline
\end{tabular}

a. Opt_Pess $=2.00$

b. Covariates appearing in the model are evaluated at the following values: $\mathrm{BMI}=$ 25.3462, STAI_total $=53.4615$, Negative_emotionality $=43.5000$, SysRest_AVER $=$ 111.2885 . 


\section{DBP}

\section{Tests of Between-Subjects Effects ${ }^{\mathrm{a}}$}

Dependent Variable: DiaStress_AVER

\begin{tabular}{|c|c|c|c|c|c|c|}
\hline Source & $\begin{array}{c}\text { Type III Sum of } \\
\text { Squares } \\
\end{array}$ & df & Mean Square & $\mathrm{F}$ & Sig. & $\begin{array}{c}\text { Partial Eta } \\
\text { Squared } \\
\end{array}$ \\
\hline Corrected Model & $3798.792^{\mathrm{b}}$ & 5 & 759.758 & 20.637 & .000 & .589 \\
\hline Intercept & 310.138 & 1 & 310.138 & 8.424 & .005 & .105 \\
\hline BMI & 26.997 & 1 & 26.997 & .733 & .395 & .010 \\
\hline STAI_total & 6.443 & 1 & 6.443 & .175 & .677 & .002 \\
\hline Negative_emotionality & 45.714 & 1 & 45.714 & 1.242 & .269 & .017 \\
\hline DiaRest_AVER & 2654.310 & 1 & 2654.310 & 72.099 & .000 & .500 \\
\hline true_Pessimist & 13.296 & 1 & 13.296 & .361 & .550 & .005 \\
\hline Error & 2650.651 & 72 & 36.815 & & & \\
\hline Total & 392251.222 & 78 & & & & \\
\hline Corrected Total & 6449.443 & 77 & & & & \\
\hline
\end{tabular}

a. Opt_Pess $=2.00$

b. R Squared $=.589($ Adjusted R Squared $=.560)$

\section{MAP}

\section{Tests of Between-Subjects Effects ${ }^{\mathrm{a}}$}

Dependent Variable: MAPTask_AVER

Type III Sum of

\begin{tabular}{l|r|r|r|r|r|r} 
Source & \multicolumn{1}{c}{ Squares } & df & Mean Square & \multicolumn{1}{c|}{ F } & \multicolumn{1}{c}{ Sig. } & \multicolumn{1}{c}{ Squared } \\
\hline Corrected Model & $3246.396^{\mathrm{b}}$ & 5 & 649.279 & 23.166 & .000 & .617 \\
\hline Intercept & 310.211 & 1 & 310.211 & 11.068 & .001 & .133 \\
\hline BMI & 28.773 & 1 & 28.773 & 1.027 & .314 & .014 \\
\hline STAI_total & .825 & 1 & .825 & .029 & .864 & .000 \\
\hline Negative_emotionality & 62.785 & 1 & 62.785 & 2.240 & .139 & .030 \\
\hline MAP_Rest_AVER & 2002.917 & 1 & 2002.917 & 71.464 & .000 & .498 \\
\hline true_Pessimist & 67.572 & 1 & 67.572 & 2.411 & .125 & .032 \\
\hline Error & 2017.944 & 72 & 28.027 & & & \\
\hline Total & 588610.759 & 78 & & & & \\
\hline Corrected Total & 5264.339 & 77 & & & & \\
\hline
\end{tabular}

a. Opt_Pess $=2.00$

b. R Squared $=.617($ Adjusted R Squared $=.590)$ 
60. HR

\section{Tests of Between-Subjects Effects ${ }^{\mathrm{a}}$}

Dependent Variable: HRTask_AVER

\begin{tabular}{|c|c|c|c|c|c|c|}
\hline Source & $\begin{array}{c}\text { Type III Sum of } \\
\text { Squares } \\
\end{array}$ & df & Mean Square & $\mathrm{F}$ & Sig. & $\begin{array}{c}\text { Partial Eta } \\
\text { Squared }\end{array}$ \\
\hline Corrected Model & $7047.275^{\mathrm{b}}$ & 5 & 1409.455 & 33.124 & .000 & .706 \\
\hline Intercept & 81.055 & 1 & 81.055 & 1.905 & .172 & .027 \\
\hline BMI & 5.923 & 1 & 5.923 & .139 & .710 & .002 \\
\hline STAI_total & 8.068 & 1 & 8.068 & .190 & .665 & .003 \\
\hline Negative_emotionality & 3.544 & 1 & 3.544 & .083 & .774 & .001 \\
\hline HRRest_AVER & 6319.910 & 1 & 6319.910 & 148.525 & .000 & .683 \\
\hline true_Pessimist & 55.015 & 1 & 55.015 & 1.293 & .259 & .018 \\
\hline Error & 2936.039 & 69 & 42.551 & & & \\
\hline Total & 499453.570 & 75 & & & & \\
\hline Corrected Total & 9983.314 & 74 & & & & \\
\hline
\end{tabular}

a. Opt_Pess $=2.00$

b. R Squared $=.706$ (Adjusted R Squared $=.685$ )

\section{HF-HRV}

\section{Tests of Between-Subjects Effects ${ }^{\mathbf{a}}$}

Dependent Variable: HFTask_transformed

Type III Sum of

\begin{tabular}{l|r|r|r|r|r|r} 
Source & \multicolumn{1}{c}{ Squares } & df & Mean Square & \multicolumn{1}{c|}{ F } & \multicolumn{1}{c}{ Sig. } & \multicolumn{1}{c}{ Squared } \\
\hline Corrected Model & $14.682^{\mathrm{b}}$ & 5 & 2.936 & 32.012 & .000 & .699 \\
\hline Intercept & .130 & 1 & .130 & 1.417 & .238 & .020 \\
\hline BMI & $6.652 \mathrm{E}-8$ & 1 & $6.652 \mathrm{E}-8$ & .000 & .999 & .000 \\
\hline STAI_total & .090 & 1 & .090 & .977 & .326 & .014 \\
\hline Negative_emotionality & .134 & 1 & .134 & 1.459 & .231 & .021 \\
\hline HFRest_transformed & 13.681 & 1 & 13.681 & 149.146 & .000 & .684 \\
\hline true_Pessimist & .313 & 1 & .313 & 3.413 & .069 & .047 \\
\hline Error & 6.329 & 69 & .092 & & & \\
\hline Total & 622.467 & 75 & & & & \\
\hline Corrected Total & 21.012 & 74 & & & & \\
\hline
\end{tabular}

a. Opt_Pess $=2.00$

b. R Squared $=.699$ (Adjusted R Squared $=.677)$ 


\section{SDNN}

Tests of Between-Subjects Effects ${ }^{\mathrm{a}}$

Dependent Variable：SDNN_Task

\begin{tabular}{|c|c|c|c|c|c|c|}
\hline Source & $\begin{array}{c}\text { Type III Sum of } \\
\text { Squares } \\
\end{array}$ & $\mathrm{df}$ & Mean Square & $\mathrm{F}$ & Sig. & $\begin{array}{c}\text { Partial Eta } \\
\text { Squared } \\
\end{array}$ \\
\hline Corrected Model & $48801.619^{\mathrm{b}}$ & 5 & 9760.324 & 9.483 & .000 & .407 \\
\hline Intercept & 271.325 & 1 & 271.325 & .264 & 609 & .004 \\
\hline BMI & 9.680 & 1 & 9.680 & .009 & .923 & .000 \\
\hline STAI_total & 320.169 & 1 & 320.169 & .311 & .579 & .004 \\
\hline Negative_emotionality & 1102.403 & 1 & 1102.403 & 1.071 & .304 & .015 \\
\hline SDNN_Rest & 45150.147 & 1 & 45150.147 & 43.865 & .000 & .389 \\
\hline true_Pessimist & 15.413 & 1 & 15.413 & .015 & .903 & .000 \\
\hline Error & 71020.788 & 69 & 1029.287 & & & \\
\hline Total & 416993.620 & 75 & & & & \\
\hline Corrected Total & 119822.407 & 74 & & & & \\
\hline
\end{tabular}

a. Opt_Pess $=2.00$

b. R Squared $=.407($ Adjusted R Squared $=.364)$

\section{LF-HRV}

Tests of Between-Subjects Effects ${ }^{\mathrm{a}}$

Dependent Variable: LFTask_transformed

\begin{tabular}{|c|c|c|c|c|c|c|}
\hline Source & $\begin{array}{c}\text { Type III Sum of } \\
\text { Squares } \\
\end{array}$ & $\mathrm{df}$ & Mean Square & $\mathrm{F}$ & Sig. & $\begin{array}{c}\text { Partial Eta } \\
\text { Squared } \\
\end{array}$ \\
\hline Corrected Model & $5.739^{b}$ & 5 & 1.148 & 12.170 & .000 & .469 \\
\hline Intercept & .277 & 1 & .277 & 2.941 & .091 & .041 \\
\hline BMI & .000 & 1 & .000 & .005 & .944 & .000 \\
\hline STAI_total & .218 & 1 & .218 & 2.308 & .133 & .032 \\
\hline Negative_emotionality & .364 & 1 & .364 & 3.858 & .054 & .053 \\
\hline LFRest_transformed & 5.217 & 1 & 5.217 & 55.311 & .000 & .445 \\
\hline true_Pessimist & .068 & 1 & .068 & .722 & .398 & .010 \\
\hline Error & 6.508 & 69 & .094 & & & \\
\hline Total & 660.880 & 75 & & & & \\
\hline Corrected Total & 12.247 & 74 & & & & \\
\hline
\end{tabular}
a. Opt_Pess $=2.00$
b. R Squared $=.469($ Adjusted R Squared $=.430)$ 


\section{Primary Analyses: Cardiovascular Recovery from Stress}

64. SBP

\section{Tests of Between-Subjects Effects}

Dependent Variable: SYS_AUC

\begin{tabular}{|c|c|c|c|c|c|c|}
\hline Source & $\begin{array}{c}\text { Type III Sum of } \\
\text { Squares } \\
\end{array}$ & $\mathrm{df}$ & Mean Square & $\mathrm{F}$ & Sig. & $\begin{array}{c}\text { Partial Eta } \\
\text { Squared } \\
\end{array}$ \\
\hline Corrected Model & $39215146.570^{a}$ & 7 & 5602163.796 & 1.390 & .214 & .064 \\
\hline Intercept & 398591.004 & 1 & 398591.004 & .099 & .754 & .001 \\
\hline STAI_total & 2533597.244 & 1 & 2533597.244 & .628 & .429 & .004 \\
\hline Negative_emotionality & 1062499.419 & 1 & 1062499.419 & .264 & .608 & .002 \\
\hline BMI & 12557984.110 & 1 & 12557984.110 & 3.115 & .080 & .021 \\
\hline SysStress_AVER & 12597162.610 & 1 & 12597162.610 & 3.125 & .079 & .021 \\
\hline Opt_Pess & 3029503.733 & 1 & 3029503.733 & .751 & .387 & .005 \\
\hline TASK_difficult_easy & 12197494.950 & 1 & 12197494.950 & 3.026 & .084 & .021 \\
\hline $\begin{array}{l}\text { Opt_Pess * } \\
\text { TASK_difficult_easy }\end{array}$ & 1242963.196 & 1 & 1242963.196 & .308 & .580 & .002 \\
\hline Error & 576476618.100 & 143 & 4031305.022 & & & \\
\hline Total & 648063891.400 & 151 & & & & \\
\hline Corrected Total & 615691764.700 & 150 & & & & \\
\hline
\end{tabular}

a. R Squared $=.064$ (Adjusted R Squared $=.018)$ 


\section{DBP}

\section{Tests of Between-Subjects Effects}

Dependent Variable: DIA_AUC

\begin{tabular}{|c|c|c|c|c|c|c|}
\hline Source & $\begin{array}{c}\text { Type III Sum of } \\
\text { Squares } \\
\end{array}$ & df & Mean Square & $\mathrm{F}$ & Sig. & $\begin{array}{c}\text { Partial Eta } \\
\text { Squared } \\
\end{array}$ \\
\hline Corrected Model & $38107035.140^{\mathrm{a}}$ & 7 & 5443862.162 & 1.262 & .273 & .058 \\
\hline Intercept & 471369.774 & 1 & 471369.774 & .109 & .741 & .001 \\
\hline STAI_total & 8634407.998 & 1 & 8634407.998 & 2.002 & .159 & .014 \\
\hline Negative_emotionality & 1084364.339 & 1 & 1084364.339 & .251 & .617 & .002 \\
\hline BMI & 4268365.734 & 1 & 4268365.734 & .990 & .321 & .007 \\
\hline DiaStress_AVER & 919224.646 & 1 & 919224.646 & .213 & .645 & .001 \\
\hline Opt_Pess & 6710398.950 & 1 & 6710398.950 & 1.556 & .214 & .011 \\
\hline TASK_difficult_easy & 16136766.750 & 1 & 16136766.750 & 3.742 & .055 & .026 \\
\hline $\begin{array}{l}\text { Opt_Pess * } \\
\text { TASK_difficult_easy }\end{array}$ & 7821003.301 & 1 & 7821003.301 & 1.814 & .180 & .013 \\
\hline Error & 616644953.200 & 143 & 4312202.470 & & & \\
\hline Total & 720084816.000 & 151 & & & & \\
\hline Corrected Total & 654751988.300 & 150 & & & & \\
\hline
\end{tabular}

a. R Squared $=.058($ Adjusted R Squared $=.012)$ 


\section{MAP}

\section{Tests of Between-Subjects Effects}

Dependent Variable: MAP_AUC

\begin{tabular}{|c|c|c|c|c|c|c|}
\hline Source & $\begin{array}{c}\text { Type III Sum of } \\
\text { Squares } \\
\end{array}$ & $\mathrm{df}$ & Mean Square & $\mathrm{F}$ & Sig. & $\begin{array}{c}\text { Partial Eta } \\
\text { Squared } \\
\end{array}$ \\
\hline Corrected Model & $22657149.450^{\mathrm{a}}$ & 7 & 3236735.636 & 1.207 & .302 & .056 \\
\hline Intercept & 1815829.473 & 1 & 1815829.473 & .677 & .412 & .005 \\
\hline STAI_total & 1458680.062 & 1 & 1458680.062 & .544 & .462 & .004 \\
\hline Negative_emotionality & 20358.091 & 1 & 20358.091 & .008 & .931 & .000 \\
\hline BMI & 8109658.633 & 1 & 8109658.633 & 3.025 & .084 & .021 \\
\hline MAPTask_AVER & 6800919.197 & 1 & 6800919.197 & 2.537 & .113 & .017 \\
\hline Opt_Pess & 997722.350 & 1 & 997722.350 & .372 & .543 & .003 \\
\hline TASK_difficult_easy & 2187783.939 & 1 & 2187783.939 & .816 & .368 & .006 \\
\hline $\begin{array}{l}\text { Opt_Pess * } \\
\text { TASK_difficult_easy }\end{array}$ & 4892314.840 & 1 & 4892314.840 & 1.825 & .179 & .013 \\
\hline Error & 383365832.600 & 143 & 2680879.949 & & & \\
\hline Total & 459096129.400 & 151 & & & & \\
\hline Corrected Total & 406022982.100 & 150 & & & & \\
\hline
\end{tabular}

a. R Squared $=.056$ (Adjusted R Squared $=.010)$

\section{HR}

\section{Tests of Between-Subjects Effects}

Dependent Variable: HR_AUC

\begin{tabular}{lr|r|r|r|r|r} 
Source & $\begin{array}{c}\text { Type III Sum of } \\
\text { Squares }\end{array}$ & df & Mean Square & F & Sig. & $\begin{array}{c}\text { Partial Eta } \\
\text { Squared }\end{array}$ \\
\hline Corrected Model & $3040709.367^{\mathrm{a}}$ & 6 & 506784.895 & .376 & .893 & .016 \\
\hline Intercept & 787556.097 & 1 & 787556.097 & .585 & .446 & .004 \\
\hline STAI_total & 62596.138 & 1 & 62596.138 & .046 & .830 & .000 \\
\hline Negative_emotionality & 23332.378 & 1 & 23332.378 & .017 & .895 & .000 \\
\hline HRTask_AVER & 114434.578 & 1 & 114434.578 & .085 & .771 & .001 \\
\hline Opt_Pess & 128.019 & 1 & 128.019 & .000 & .992 & .000 \\
\hline TASK_difficult_easy & 2637693.656 & 1 & 2637693.656 & 1.958 & .164 & .014 \\
\hline Opt_Pess $*$ & 158201.371 & 1 & 158201.371 & .117 & .732 & .001 \\
TASK_difficult_easy & & & & & & \\
\hline Error & 191300809.400 & 142 & 1347188.798 & & & \\
\hline Total & 216243857.200 & 149 & & & & \\
\hline Corrected Total & 194341518.700 & 148 & & & & \\
\hline
\end{tabular}




\section{HF-HRV}

\section{Tests of Between-Subjects Effects}

Dependent Variable: HFRecov_transformed

\begin{tabular}{|c|c|c|c|c|c|c|}
\hline Source & $\begin{array}{c}\text { Type III Sum of } \\
\text { Squares } \\
\end{array}$ & $\mathrm{df}$ & Mean Square & $\mathrm{F}$ & Sig. & $\begin{array}{c}\text { Partial Eta } \\
\text { Squared } \\
\end{array}$ \\
\hline Corrected Model & $23.041^{\mathrm{a}}$ & 6 & 3.840 & 38.002 & .000 & .616 \\
\hline Intercept & 1.593 & 1 & 1.593 & 15.766 & .000 & .100 \\
\hline STAI_total & $7.943 \mathrm{E}-7$ & 1 & $7.943 \mathrm{E}-7$ & .000 & .998 & .000 \\
\hline Negative_emotionality & .177 & 1 & .177 & 1.753 & .188 & .012 \\
\hline HFTask_transformed & 22.476 & 1 & 22.476 & 222.419 & .000 & .610 \\
\hline Opt_Pess & .024 & 1 & .024 & .234 & .630 & .002 \\
\hline TASK_difficult_easy & .068 & 1 & .068 & 670 & .415 & .005 \\
\hline $\begin{array}{l}\text { Opt_Pess } * \\
\text { TASK_difficult_easy }\end{array}$ & .008 & 1 & .008 & .078 & .781 & .001 \\
\hline Error & 14.350 & 142 & .101 & & & \\
\hline Total & 1249.507 & 149 & & & & \\
\hline Corrected Total & 37.391 & 148 & & & & \\
\hline
\end{tabular}

a. R Squared $=.616($ Adjusted R Squared $=.600)$

\section{SDNN}

\section{Tests of Between-Subjects Effects}

Dependent Variable：SDNN_Recov

\begin{tabular}{|c|c|c|c|c|c|c|}
\hline Source & $\begin{array}{c}\text { Type III Sum of } \\
\text { Squares } \\
\end{array}$ & $\mathrm{df}$ & Mean Square & $\mathrm{F}$ & Sig. & $\begin{array}{c}\text { Partial Eta } \\
\text { Squared } \\
\end{array}$ \\
\hline Corrected Model & $38800.089^{a}$ & 6 & 6466.681 & 14.945 & .000 & .387 \\
\hline Intercept & 6562.106 & 1 & 6562.106 & 15.165 & .000 & .096 \\
\hline STAI_total & 214.311 & 1 & 214.311 & .495 & .483 & .003 \\
\hline Negative_emotionality & 47.812 & 1 & 47.812 & .110 & .740 & .001 \\
\hline SDNN_Task & 37210.995 & 1 & 37210.995 & 85.996 & .000 & .377 \\
\hline Opt_Pess & 17.449 & 1 & 17.449 & .040 & .841 & .000 \\
\hline TASK_difficult_easy & 316.669 & 1 & 316.669 & .732 & .394 & .005 \\
\hline $\begin{array}{l}\text { Opt_Pess } * \\
\text { TASK_difficult_easy }\end{array}$ & 952.249 & 1 & 952.249 & 2.201 & .140 & .015 \\
\hline Error & 61444.359 & 142 & 432.707 & & & \\
\hline Total & 745821.490 & 149 & & & & \\
\hline Corrected Total & 100244.448 & 148 & & & & \\
\hline
\end{tabular}

a. $\quad$ R Squared $=.387$ (Adjusted R Squared $=.361$ ) 


\section{LF-HRV}

\section{Tests of Between-Subjects Effects}

Dependent Variable: LFRecov_transformed

\begin{tabular}{|c|c|c|c|c|c|c|}
\hline Source & $\begin{array}{c}\text { Type III Sum of } \\
\text { Squares } \\
\end{array}$ & df & Mean Square & $\mathrm{F}$ & Sig. & $\begin{array}{c}\text { Partial Eta } \\
\text { Squared } \\
\end{array}$ \\
\hline Corrected Model & $8.972^{\mathrm{a}}$ & 6 & 1.495 & 19.439 & .000 & .451 \\
\hline Intercept & 1.224 & 1 & 1.224 & 15.909 & .000 & .101 \\
\hline STAI_total & .012 & 1 & .012 & .156 & .693 & .001 \\
\hline Negative_emotionality & .024 & 1 & .024 & .311 & .578 & .002 \\
\hline LFTask_transformed & 8.734 & 1 & 8.734 & 113.546 & .000 & .444 \\
\hline Opt_Pess & .108 & 1 & .108 & 1.401 & .238 & .010 \\
\hline TASK_difficult_easy & .450 & 1 & .450 & 5.844 & .017 & .040 \\
\hline $\begin{array}{l}\text { Opt_Pess * } \\
\text { TASK_difficult_easy }\end{array}$ & .007 & 1 & .007 & .089 & .766 & .001 \\
\hline Error & 10.923 & 142 & .077 & & & \\
\hline Total & 1385.335 & 149 & & & & \\
\hline Corrected Total & 19.894 & 148 & & & & \\
\hline
\end{tabular}

a. $\quad$ R Squared $=.451$ (Adjusted R Squared $=.428)$

71.

\section{Estimates}

Dependent Variable: LF_Recov

\begin{tabular}{ll|r|r|r} 
& & & \multicolumn{2}{|c}{$95 \%$ Confidence Interval } \\
TASK_difficult_easy & Mean & Std. Error & \multicolumn{1}{c}{ Lower Bound } & \multicolumn{1}{c}{ Upper Bound } \\
\hline 1.00 & $1614.361^{\mathrm{a}}$ & 135.263 & 1346.972 & 1881.750 \\
\hline 2.00 & $1330.363^{\mathrm{a}}$ & 136.053 & 1061.413 & 1599.313 \\
\hline
\end{tabular}

a. Covariates appearing in the model are evaluated at the following values: STAI_total

$=44.7383$, Negative_emotionality $=37.1007$, LF_Task $=1198.5570$. 


\section{Task Score}

72.

\section{Tests of Between-Subjects Effects}

Dependent Variable: Stress_Task_score

\begin{tabular}{|c|c|c|c|c|c|c|}
\hline Source & $\begin{array}{c}\text { Type III Sum of } \\
\text { Squares } \\
\end{array}$ & $\mathrm{df}$ & Mean Square & $\mathrm{F}$ & Sig. & $\begin{array}{c}\text { Partial Eta } \\
\text { Squared } \\
\end{array}$ \\
\hline Corrected Model & $1943.770^{\mathrm{a}}$ & 4 & 485.943 & 205.759 & .000 & .848 \\
\hline Intercept & 119.622 & 1 & 119.622 & 50.651 & .000 & .256 \\
\hline digitspan_score & .055 & 1 & .055 & .023 & .879 & .000 \\
\hline Opt_Pess & .561 & 1 & .561 & .237 & .627 & .002 \\
\hline TASK_difficult_easy & 1909.246 & 1 & 1909.246 & 808.419 & .000 & .846 \\
\hline $\begin{array}{l}\text { Opt_Pess * } \\
\text { TASK_difficult_easy }\end{array}$ & 3.446 & 1 & 3.446 & 1.459 & .229 & .010 \\
\hline Error & 347.170 & 147 & 2.362 & & & \\
\hline Total & 7799.000 & 152 & & & & \\
\hline Corrected Total & 2290.941 & 151 & & & & \\
\hline
\end{tabular}

a. R Squared $=.848($ Adjusted R Squared $=.844)$

73.

\section{Estimates}

Dependent Variable: Stress_Task_score

\begin{tabular}{lc|r|r|r} 
& & & \multicolumn{2}{|c}{$95 \%$ Confidence Interval } \\
TASK_difficult_easy & \multicolumn{1}{c}{ Mean } & Std. Error & Lower Bound & \multicolumn{1}{c}{ Upper Bound } \\
\hline Difficult & $2.452^{\mathrm{a}}$ & .177 & 2.102 & 2.801 \\
\hline Easy & $9.584^{\mathrm{a}}$ & .177 & 9.235 & 9.934 \\
\hline
\end{tabular}

a. Covariates appearing in the model are evaluated at the following values: digitspan_score $=63.5329$. 
74. True Optimists vs. True pessimists task score

\section{Tests of Between-Subjects Effects}

Dependent Variable: Stress_Task_score

\begin{tabular}{|c|c|c|c|c|c|c|}
\hline Source & $\begin{array}{c}\text { Type III Sum of } \\
\text { Squares } \\
\end{array}$ & df & Mean Square & $\mathrm{F}$ & Sig. & $\begin{array}{l}\text { Partial Eta } \\
\text { Squared }\end{array}$ \\
\hline Corrected Model & $886.588^{a}$ & 4 & 221.647 & 94.233 & .000 & .859 \\
\hline Intercept & 50.816 & 1 & 50.816 & 21.605 & .000 & .258 \\
\hline digitspan_score & .283 & 1 & .283 & .120 & .730 & .002 \\
\hline true_Pessimist & 5.587 & 1 & 5.587 & 2.375 & .128 & .037 \\
\hline TASK_difficult_easy & 803.448 & 1 & 803.448 & 341.587 & .000 & .846 \\
\hline $\begin{array}{l}\text { true_Pessimist * } \\
\text { TASK_difficult_easy }\end{array}$ & 5.616 & 1 & 5.616 & 2.388 & .127 & .037 \\
\hline Error & 145.830 & 62 & 2.352 & & & \\
\hline Total & 3703.000 & 67 & & & & \\
\hline Corrected Total & 1032.418 & 66 & & & & \\
\hline
\end{tabular}

a. R Squared $=.859($ Adjusted R Squared $=.850)$

75.

\section{Estimates}

Dependent Variable: Stress_Task_score

\begin{tabular}{lr|r|r|r} 
& & & \multicolumn{2}{|c}{$95 \%$ Confidence Interval } \\
TASK_difficult_easy & \multicolumn{1}{l|}{ Mean } & Std. Error & Lower Bound & Upper Bound \\
\hline 1.00 & $2.364^{\mathrm{a}}$ & .288 & 1.789 & 2.939 \\
\hline 2.00 & $9.583^{\mathrm{a}}$ & .258 & 9.066 & 10.099 \\
\hline
\end{tabular}

a. Covariates appearing in the model are evaluated at the following values:

digitspan_score $=63.2090$. 
76. DBP with Task score covariate

\section{Tests of Between-Subjects Effects}

Dependent Variable: DiaStress_AVER

\begin{tabular}{|c|c|c|c|c|c|c|}
\hline Source & $\begin{array}{c}\text { Type III Sum of } \\
\text { Squares } \\
\end{array}$ & $\mathrm{df}$ & Mean Square & $\mathrm{F}$ & Sig. & $\begin{array}{c}\text { Partial Eta } \\
\text { Squared } \\
\end{array}$ \\
\hline Corrected Model & $7533.704^{\mathrm{a}}$ & 8 & 941.713 & 27.667 & .000 & .609 \\
\hline Intercept & 311.285 & 1 & 311.285 & 9.145 & .003 & .061 \\
\hline BMI & 27.066 & 1 & 27.066 & .795 & .374 & .006 \\
\hline STAI_total & 118.845 & 1 & 118.845 & 3.492 & .064 & .024 \\
\hline Negative_emotionality & 23.341 & 1 & 23.341 & .686 & .409 & .005 \\
\hline DiaRest_AVER & 6244.487 & 1 & 6244.487 & 183.462 & .000 & .564 \\
\hline Stress_Task_score & 46.257 & 1 & 46.257 & 1.359 & .246 & .009 \\
\hline Opt_Pess & 212.864 & 1 & 212.864 & 6.254 & .014 & .042 \\
\hline TASK_difficult_easy & 18.932 & 1 & 18.932 & .556 & .457 & .004 \\
\hline $\begin{array}{l}\text { Opt_Pess * } \\
\text { TASK_difficult_easy }\end{array}$ & 10.440 & 1 & 10.440 & .307 & .581 & .002 \\
\hline Error & 4833.260 & 142 & 34.037 & & & \\
\hline Total & 773226.667 & 151 & & & & \\
\hline Corrected Total & 12366.964 & 150 & & & & \\
\hline
\end{tabular}

a. R Squared $=.609$ (Adjusted R Squared $=.587)$ 


\section{Measures of Affect}

77. Positive affect

\section{Tests of Between-Subjects Effects}

Dependent Variable: PosAffect_transformed

\begin{tabular}{|c|c|c|c|c|c|c|}
\hline Source & $\begin{array}{c}\text { Type III Sum of } \\
\text { Squares } \\
\end{array}$ & $\mathrm{df}$ & Mean Square & $\mathrm{F}$ & Sig. & $\begin{array}{c}\text { Partial Eta } \\
\text { Squared } \\
\end{array}$ \\
\hline Corrected Model & $50.628^{\mathrm{a}}$ & 3 & 16.876 & 30.119 & .000 & .379 \\
\hline Intercept & 310.349 & 1 & 310.349 & 553.899 & .000 & .789 \\
\hline Opt_Pess & 19.815 & 1 & 19.815 & 35.364 & .000 & .193 \\
\hline TASK_difficult_easy & 30.801 & 1 & 30.801 & 54.972 & .000 & .271 \\
\hline $\begin{array}{l}\text { Opt_Pess * } \\
\text { TASK_difficult_easy }\end{array}$ & .001 & 1 & .001 & .002 & .962 & .000 \\
\hline Error & 82.924 & 148 & .560 & & & \\
\hline Total & 440.000 & 152 & & & & \\
\hline Corrected Total & 133.552 & 151 & & & & \\
\hline
\end{tabular}

a. R Squared $=.379($ Adjusted R Squared $=.367)$

78.

\section{Estimates}

Dependent Variable: MAACl_R_pos

\begin{tabular}{lr|r|r|r} 
& & & \multicolumn{2}{|c}{$95 \%$ Confidence Interval } \\
Opt_Pess & Mean & \multicolumn{1}{c}{ Std. Error } & Lower Bound & \multicolumn{1}{c}{ Upper Bound } \\
\hline Optimist & 4.027 & .274 & 3.486 & 4.568 \\
\hline Pessimist & 1.821 & .267 & 1.293 & 2.348 \\
\hline
\end{tabular}

79.

\section{Estimates}

Dependent Variable: MAACl_R_pos

\begin{tabular}{lr|r|r|r} 
& & & \multicolumn{2}{|c}{$95 \%$ Confidence Interval } \\
TASK_difficult_easy & \multicolumn{1}{c|}{ Mean } & Std. Error & Lower Bound & Upper Bound \\
\hline Difficult & 1.666 & .270 & 1.131 & 2.200 \\
\hline Easy & 4.182 & .270 & 3.648 & 4.716 \\
\hline
\end{tabular}




\section{Negative Affect}

\section{Tests of Between-Subjects Effects}

Dependent Variable: NegAffect_transformed

\begin{tabular}{|c|c|c|c|c|c|c|}
\hline Source & $\begin{array}{c}\text { Type III Sum of } \\
\text { Squares } \\
\end{array}$ & $\mathrm{df}$ & Mean Square & $\mathrm{F}$ & Sig. & $\begin{array}{c}\text { Partial Eta } \\
\text { Squared } \\
\end{array}$ \\
\hline Corrected Model & $20.377^{\mathrm{a}}$ & 3 & 6.792 & 9.437 & .000 & .161 \\
\hline Intercept & 444.832 & 1 & 444.832 & 618.052 & .000 & .807 \\
\hline Opt_Pess & 3.113 & 1 & 3.113 & 4.325 & .039 & .028 \\
\hline TASK_difficult_easy & 16.348 & 1 & 16.348 & 22.713 & .000 & .133 \\
\hline $\begin{array}{l}\text { Opt_Pess * } \\
\text { TASK_difficult_easy }\end{array}$ & 1.131 & 1 & 1.131 & 1.572 & .212 & .011 \\
\hline Error & 106.520 & 148 & .720 & & & \\
\hline Total & 574.000 & 152 & & & & \\
\hline Corrected Total & 126.898 & 151 & & & & \\
\hline
\end{tabular}

a. R Squared $=.161($ Adjusted R Squared $=.144)$

81.

\section{Estimates}

Dependent Variable: MAACL_r_dys

\begin{tabular}{lr|r|r|r} 
& & & \multicolumn{2}{|c}{$95 \%$ Confidence Interval } \\
Opt_Pess & Mean & Std. Error & Lower Bound & \multicolumn{1}{c}{ Upper Bound } \\
\hline Optimist & 3.324 & .351 & 2.631 & 4.018 \\
\hline Pessimist & 4.205 & .342 & 3.530 & 4.880 \\
\hline
\end{tabular}

82.

Estimates

Dependent Variable: MAACL_r_dys

\begin{tabular}{lr|r|r|r} 
& & & \multicolumn{2}{|c}{$95 \%$ Confidence Interval } \\
TASK_difficult_easy & \multicolumn{1}{c}{ Mean } & Std. Error & Lower Bound & \multicolumn{1}{c}{ Upper Bound } \\
\hline Difficult & 4.953 & .346 & 4.269 & 5.637 \\
\hline Easy & 2.576 & .346 & 1.892 & 3.261 \\
\hline
\end{tabular}




\section{Post-experimental questionnaire}

83.

Tests of Between-Subjects Effects

Dependent Variable: How_Stressful_was_task

Type III Sum of

Source Squares

df Mean Square

\begin{tabular}{|l|l|c} 
& & $\begin{array}{c}\text { Partial Eta } \\
\text { Squared }\end{array}$ \\
\hline
\end{tabular}

Corrected Model

$49.970^{a}$

Intercept

1265.588

16.657

23.012

1265.588

1748.437

\begin{tabular}{|l|r|}
\hline 2 & .000
\end{tabular}

.318

Opt_Pess

.588

TASK_difficult_easy

Opt_Pess * 47.008

TASK_difficult_easy

Error

1.850

.588

.812

.000

Total

Corrected Total

2

1

$1 \quad 47.008$

\begin{tabular}{|l|l|}
107.128 & 148 \\
\hline
\end{tabular}

a. R Squared $=.318($ Adjusted R Squared $=.304)$

84.

Estimates

Dependent Variable: How_Stressful_was_task

\begin{tabular}{lr|r|r|r}
\hline TASK_difficult_easy & \multicolumn{1}{c}{ Mean } & Std. Error & Lower Bound & \multicolumn{1}{c}{ Upper Bound } \\
\hline Difficult & 3.443 & .098 & 3.250 & 3.636 \\
\hline Easy & 2.330 & .098 & 2.137 & 2.523 \\
\hline
\end{tabular}


85.

\section{Tests of Between-Subjects Effects}

Dependent Variable: How_Difficult_were_problems

\begin{tabular}{|c|c|c|c|c|c|c|}
\hline Source & $\begin{array}{c}\text { Type III Sum of } \\
\text { Squares } \\
\end{array}$ & $\mathrm{df}$ & Mean Square & $\mathrm{F}$ & Sig. & $\begin{array}{c}\text { Partial Eta } \\
\text { Squared } \\
\end{array}$ \\
\hline Corrected Model & $120.197^{\mathrm{a}}$ & 3 & 40.066 & 64.890 & .000 & .568 \\
\hline Intercept & 1803.318 & 1 & 1803.318 & 2920.614 & .000 & .952 \\
\hline Opt_Pess & .686 & 1 & .686 & 1.112 & .293 & .007 \\
\hline TASK_difficult_easy & 117.379 & 1 & 117.379 & 190.105 & .000 & .562 \\
\hline $\begin{array}{l}\text { Opt_Pess * } \\
\text { TASK_difficult_easy }\end{array}$ & 1.379 & 1 & 1.379 & 2.234 & .137 & .015 \\
\hline Error & 91.382 & 148 & 617 & & & \\
\hline Total & 2018.000 & 152 & & & & \\
\hline Corrected Total & 211.579 & 151 & & & & \\
\hline
\end{tabular}

a. R Squared $=.568($ Adjusted R Squared $=.559)$

86.

Estimates

Dependent Variable: How_Difficult_were_problems

95\% Confidence Interval

\begin{tabular}{lr|r|r|r} 
TASK_difficult_easy & \multicolumn{1}{c}{ Mean } & \multicolumn{1}{c}{ Std. Error } & Lower Bound & \multicolumn{1}{c}{ Upper Bound } \\
\hline difficult & 4.325 & .090 & 4.146 & 4.503 \\
\hline easy & 2.567 & .090 & 2.388 & 2.745 \\
\hline
\end{tabular}

87.

Tests of Between-Subjects Effects

Dependent Variable: How_much_effort_to_complete_tasks

\begin{tabular}{|c|c|c|c|c|c|c|}
\hline Source & $\begin{array}{c}\text { Type III Sum of } \\
\text { Squares } \\
\end{array}$ & df & Mean Square & $\mathrm{F}$ & Sig. & $\begin{array}{c}\text { Partial Eta } \\
\text { Squared } \\
\end{array}$ \\
\hline Corrected Model & $11.233^{\mathrm{a}}$ & 3 & 3.744 & 6.170 & .001 & .111 \\
\hline Intercept & 2336.915 & 1 & 2336.915 & 3850.636 & .000 & .963 \\
\hline Opt_Pess & .389 & 1 & .389 & .641 & .425 & .004 \\
\hline TASK_difficult_easy & 10.423 & 1 & 10.423 & 17.174 & .000 & .104 \\
\hline $\begin{array}{l}\text { Opt_Pess * } \\
\text { TASK_difficult_easy }\end{array}$ & .318 & 1 & .318 & .524 & .470 & .004 \\
\hline Error & 89.820 & 148 & .607 & & & \\
\hline Total & 2438.000 & 152 & & & & \\
\hline Corrected Total & 101.053 & 151 & & & & \\
\hline
\end{tabular}


88.

\section{Estimates}

Dependent Variable: How_much_effort_to_complete_tasks

\begin{tabular}{lr|r|r|r} 
& & & \multicolumn{2}{c}{$95 \%$ Confidence Interval } \\
TASK_difficult_easy & \multicolumn{1}{c}{ Mean } & Std. Error & Lower Bound & Upper Bound \\
\hline difficult & 4.184 & .089 & 4.008 & 4.361 \\
\hline easy & 3.660 & .089 & 3.484 & 3.837 \\
\hline
\end{tabular}


89.

\section{Tests of Between-Subjects Effects}

Dependent Variable: How_Well_did_you_perform_on_task

\begin{tabular}{|c|c|c|c|c|c|c|}
\hline Source & $\begin{array}{c}\text { Type III Sum of } \\
\text { Squares } \\
\end{array}$ & $\mathrm{df}$ & Mean Square & $\mathrm{F}$ & Sig. & $\begin{array}{c}\text { Partial Eta } \\
\text { Squared } \\
\end{array}$ \\
\hline Corrected Model & $186.599^{\mathrm{a}}$ & 3 & 62.200 & 110.876 & .000 & .692 \\
\hline Intercept & 1049.622 & 1 & 1049.622 & 1871.037 & .000 & .927 \\
\hline Opt_Pess & 3.043 & 1 & 3.043 & 5.425 & .021 & .035 \\
\hline TASK_difficult_easy & 183.550 & 1 & 183.550 & 327.192 & .000 & .689 \\
\hline $\begin{array}{l}\text { Opt_Pess * } \\
\text { TASK_difficult_easy }\end{array}$ & .076 & 1 & .076 & .135 & .714 & .001 \\
\hline Error & 83.026 & 148 & .561 & & & \\
\hline Total & 1317.000 & 152 & & & & \\
\hline Corrected Total & 269.625 & 151 & & & & \\
\hline
\end{tabular}

a. $\quad$ R Squared $=.692($ Adjusted R Squared $=.686$ )

90.

\section{Estimates}

Dependent Variable: How_Well_did_you_perform_on_task

\begin{tabular}{l|r|r|r|r} 
& & & \multicolumn{2}{c}{$95 \%$ Confidence Interval } \\
Opt_Pess & Mean & \multicolumn{1}{c}{ Std. Error } & Lower Bound & Upper Bound \\
\hline 1.00 & 2.770 & .087 & 2.598 & 2.942 \\
\hline 2.00 & 2.487 & .085 & 2.320 & 2.655 \\
\hline
\end{tabular}

91.

\section{Estimates}

Dependent Variable: How_Well_did_you_perform_on_task 95\% Confidence Interval

\begin{tabular}{lr|r|r|r} 
TASK_difficult_easy & \multicolumn{1}{c|}{ Mean } & Std. Error & Lower Bound & Upper Bound \\
\hline difficult & 1.529 & .086 & 1.360 & 1.699 \\
\hline easy & 3.728 & .086 & 3.558 & 3.898 \\
\hline
\end{tabular}


92.

\section{Tests of Between-Subjects Effects}

Dependent Variable: How_persistent_were_you_on_task

\begin{tabular}{|c|c|c|c|c|c|c|}
\hline Source & $\begin{array}{c}\text { Type III Sum of } \\
\text { Squares } \\
\end{array}$ & df & Mean Square & $\mathrm{F}$ & Sig. & $\begin{array}{c}\text { Partial Eta } \\
\text { Squared } \\
\end{array}$ \\
\hline Corrected Model & $23.093^{\mathrm{a}}$ & 3 & 7.698 & 9.338 & .000 & .159 \\
\hline Intercept & 2302.157 & 1 & 2302.157 & 2792.653 & .000 & .950 \\
\hline Opt_Pess & 5.367 & 1 & 5.367 & 6.511 & .012 & .042 \\
\hline TASK_difficult_easy & 16.930 & 1 & 16.930 & 20.537 & .000 & .122 \\
\hline $\begin{array}{l}\text { Opt_Pess * } \\
\text { TASK_difficult_easy }\end{array}$ & .614 & 1 & .614 & .745 & .389 & .005 \\
\hline Error & 122.006 & 148 & .824 & & & \\
\hline Total & 2443.000 & 152 & & & & \\
\hline Corrected Total & 145.099 & 151 & & & & \\
\hline
\end{tabular}

a. R Squared $=.159($ Adjusted R Squared $=.142)$

93.

\section{Estimates}

Dependent Variable: How_persistent_were_you_on_task

95\% Confidence Interval

\begin{tabular}{ll|l|l} 
Opt_Pess Mean & Std. Error Lower Bound & Upper Bound \\
\hline
\end{tabular}

\begin{tabular}{l|l|l|l|l}
\hline Optimist & 4.081 & .106 & 3.873 & 4.290 \\
\hline Pessimist & 3.705 & .103 & 3.502 & 3.908 \\
\hline
\end{tabular}

94.

Estimates

Dependent Variable: How_persistent_were_you_on_task

95\% Confidence Interval

\begin{tabular}{llll|l} 
TASK_difficult_easy Mean & Std. Error & Lower Bound & Upper Bound \\
\hline
\end{tabular}

\begin{tabular}{l|l|l|l|l|}
\hline difficult & 3.559 & .104 & 3.353 & 3.765 \\
\hline easy & 4.227 & .104 & 4.021 & 4.433 \\
\hline
\end{tabular}


95.

\section{Tests of Between-Subjects Effects}

Dependent Variable: How_upset_are_you_about_performance_on_task

\begin{tabular}{|c|c|c|c|c|c|c|}
\hline Source & $\begin{array}{c}\text { Type III Sum of } \\
\text { Squares } \\
\end{array}$ & df & Mean Square & $\mathrm{F}$ & Sig. & $\begin{array}{c}\text { Partial Eta } \\
\text { Squared } \\
\end{array}$ \\
\hline Corrected Model & $37.988^{\mathrm{a}}$ & 3 & 12.663 & 11.605 & .000 & .190 \\
\hline Intercept & 757.523 & 1 & 757.523 & 694.262 & .000 & .824 \\
\hline Opt_Pess & 2.918 & 1 & 2.918 & 2.674 & .104 & .018 \\
\hline TASK_difficult_easy & 33.781 & 1 & 33.781 & 30.959 & .000 & .173 \\
\hline $\begin{array}{l}\text { Opt_Pess * } \\
\text { TASK_difficult_easy }\end{array}$ & .965 & 1 & .965 & .884 & .349 & .006 \\
\hline Error & 161.486 & 148 & 1.091 & & & \\
\hline Total & 960.000 & 152 & & & & \\
\hline Corrected Total & 199.474 & 151 & & & & \\
\hline
\end{tabular}

a. R Squared $=.190($ Adjusted R Squared $=.174)$

96.

Estimates

Dependent Variable: How_upset_are_you_about_performance_on_task

95\% Confidence Interval

\begin{tabular}{lr|r|r|r} 
TASK_difficult_easy & \multicolumn{1}{c|}{ Mean } & Std. Error & Lower Bound & \multicolumn{1}{c}{ Upper Bound } \\
\hline difficult & 2.705 & .120 & 2.468 & 2.942 \\
\hline easy & 1.762 & .120 & 1.525 & 1.998 \\
\hline
\end{tabular}




\section{Self-Efficacy Ratings}

97.

\section{Tests of Between-Subjects Effects}

Dependent Variable: Self_efficacy

\begin{tabular}{|c|c|c|c|c|c|c|}
\hline Source & $\begin{array}{c}\text { Type III Sum of } \\
\text { Squares } \\
\end{array}$ & $\mathrm{df}$ & Mean Square & $\mathrm{F}$ & Sig. & $\begin{array}{c}\text { Partial Eta } \\
\text { Squared } \\
\end{array}$ \\
\hline Corrected Model & $.090^{\mathrm{a}}$ & 3 & .030 & .116 & .951 & .002 \\
\hline Intercept & 1974.775 & 1 & 1974.775 & 7645.775 & .000 & .981 \\
\hline Opt_Pess & .039 & 1 & .039 & .149 & .700 & .001 \\
\hline TASK_difficult_easy & .025 & 1 & .025 & .097 & .756 & .001 \\
\hline $\begin{array}{l}\text { Opt_Pess * } \\
\text { TASK_difficult_easy }\end{array}$ & .025 & 1 & .025 & .097 & .756 & .001 \\
\hline Error & 38.226 & 148 & .258 & & & \\
\hline Total & 2014.000 & 152 & & & & \\
\hline Corrected Total & 38.316 & 151 & & & & \\
\hline
\end{tabular}

a. R Squared $=.002$ (Adjusted R Squared $=-.018)$

\section{Self-efficacy and digit-symbol predicting task score.}

98. Difficult task

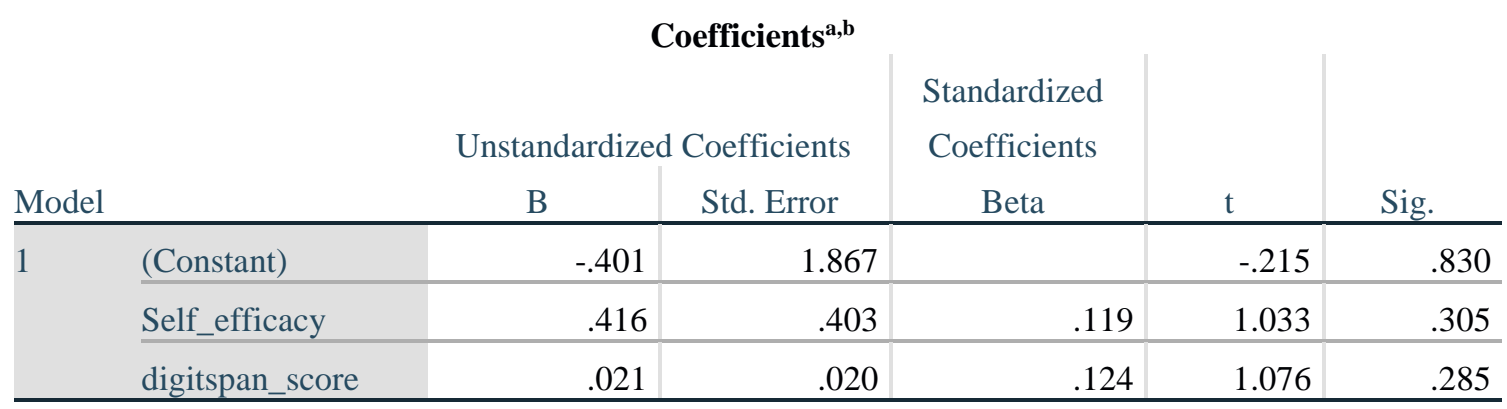

b. Dependent Variable: Stress_Task_score

99. Easy task

\begin{tabular}{|c|c|c|c|c|c|c|}
\hline \multicolumn{7}{|c|}{ Coefficients $^{\mathrm{a}, \mathrm{b}}$} \\
\hline \multirow[b]{3}{*}{ Model } & & \multirow{2}{*}{\multicolumn{2}{|c|}{ Unstandardized Coefficients }} & \multirow{3}{*}{$\begin{array}{c}\text { Standardized } \\
\text { Coefficients } \\
\text { Beta } \\
\end{array}$} & \multirow[b]{3}{*}{$\mathrm{t}$} & \multirow[b]{3}{*}{ Sig. } \\
\hline & & & & & & \\
\hline & & $\mathrm{B}$ & Std. Error & & & \\
\hline \multirow[t]{3}{*}{1} & (Constant) & 8.613 & 1.360 & & 6.336 & .000 \\
\hline & Self_efficacy & .735 & .282 & .288 & 2.610 & .011 \\
\hline & digitspan_score & -.026 & .015 & -.191 & -1.730 & .088 \\
\hline
\end{tabular}

b. Dependent Variable: Stress_Task_score 


\section{Analysis of Optimism and Pessimism Subscales}

100. SBP

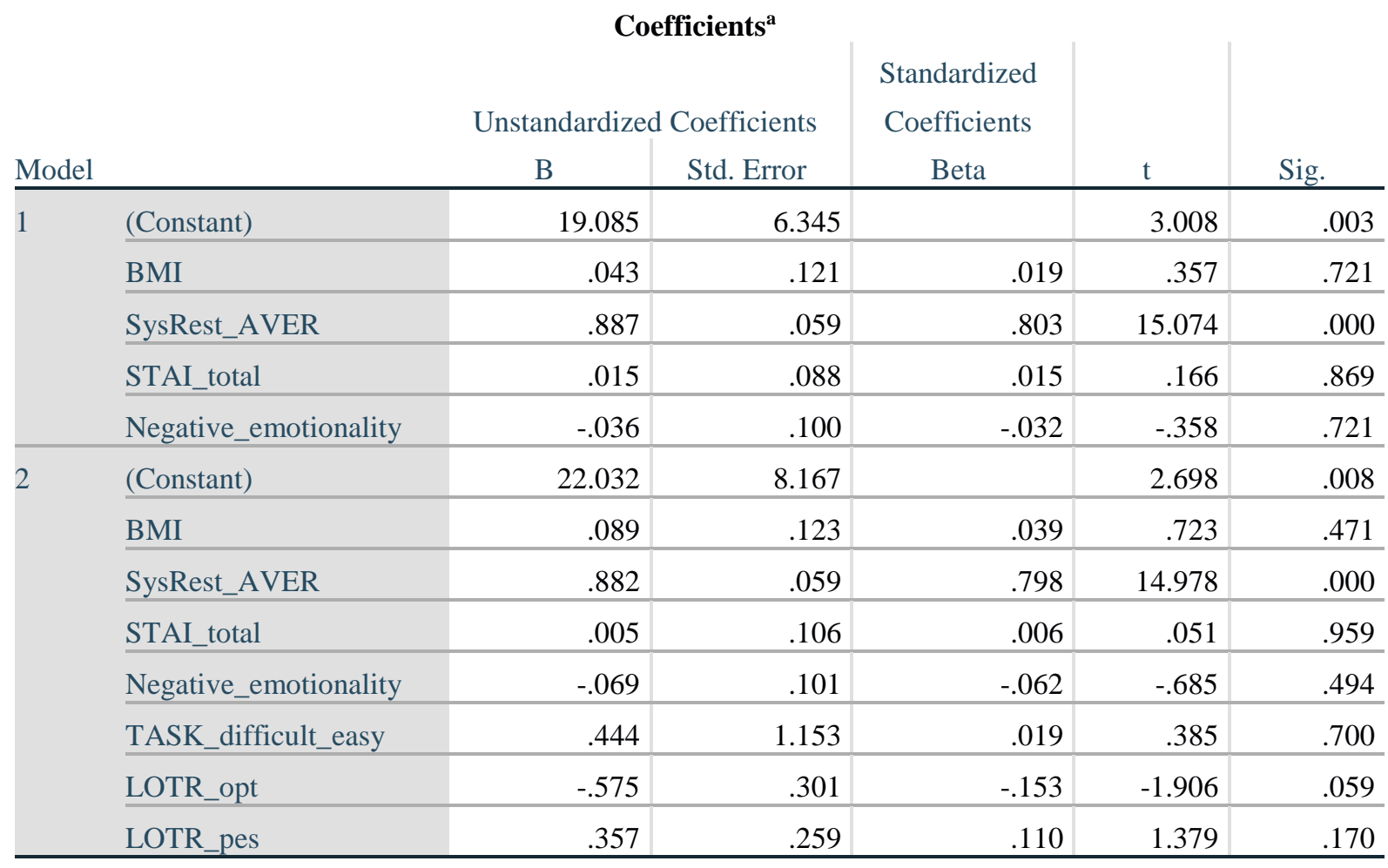

a. Dependent Variable: SysStress_AVER 


\section{DBP}

\begin{tabular}{|c|c|c|c|c|c|c|}
\hline \multicolumn{7}{|c|}{ Coefficients $^{a}$} \\
\hline \multirow[b]{3}{*}{ Mod } & & \multirow{2}{*}{\multicolumn{2}{|c|}{ Unstandardized Coefficients }} & \multirow{3}{*}{$\begin{array}{c}\text { Standardized } \\
\text { Coefficients } \\
\text { Beta } \\
\end{array}$} & \multirow[b]{3}{*}{$\mathrm{t}$} & \multirow[b]{3}{*}{ Sig. } \\
\hline & & & & & & \\
\hline & & $\mathrm{B}$ & Std. Error & & & \\
\hline \multirow[t]{5}{*}{1} & (Constant) & 18.396 & 4.403 & & 4.178 & .000 \\
\hline & DiaRest_AVER & .774 & .058 & .743 & 13.308 & .000 \\
\hline & BMI & .102 & .097 & .058 & 1.057 & .292 \\
\hline & STAI_total & .035 & .075 & .046 & .468 & .640 \\
\hline & Negative_emotionality & -.057 & .086 & -.066 & -.664 & .507 \\
\hline \multirow[t]{8}{*}{2} & (Constant) & 10.292 & 6.196 & & 1.661 & .099 \\
\hline & DiaRest_AVER & .769 & .057 & .738 & 13.539 & .000 \\
\hline & BMI & .115 & .096 & .066 & 1.200 & .232 \\
\hline & STAI_total & .169 & .088 & .222 & 1.911 & .058 \\
\hline & Negative_emotionality & -.077 & .085 & -.089 & -.909 & .365 \\
\hline & TASK_difficult_easy & -1.010 & .954 & -.056 & -1.058 & .292 \\
\hline & LOTR_opt & -.147 & .250 & -.051 & -.589 & .557 \\
\hline & LOTR_pes & .653 & .214 & .260 & 3.054 & .003 \\
\hline
\end{tabular}


a. Dependent Variable: DiaStress_AVER

102. MAP

\begin{tabular}{|c|c|c|c|c|c|c|}
\hline \multicolumn{7}{|c|}{ Coefficients $^{a}$} \\
\hline \multirow[b]{2}{*}{ Model } & & \multicolumn{2}{|c|}{ Unstandardized Coefficients } & \multirow{2}{*}{$\begin{array}{c}\text { Standardized } \\
\text { Coefficients } \\
\text { Beta } \\
\end{array}$} & \multirow[b]{2}{*}{$t$} & \multirow[b]{2}{*}{ Sig. } \\
\hline & & $\mathrm{B}$ & Std. Error & & & \\
\hline \multirow[t]{5}{*}{1} & (Constant) & 18.954 & 4.746 & & 3.993 & .000 \\
\hline & BMI & .088 & .089 & .055 & .996 & .321 \\
\hline & STAI_total & .025 & .066 & .036 & .379 & .705 \\
\hline & Negative_emotionality & -.045 & .075 & -.056 & -.599 & .550 \\
\hline & MAP_Rest_AVER & .820 & .059 & .764 & 13.797 & .000 \\
\hline \multirow[t]{8}{*}{2} & (Constant) & 14.960 & 6.049 & & 2.473 & .015 \\
\hline & BMI & .117 & .089 & .072 & 1.317 & .190 \\
\hline & STAI_total & .114 & .078 & .163 & 1.462 & .146 \\
\hline & Negative_emotionality & -.071 & .075 & -.089 & -.951 & .343 \\
\hline & MAP_Rest_AVER & .807 & .058 & .752 & 13.813 & .000 \\
\hline & TASK_difficult_easy & -.559 & .842 & -.033 & -.663 & .508 \\
\hline & LOTR_opt & -.288 & .221 & -.108 & -1.307 & .193 \\
\hline & LOTR_pes & .561 & .189 & .242 & 2.967 & .004 \\
\hline
\end{tabular}


103. $\mathrm{HR}$

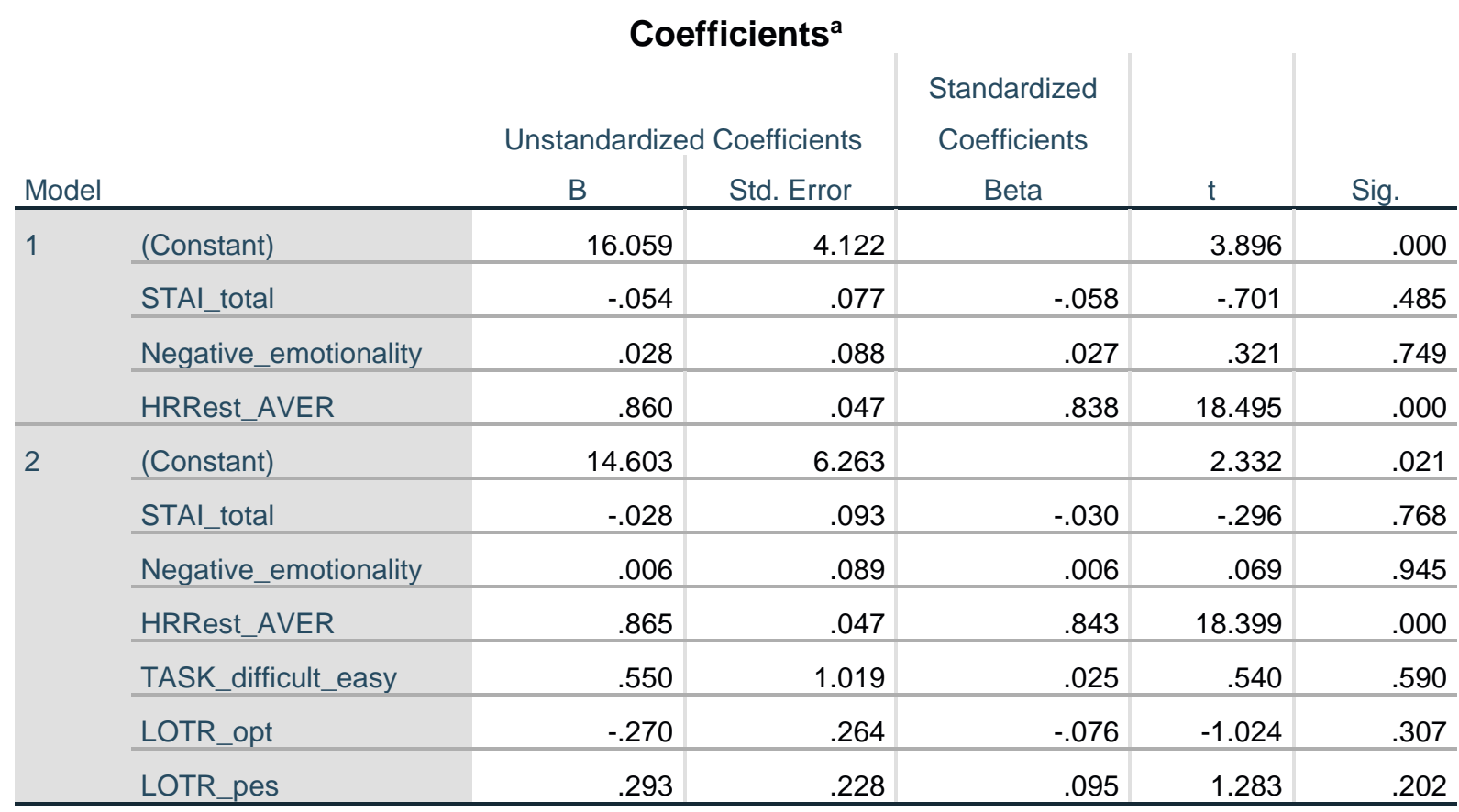

a. Dependent Variable: HRTask_AVER

104. HF-HRV

\begin{tabular}{|c|c|c|c|c|c|c|}
\hline & & Coe & icients ${ }^{a}$ & & & \\
\hline & & Unstandardize & Coefficients & $\begin{array}{l}\text { Standardized } \\
\text { Coefficients }\end{array}$ & & \\
\hline Model & & $\mathrm{B}$ & Std. Error & Beta & $\mathrm{t}$ & Sig. \\
\hline 1 & (Constant) & .744 & .198 & & 3.751 & .000 \\
\hline & STAI_total & -.004 & .004 & -.092 & -.864 & .389 \\
\hline & Negative_emotionality & .010 & .005 & .207 & 1.950 & .053 \\
\hline & HFRest_transformed & .645 & .053 & .708 & 12.162 & .000 \\
\hline 2 & (Constant) & .762 & .344 & & 2.214 & .028 \\
\hline & STAI_total & -.006 & .005 & -.152 & -1.195 & .234 \\
\hline & Negative_emotionality & .010 & .005 & .219 & 2.041 & .043 \\
\hline & HFRest_transformed & .635 & .053 & .697 & 11.923 & .000 \\
\hline & TASK_difficult_easy & .098 & .059 & .099 & 1.671 & .097 \\
\hline & LOTR_opt & .012 & .015 & .075 & .793 & .429 \\
\hline & LOTR_pes & -.019 & .013 & -.134 & -1.421 & .157 \\
\hline
\end{tabular}

a. Dependent Variable: HFTask_transformed 


\section{SDNN}

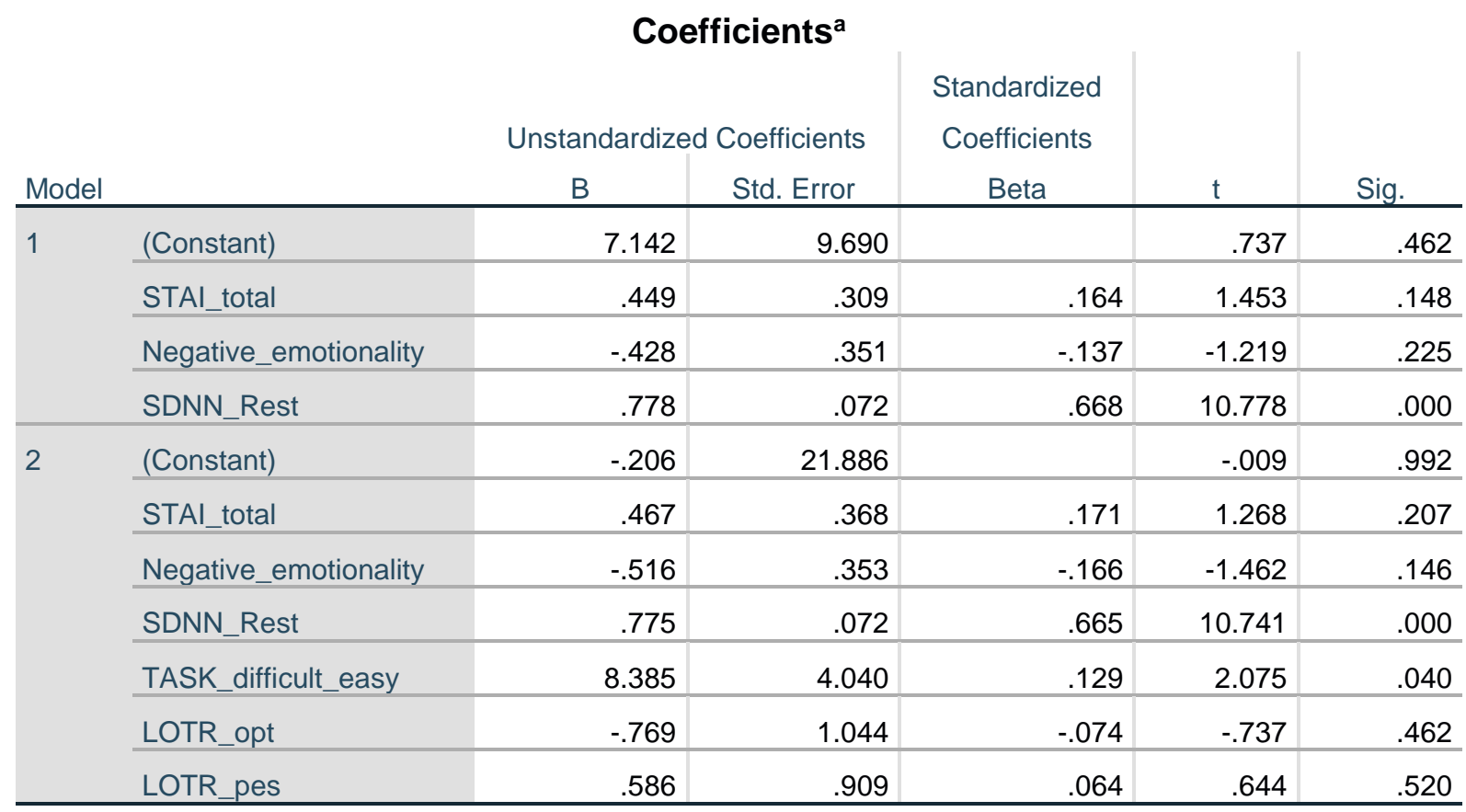

a. Dependent Variable: SDNN_Task

106. LF-HRV

\section{Coefficients $^{\mathrm{a}}$}

\begin{tabular}{|c|c|c|c|c|c|c|}
\hline \multirow[b]{2}{*}{ Model } & & \multicolumn{2}{|c|}{ Unstandardized Coefficients } & \multirow{2}{*}{$\begin{array}{c}\text { Standardized } \\
\text { Coefficients } \\
\text { Beta }\end{array}$} & \multirow[b]{2}{*}{$\mathrm{t}$} & \multirow[b]{2}{*}{ Sig. } \\
\hline & & B & Std. Error & & & \\
\hline \multirow[t]{4}{*}{1} & (Constant) & .918 & .219 & & 4.193 & .000 \\
\hline & STAI_total & .007 & .003 & .220 & 1.911 & .058 \\
\hline & Negative_emotionality & -.006 & .004 & -.178 & -1.545 & .125 \\
\hline & LFRest_transformed & .651 & .064 & .648 & 10.220 & .000 \\
\hline \multirow[t]{7}{*}{2} & (Constant) & .901 & .294 & & 3.065 & .003 \\
\hline & STAI_total & .005 & .004 & . 181 & 1.328 & .186 \\
\hline & Negative_emotionality & -.007 & .004 & -.201 & -1.746 & .083 \\
\hline & LFRest_transformed & .645 & .063 & .643 & 10.243 & .000 \\
\hline & TASK_difficult_easy & .123 & .045 & .174 & 2.768 & .006 \\
\hline & LOTR_opt & -.006 & .012 & -.049 & -.485 & .628 \\
\hline & LOTR_pes & -.001 & .010 & -.013 & -.129 & .897 \\
\hline
\end{tabular}

a. Dependent Variable: LFTask_transformed

\section{Recovery following task}




\section{SBP}

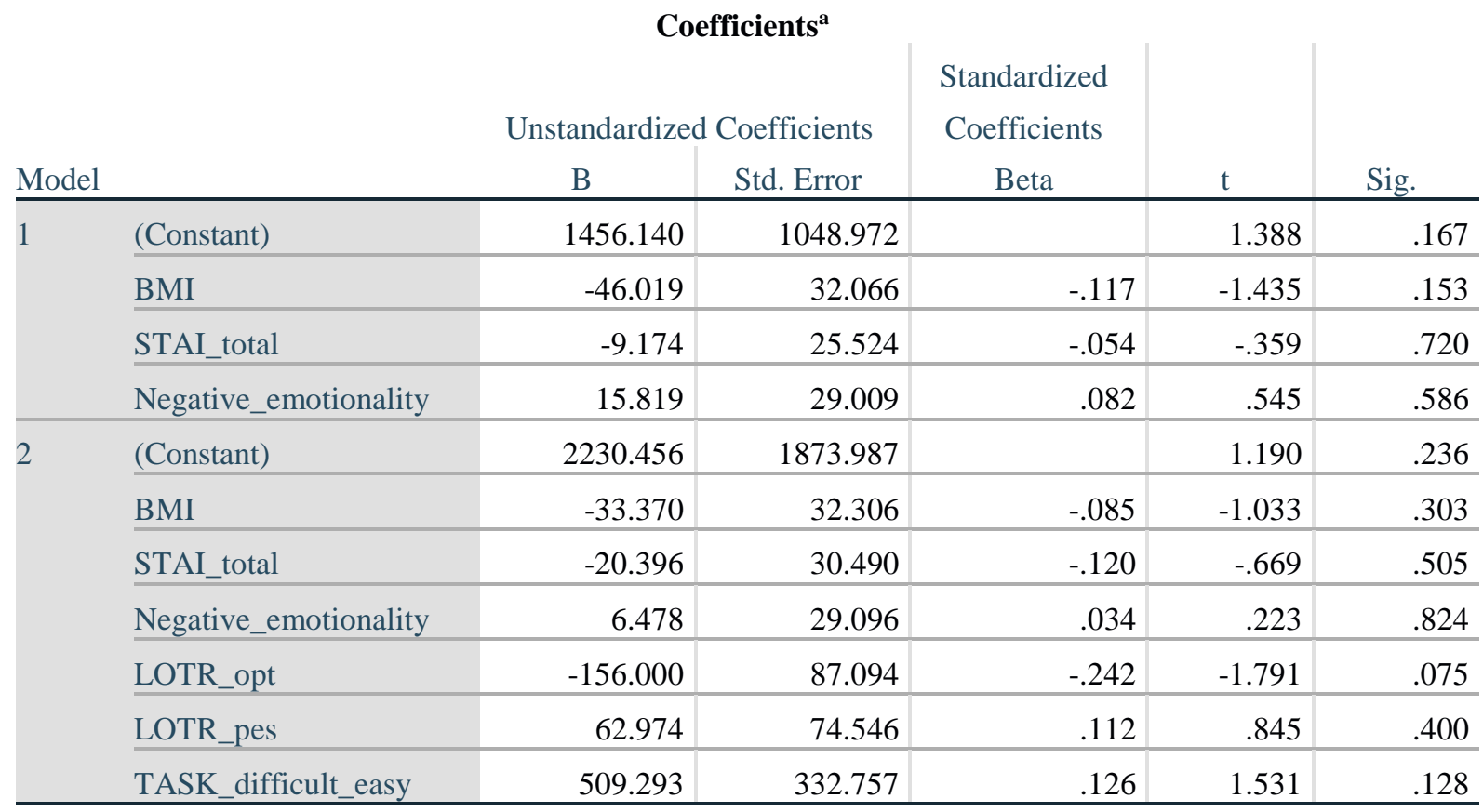

a. Dependent Variable: SYS_AUC

\section{DBP}

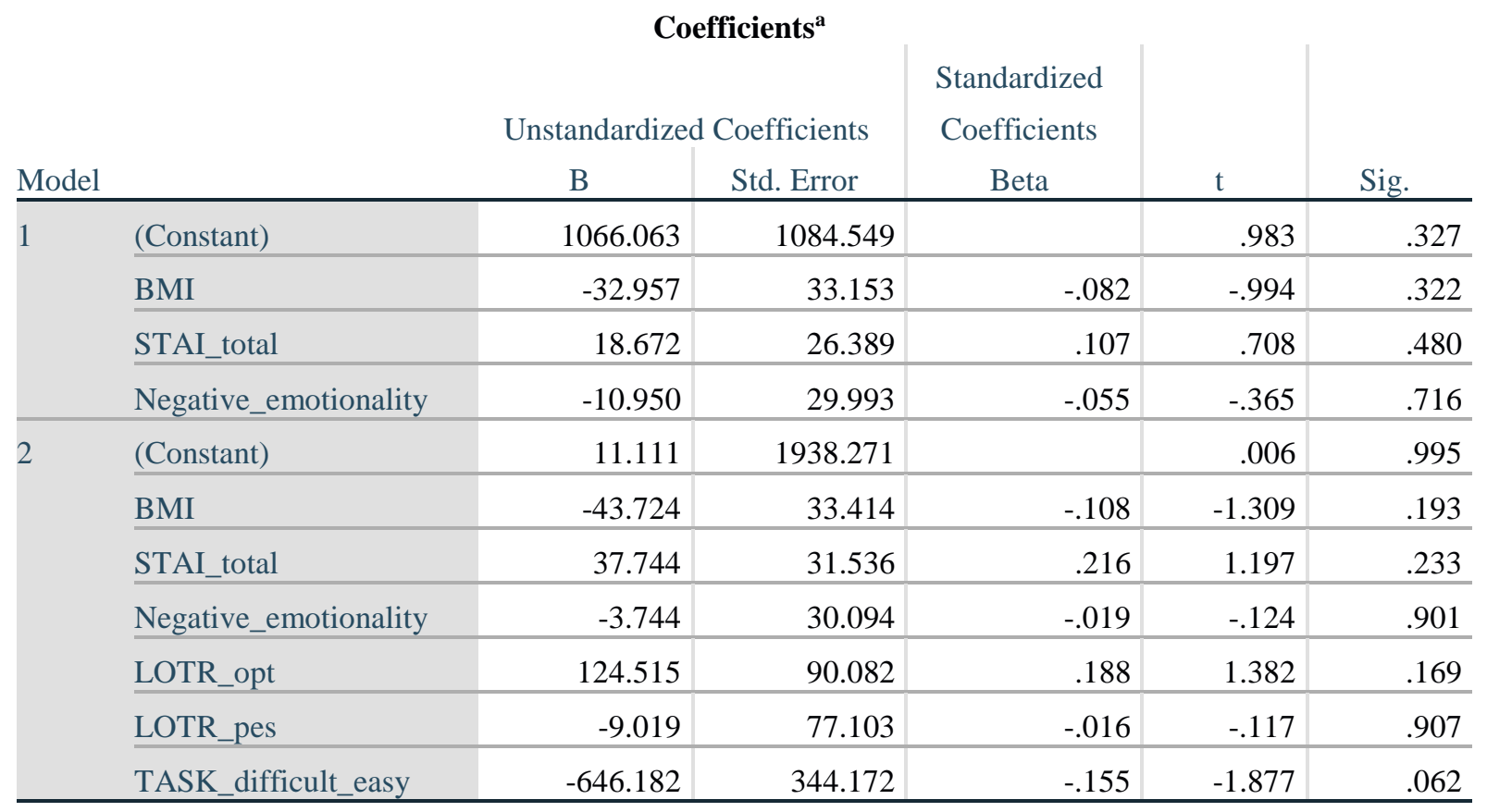

a. Dependent Variable: DIA_AUC

109. MAP 


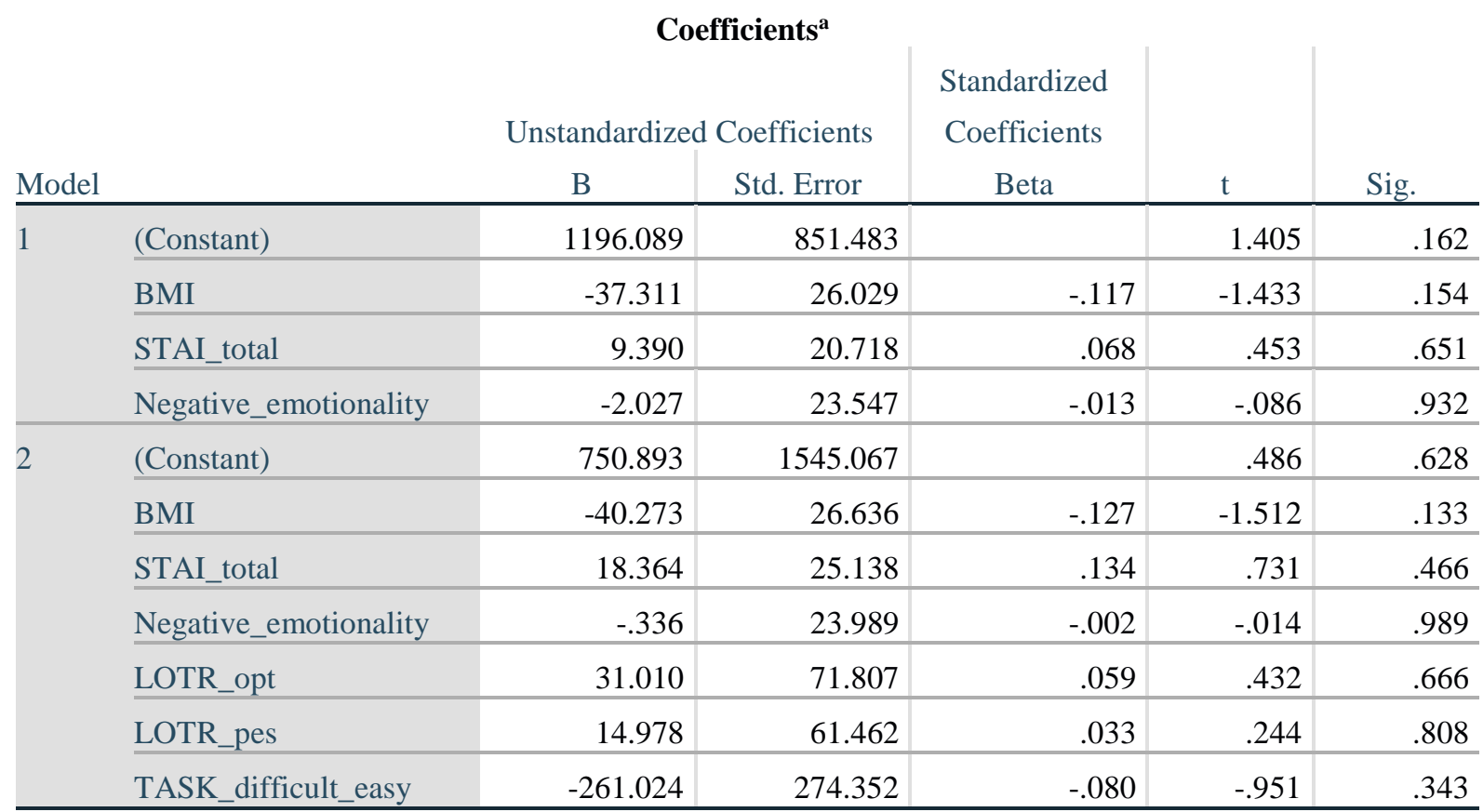

a. Dependent Variable: MAP_AUC 
110. HR

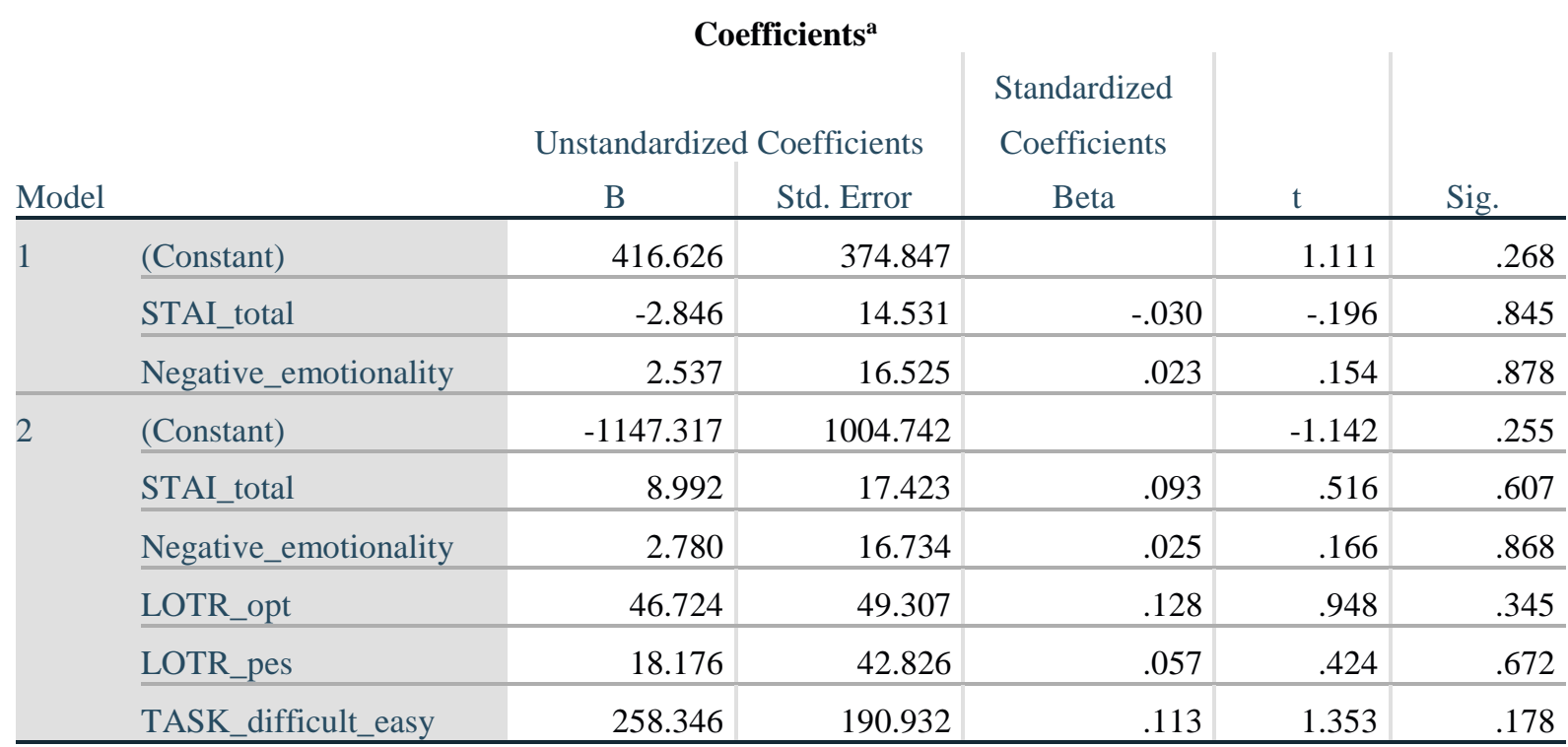

a. Dependent Variable: HR_AUC

111. HF-HRV

\begin{tabular}{|c|c|c|c|c|c|c|}
\hline & & Co & ficients $^{a}$ & & & \\
\hline & & Unstandardizec & Coefficients & $\begin{array}{l}\text { Standardized } \\
\text { Coefficients }\end{array}$ & & \\
\hline Model & & $\mathrm{B}$ & Std. Error & Beta & $\mathrm{t}$ & Sig. \\
\hline 1 & (Constant) & .812 & .175 & & 4.642 & .000 \\
\hline & STAI_total & .001 & .004 & .022 & .231 & .817 \\
\hline & Negative_emotionality & -.006 & .005 & -.128 & -1.346 & .180 \\
\hline & HFTask_transformed & .790 & .052 & .786 & 15.123 & .000 \\
\hline 2 & (Constant) & .918 & .311 & & 2.950 & .004 \\
\hline & STAI_total & .001 & .005 & .016 & .140 & .889 \\
\hline & Negative_emotionality & -.006 & .005 & -.133 & -1.373 & .172 \\
\hline & HFTask_transformed & .800 & .054 & .795 & 14.906 & .000 \\
\hline & LOTR_opt & -.007 & .014 & -.044 & -.519 & .605 \\
\hline & LOTR_pes & .004 & .012 & .025 & .298 & .766 \\
\hline & TASK_difficult_easy & -.048 & .054 & -.048 & -.899 & .370 \\
\hline
\end{tabular}

a. Dependent Variable: HFRecov_transformed 


\section{SDNN}

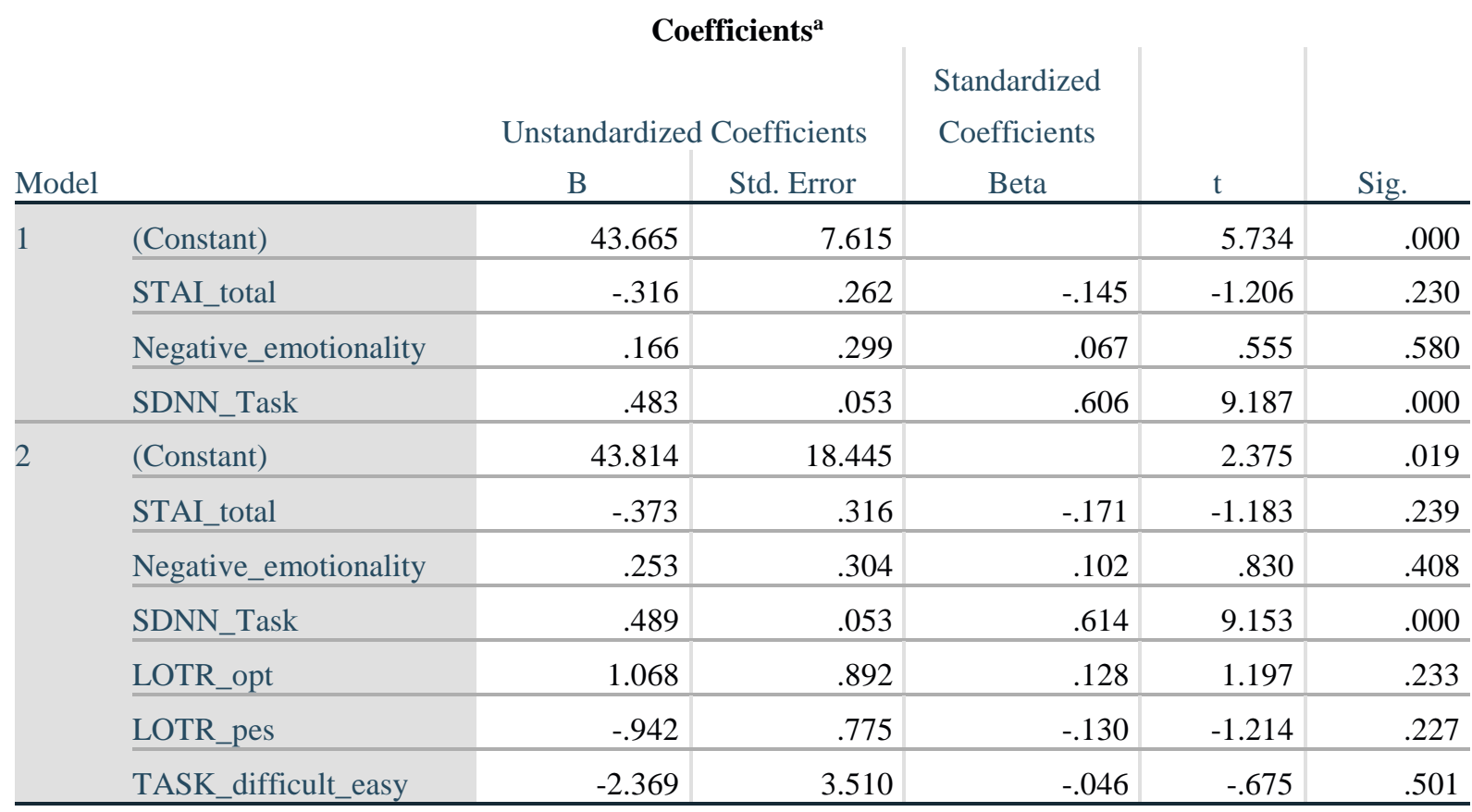

a. Dependent Variable: SDNN_Recov

\section{LF-HRV}

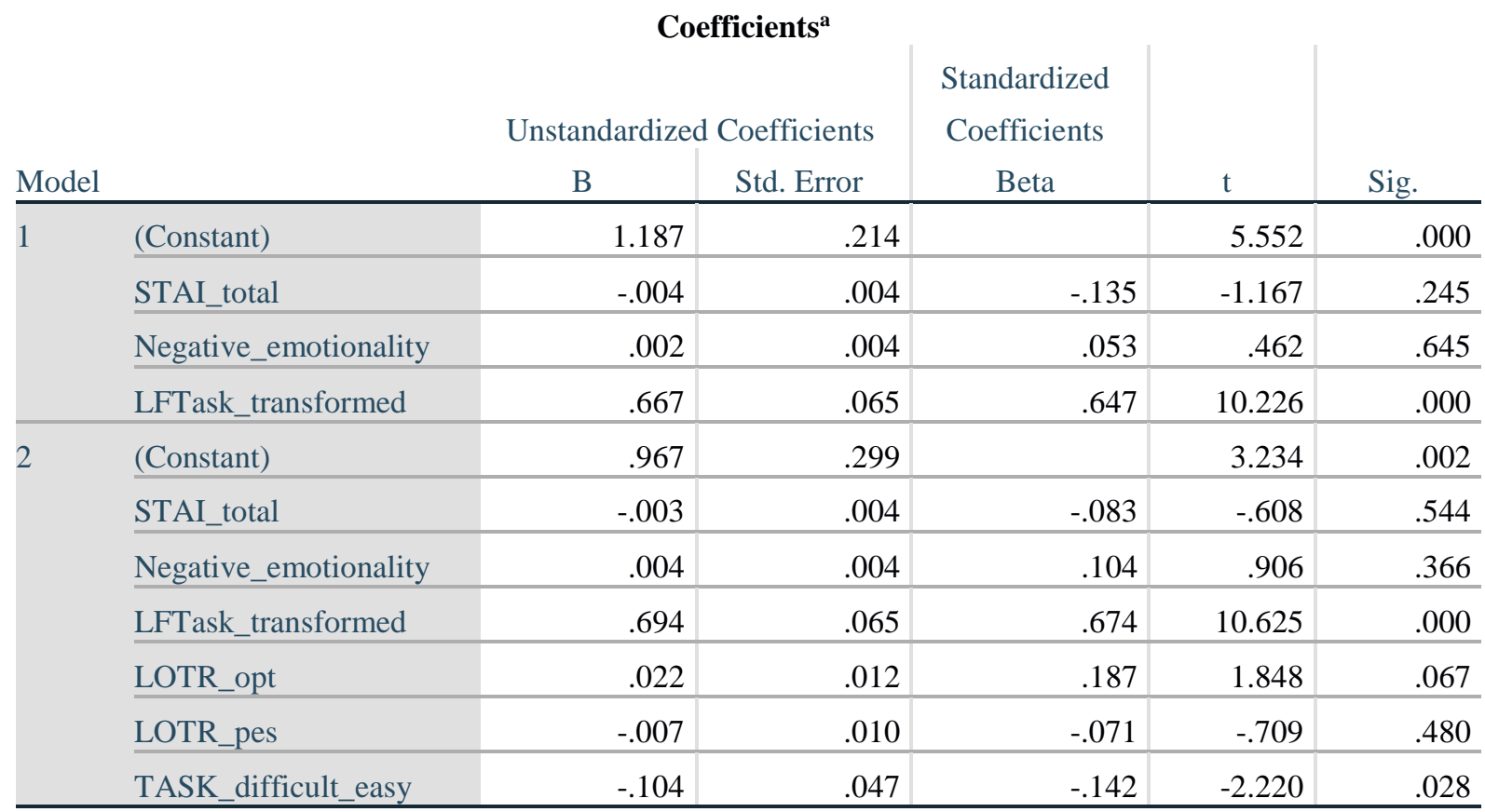

a. Dependent Variable: LFRecov_transformed 
Health behaviors and demographic differences between optimists and pessimists

114. Caffeine intake

\section{Tests of Between-Subjects Effects}

Dependent Variable: Caffeine_intake

\begin{tabular}{|c|c|c|c|c|c|c|}
\hline Source & $\begin{array}{l}\text { Type III Sum of } \\
\text { Squares } \\
\end{array}$ & df & Mean Square & $\mathrm{F}$ & Sig. & $\begin{array}{c}\text { Partial Eta } \\
\text { Squared } \\
\end{array}$ \\
\hline Corrected Model & $.785^{\mathrm{a}}$ & 3 & .262 & .509 & .676 & .010 \\
\hline Intercept & 499.785 & 1 & 499.785 & 972.539 & .000 & .868 \\
\hline Opt_Pess & .759 & 1 & .759 & 1.477 & .226 & .010 \\
\hline TASK_difficult_easy & .026 & 1 & .026 & .051 & .821 & .000 \\
\hline $\begin{array}{l}\text { Opt_Pess * } \\
\text { TASK_difficult_easy }\end{array}$ & $1.824 \mathrm{E}-5$ & 1 & $1.824 \mathrm{E}-5$ & .000 & .995 & .000 \\
\hline Error & 76.057 & 148 & .514 & & & \\
\hline Total & 578.000 & 152 & & & & \\
\hline Corrected Total & 76.842 & 151 & & & & \\
\hline
\end{tabular}

a. $\mathrm{R}$ Squared $=.010$ (Adjusted R Squared $=-.010)$

\section{Alcohol intake}

\section{Tests of Between-Subjects Effects}

Dependent Variable: Alcohol_intake

\begin{tabular}{|c|c|c|c|c|c|c|}
\hline Source & $\begin{array}{c}\text { Type III Sum of } \\
\text { Squares } \\
\end{array}$ & $\mathrm{df}$ & Mean Square & $\mathrm{F}$ & Sig. & $\begin{array}{c}\text { Partial Eta } \\
\text { Squared } \\
\end{array}$ \\
\hline Corrected Model & $6.303^{a}$ & 3 & 2.101 & 1.623 & .187 & .032 \\
\hline Intercept & 1287.559 & 1 & 1287.559 & 994.640 & .000 & .870 \\
\hline Opt_Pess & 1.980 & 1 & 1.980 & 1.530 & .218 & .010 \\
\hline TASK_difficult_easy & 4.158 & 1 & 4.158 & 3.212 & .075 & .021 \\
\hline $\begin{array}{l}\text { Opt_Pess * } \\
\text { TASK_difficult_easy }\end{array}$ & .211 & 1 & .211 & .163 & .687 & .001 \\
\hline Error & 191.586 & 148 & 1.294 & & & \\
\hline Total & 1489.000 & 152 & & & & \\
\hline Corrected Total & 197.888 & 151 & & & & \\
\hline
\end{tabular}

a. R Squared $=.032($ Adjusted R Squared $=.012)$ 


\section{Exercise}

\section{Tests of Between-Subjects Effects}

Dependent Variable: Exercise_total

\begin{tabular}{|c|c|c|c|c|c|c|}
\hline Source & $\begin{array}{c}\text { Type III Sum of } \\
\text { Squares } \\
\end{array}$ & $\mathrm{df}$ & Mean Square & $\mathrm{F}$ & Sig. & $\begin{array}{c}\text { Partial Eta } \\
\text { Squared } \\
\end{array}$ \\
\hline Corrected Model & $73.390^{\mathrm{a}}$ & 3 & 24.463 & 1.277 & .284 & .025 \\
\hline Intercept & 10421.436 & 1 & 10421.436 & 544.046 & .000 & .786 \\
\hline Opt_Pess & 10.068 & 1 & 10.068 & .526 & .470 & .004 \\
\hline TASK_difficult_easy & .138 & 1 & .138 & .007 & .932 & .000 \\
\hline $\begin{array}{l}\text { Opt_Pess * } \\
\text { TASK_difficult_easy }\end{array}$ & 63.296 & 1 & 63.296 & 3.304 & .071 & .022 \\
\hline Error & 2835.005 & 148 & 19.155 & & & \\
\hline Total & 13320.000 & 152 & & & & \\
\hline Corrected Total & 2908.395 & 151 & & & & \\
\hline
\end{tabular}

a. R Squared $=.025$ (Adjusted R Squared $=.005$ )

\section{Perceived SES}

\section{Tests of Between-Subjects Effects}

Dependent Variable: perceived_SES

\begin{tabular}{|c|c|c|c|c|c|c|}
\hline Source & $\begin{array}{c}\text { Type III Sum of } \\
\text { Squares } \\
\end{array}$ & $\mathrm{df}$ & Mean Square & $\mathrm{F}$ & Sig. & $\begin{array}{c}\text { Partial Eta } \\
\text { Squared }\end{array}$ \\
\hline Corrected Model & $10.533^{\mathrm{a}}$ & 3 & 3.511 & 1.317 & .271 & .026 \\
\hline Intercept & 5022.625 & 1 & 5022.625 & 1884.470 & .000 & .927 \\
\hline Opt_Pess & 10.520 & 1 & 10.520 & 3.947 & .049 & .026 \\
\hline TASK_difficult_easy & .007 & 1 & .007 & .003 & .959 & .000 \\
\hline $\begin{array}{l}\text { Opt_Pess * } \\
\text { TASK_difficult_easy }\end{array}$ & .007 & 1 & .007 & .003 & .959 & .000 \\
\hline Error & 394.460 & 148 & 2.665 & & & \\
\hline Total & 5419.000 & 152 & & & & \\
\hline Corrected Total & 404.993 & 151 & & & & \\
\hline
\end{tabular}

a. R Squared $=.026$ (Adjusted R Squared $=.006$ )

118.

\section{Estimates}

Dependent Variable: perceived_SES

95\% Confidence Interval

\begin{tabular}{lllll} 
Opt_Pess & Mean & Std. Error & Lower Bound & Upper Bound \\
\hline 1.00
\end{tabular}

\begin{tabular}{l|l|l|l|l}
\hline 1.00 & 6.014 & .190 & 5.638 & 6.389 \\
\hline 2.00 & 5.487 & .185 & 5.122 & 5.852 \\
\hline
\end{tabular}




\section{Chaos Theory}

\section{LOT-R score \\ 119. SBP}

\section{Tests of Between-Subjects Effects}

Dependent Variable: LOTR_tot

\begin{tabular}{lr|r|r|r|r|r} 
Source & $\begin{array}{c}\text { Type III Sum of } \\
\text { Squares }\end{array}$ & df & Mean Square & \multicolumn{1}{c|}{ F } & Sig. & \multicolumn{2}{c}{$\begin{array}{c}\text { Partial Eta } \\
\text { Squared }\end{array}$} \\
\hline Corrected Model & $3699.871^{\mathrm{a}}$ & 6 & 616.645 & 38.063 & .000 & .612 \\
\hline Intercept & 12732.808 & 1 & 12732.808 & 785.935 & .000 & .844 \\
\hline STAI_total & 964.851 & 1 & 964.851 & 59.556 & .000 & .291 \\
\hline Negative_emotionality & 2.705 & 1 & 2.705 & .167 & .683 & .001 \\
\hline chaos_SBP & 47.022 & 4 & 11.755 & .726 & .576 & .020 \\
\hline Error & 2349.122 & 145 & 16.201 & & & \\
\hline Total & 60959.000 & 152 & & & & \\
\hline Corrected Total & 6048.993 & 151 & & & & \\
\hline
\end{tabular}

a. R Squared $=.612($ Adjusted R Squared $=.596)$

\section{DBP}

\section{Tests of Between-Subjects Effects}

Dependent Variable: LOTR_tot

\begin{tabular}{l|r|r|r|r|r|r} 
Source & $\begin{array}{c}\text { Type III Sum of } \\
\text { Squares }\end{array}$ & df & Mean Square & F & Sig. & \multicolumn{2}{c}{$\begin{array}{c}\text { Partial Eta } \\
\text { Squared }\end{array}$} \\
\hline Corrected Model & $3891.267^{\mathrm{a}}$ & 6 & 648.545 & 43.582 & .000 & .643 \\
\hline Intercept & 12823.487 & 1 & 12823.487 & 861.743 & .000 & .856 \\
\hline STAI_total & 966.014 & 1 & 966.014 & 64.916 & .000 & .309 \\
\hline Negative_emotionality & .975 & 1 & .975 & .066 & .798 & .000 \\
\hline chaos_DBP & 238.418 & 4 & 59.604 & 4.005 & .004 & .100 \\
\hline Error & 2157.726 & 145 & 14.881 & & & \\
\hline Total & 60959.000 & 152 & & & & \\
\hline Corrected Total & 6048.993 & 151 & & & & \\
\hline
\end{tabular}

a. R Squared $=.643$ (Adjusted R Squared $=.629)$ 
121.

Pairwise Comparisons

Dependent Variable: LOTR_tot

95\% Confidence Interval for Difference $^{\mathrm{b}}$

\begin{tabular}{|c|c|c|c|c|c|c|}
\hline (I) chaos_DBP & (J) chaos_DBP & $(\mathrm{I}-\mathrm{J})$ & Std. Error & Sig. ${ }^{b}$ & Lower Bound & Upper Bound \\
\hline \multirow[t]{4}{*}{1.00} & 2.00 & 1.208 & .884 & 1.000 & -1.312 & 3.728 \\
\hline & 3.00 & -.563 & 1.081 & 1.000 & -3.644 & 2.517 \\
\hline & 4.00 & 2.561 & 1.313 & .530 & -1.181 & 6.302 \\
\hline & 5.00 & $3.686^{*}$ & 1.214 & .028 & .225 & 7.147 \\
\hline \multirow[t]{4}{*}{2.00} & 1.00 & -1.208 & .884 & 1.000 & -3.728 & 1.312 \\
\hline & 3.00 & -1.772 & .900 & .509 & -4.338 & .794 \\
\hline & 4.00 & 1.353 & 1.166 & 1.000 & -1.972 & 4.677 \\
\hline & 5.00 & 2.478 & 1.080 & .232 & -.600 & 5.555 \\
\hline \multirow[t]{4}{*}{3.00} & 1.00 & .563 & 1.081 & 1.000 & -2.517 & 3.644 \\
\hline & 2.00 & 1.772 & .900 & .509 & -.794 & 4.338 \\
\hline & 4.00 & 3.124 & 1.323 & .195 & -.647 & 6.896 \\
\hline & 5.00 & $4.249^{*}$ & 1.242 & .008 & .708 & 7.790 \\
\hline \multirow[t]{4}{*}{4.00} & 1.00 & -2.561 & 1.313 & .530 & -6.302 & 1.181 \\
\hline & 2.00 & -1.353 & 1.166 & 1.000 & -4.677 & 1.972 \\
\hline & 3.00 & -3.124 & 1.323 & .195 & -6.896 & .647 \\
\hline & 5.00 & 1.125 & 1.454 & 1.000 & -3.020 & 5.270 \\
\hline \multirow[t]{4}{*}{5.00} & 1.00 & $-3.686^{*}$ & 1.214 & .028 & -7.147 & -.225 \\
\hline & 2.00 & -2.478 & 1.080 & .232 & -5.555 & .600 \\
\hline & 3.00 & $-4.249^{*}$ & 1.242 & .008 & -7.790 & -.708 \\
\hline & 4.00 & -1.125 & 1.454 & 1.000 & -5.270 & 3.020 \\
\hline
\end{tabular}

Based on estimated marginal means

*. The mean difference is significant at the .05 level.

b. Adjustment for multiple comparisons: Bonferroni. 
122.

\section{Estimates}

Dependent Variable: LOTR_tot

\begin{tabular}{lc|r|r|r} 
& & & \multicolumn{2}{|c}{$95 \%$ Confidence Interval } \\
chaos_DBP & Mean & Std. Error & Lower Bound & Upper Bound \\
\hline 1.00 & $20.077^{\mathrm{a}}$ & .744 & 18.608 & 21.547 \\
\hline 2.00 & $18.869^{\mathrm{a}}$ & .464 & 17.953 & 19.785 \\
\hline 3.00 & $20.641^{\mathrm{a}}$ & .774 & 19.111 & 22.170 \\
\hline 4.00 & $17.517^{\mathrm{a}}$ & 1.074 & 15.394 & 19.639 \\
\hline 5.00 & $16.391^{\mathrm{a}}$ & .970 & 14.474 & 18.309 \\
\hline
\end{tabular}

a. Covariates appearing in the model are evaluated at the following values:

STAI_total $=44.9868$, Negative_emotionality $=37.3224$.

\section{MAP}

\section{Tests of Between-Subjects Effects}

Dependent Variable: LOTR_tot

\begin{tabular}{lr|r|r|r|r|r} 
Source & $\begin{array}{c}\text { Type III Sum of } \\
\text { Squares }\end{array}$ & df & Mean Square & \multicolumn{1}{c|}{ F } & \multicolumn{1}{c|}{ Sig. } & \multicolumn{2}{c}{$\begin{array}{c}\text { Sartial Eta } \\
\text { Squared }\end{array}$} \\
\hline Corrected Model & $3789.765^{\mathrm{a}}$ & 6 & 631.628 & 40.539 & .000 & .627 \\
\hline Intercept & 11661.270 & 1 & 11661.270 & 748.434 & .000 & .838 \\
\hline STAI_total & 997.321 & 1 & 997.321 & 64.009 & .000 & .306 \\
\hline Negative_emotionality & .866 & 1 & .866 & .056 & .814 & .000 \\
\hline VAR00002 & 136.916 & 4 & 34.229 & 2.197 & .072 & .057 \\
\hline Error & 2259.228 & 145 & 15.581 & & & \\
\hline Total & 60959.000 & 152 & & & & \\
\hline Corrected Total & 6048.993 & 151 & & & & \\
\hline
\end{tabular}

a. R Squared $=.627$ (Adjusted R Squared $=.611)$ 


\section{Task score}

124. SBP

Tests of Between-Subjects Effects

Dependent Variable: Stress_Task_score

\begin{tabular}{lr|r|r|r|r|r} 
Source & $\begin{array}{c}\text { Type III Sum of } \\
\text { Squares }\end{array}$ & df & Mean Square & F & Sig. & $\begin{array}{c}\text { Partial Eta } \\
\text { Squared }\end{array}$ \\
\hline Corrected Model & $112.291^{\mathrm{a}}$ & 6 & 18.715 & 1.246 & .287 & .049 \\
\hline Intercept & 119.741 & 1 & 119.741 & 7.969 & .005 & .052 \\
\hline STAI_total & 3.551 & 1 & 3.551 & .236 & .628 & .002 \\
\hline Negative_emotionality & 3.612 & 1 & 3.612 & .240 & .625 & .002 \\
\hline chaos_SBP & 71.843 & 4 & 17.961 & 1.195 & .315 & .032 \\
\hline Error & 2178.650 & 145 & 15.025 & & & \\
\hline Total & 7799.000 & 152 & & & & \\
\hline Corrected Total & 2290.941 & 151 & & & & \\
\hline
\end{tabular}

a. R Squared $=.049$ (Adjusted R Squared $=.010)$

\section{DBP}

Tests of Between-Subjects Effects

Dependent Variable: Stress_Task_score

\begin{tabular}{lr|r|r|r|r|r} 
Source & $\begin{array}{c}\text { Type III Sum of } \\
\text { Squares }\end{array}$ & df & Mean Square & F & Sig. & \multicolumn{2}{c}{$\begin{array}{c}\text { Partial Eta } \\
\text { Squared }\end{array}$} \\
\hline Corrected Model & $71.732^{\mathrm{a}}$ & 6 & 11.955 & .781 & .586 & .031 \\
\hline Intercept & 164.542 & 1 & 164.542 & 10.751 & .001 & .069 \\
\hline STAI_total & 7.727 & 1 & 7.727 & .505 & .479 & .003 \\
\hline Negative_emotionality & .211 & 1 & .211 & .014 & .907 & .000 \\
\hline chaos_DBP & 31.285 & 4 & 7.821 & .511 & .728 & .014 \\
\hline Error & 2219.208 & 145 & 15.305 & & & \\
\hline Total & 7799.000 & 152 & & & & \\
\hline Corrected Total & 2290.941 & 151 & & & & \\
\hline
\end{tabular}

a. R Squared $=.031$ (Adjusted R Squared $=-.009$ ) 


\section{MAP}

Tests of Between-Subjects Effects

Dependent Variable: Stress_Task_score

\begin{tabular}{lr|r|r|r|r|r} 
Source & $\begin{array}{c}\text { Type III Sum of } \\
\text { Squares }\end{array}$ & df & Mean Square & F & Sig. & \multicolumn{2}{c}{$\begin{array}{c}\text { Partial Eta } \\
\text { Squared }\end{array}$} \\
\hline Corrected Model & $58.040^{\mathrm{a}}$ & 6 & 9.673 & .628 & .708 & .025 \\
\hline Intercept & 152.291 & 1 & 152.291 & 9.889 & .002 & .064 \\
\hline STAI_total & 3.499 & 1 & 3.499 & .227 & .634 & .002 \\
\hline Negative_emotionality & 2.140 & 1 & 2.140 & .139 & .710 & .001 \\
\hline VAR00002 & 17.592 & 4 & 4.398 & .286 & .887 & .008 \\
\hline Error & 2232.901 & 145 & 15.399 & & & \\
\hline Total & 7799.000 & 152 & & & & \\
\hline Corrected Total & 2290.941 & 151 & & & & \\
\hline
\end{tabular}

a. R Squared $=.025$ (Adjusted R Squared $=-.015$ ) 